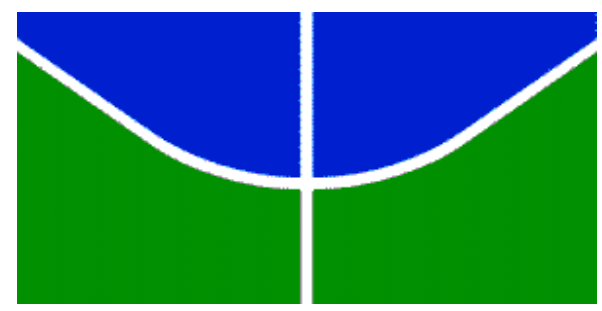

Universidade de Brasília

Faculdade de Medicina

Pós-Graduação em Ciências Médicas

LISIANE HOLDEFER

ANÁLISE DA LATÊNCIA E AMPLITUDE DOS POTENCIAIS EVOCADOS AUDITIVOS RELACIONADOS A EVENTOS MISMATCH NEGATIVITY EM ORELHAS COM E SEM ZUMBIDO

BRASÍLIA - 2014 


\section{ANÁLISE DA LATÊNCIA E AMPLITUDE DOS POTENCIAIS EVOCADOS AUDITIVOS RELACIONADOS A EVENTOS MISMATCH NEGATIVITY EM ORELHAS COM E SEM ZUMBIDO}

Tese apresentada ao Programa de PósGraduação em Ciências Médicas da Faculdade de Medicina da Universidade de Brasília (UnB), como requisito para a obtenção do título de Doutor.

Linha de Pesquisa: Tinnitus - registro de potenciais evocados corticais

Orientador: Prof. Dr. Carlos Augusto Costa Pires de Oliveira 


\section{ANÁLISE DA LATÊNCIA E AMPLITUDE DOS POTENCIAIS EVOCADOS AUDITIVOS RELACIONADOS A EVENTOS MISMATCH NEGATIVITY EM ORELHAS COM E SEM ZUMBIDO}

Aprovada em: $05 / 12 / 2014$.

Tese apresentada ao Programa de PósGraduação em Ciências Médicas da Faculdade de Medicina da Universidade de Brasília (UnB), como requisito para a obtenção do título de Doutor.

\section{Banca Examinadora}

$1^{\circ}$ Membro (presidente): Professor Doutor Carlos Augusto Costa Pires de Oliveira

$2^{\circ}$ Membro: Dra Adriane Ribeiro Teixeira

$3^{\circ}$ Membro: Dra Valéria Reis do Canto Pereira

$4^{\text {o }}$ Membro: Dr Fayez Bahmad Júnior

$5^{\circ}$ Membro: Dr Pedro Luiz Tauil

Suplente: Dra Helga Moura Kehrle 


\section{RESUMO}

O zumbido é um sintoma causado por várias doenças e pode afetar gravemente a qualidade de vida. As pessoas que apresentam muito incômodo com o zumbido podem ter um déficit em processo de habituação do córtex auditivo central. O Mismatch Negativity (MMN) é um exame que avalia a resposta neural a um som inesperado, capaz de documentar objetivamente a plasticidade neural do sistema auditivo.

Este estudo tem como objetivo avaliar o a ansiedade, depressão e o MMN em indivíduos com audição normal e zumbido e comparar os resultados com um grupo de sujeitos sem zumbido (controle).

Pacientes com audição normal e zumbido e pacientes com audição normal e sem zumbido foram submetidos ao teste MMN. O Questionário de Repercussão do Zumbido (THI) e da Escala Analógico-Visual (EAV) foram utilizados para avaliar o grau de incômodo com o zumbido. A Escala Hospitalar de Ansiedade e Depressão (HAD) foi aplicada para triar ansiedade e depressão.

O grupo sem zumbido (controle) foi composto por 26 orelhas com audição normal e ausência de zumbido. $\mathrm{O}$ grupo com zumbido foi composto por 45 orelhas com audição normal e zumbido. O incômodo com o zumbido resultou em uma média de 8,5 na EAV. A média do THI foi de $52,1 \%$. Na Escala HAD, o grupo com zumbido pontuou a média de 9,2 para ansiedade e 7,3 para depressão e o gupo controle 4,1 para ansiedade e 1,4 para depressão. A média da amplitude do MMN no grupo zumbido foi $-0,88 \mathrm{uV}$ na orelha direita (OD) e $-1,13 \mathrm{uV}$ na orelha esquerda (OE). No grupo controle, a média da amplitude foi de $1,01 \mathrm{uV}$ na OD e -1,19 uV na OE. No grupo zumbido, a média da latência foi de $208,34 \mathrm{~ms}$ na OD e 209,92 ms na OE. No grupo controle, a média da latência foi de $217,38 \mathrm{~ms}$ na OD e 215,69 ms na OE. Houve diferença estatisticamente significante nas médias latências quando o grupo de pesquisa foi comparado com o grupo controle.

Os resultados sugerem que o MMN pode ser uma ferramenta para avaliar o processo auditivo das vias auditivas centrais em pacientes com zumbido. Mais estudos são necessários nesta área para confirmar esses achados.

Palavras-chave: zumbido; cognição; Mismatch Negativity; ansiedade; depressão; potenciais evocados auditivos. 


\begin{abstract}
Tinnitus is a symptom caused by various diseases, which can severely affect quality of life. People who have very annoying tinnitus problably have a deficit in habituation process of the central auditory cortex. The Mismatch Negativity (MMN) is a test that evaluates the neural response to an unexpected sound, capable to objectively document the neural plasticity of the auditory system.

This study aims to evaluate the MMN in individuals with normal hearing and significant tinnitus, and compare the results with a control group without tinnitus

Patients with normal hearing and tinnitus and patients with normal hearing and no tinnitus were submitted to MMN test. Tinnitus Handicap Inventory (THI) and the Visual Analog Scale (VAS) were used to evaluate the tinnitus annoyance. The Hospital Anxiety and Depression Scale (HAD) was applied to screen anxiety and depression.

Group without tinnitus consisted of 13 patients with normal hearing and without tinnitus. Tinnitus group had 25 patients with normal hearing and annoying tinnitus. The mean tinnitus annoyance assessed by VAS was 8.5 . The average THI was $52.1 \%$. HAD Scale in the tinnitus group scored an average of 9.2 for anxiety and 7.3 for depression and the group without tinnitus score 4.1 for anxiety and 1.4 for depression. The average MMN amplitude in the tinnitus group was $-0.88 \mathrm{uV}$ in the right ear (RE) and -1.13 in the left ear (LE). In non-tinnitus group the amplitudes were $1.01 \mathrm{uV}$ in RE and $-1.19 \mathrm{uV}$ in LE. In tinnitus group the mean latency were $208.34 \mathrm{~ms}$ in the RE and $209.92 \mathrm{~ms}$ in the LE. In non-tinnitus group they were $217.38 \mathrm{~ms}$ in the RE and $215.69 \mathrm{~ms}$ in LE. There was a statistically significant difference in mean latencies when the research group was compared to the group control.

The findings suggest that MMN can be a tool to evaluate the habituation process of the central auditory pathways in tinnitus patients. More work is needed in this area to confirm our findings findings.
\end{abstract}

Keywords: tinnitus; cognition; Mismatch Negativity; anxiety; depression; PEALL. 


\section{LISTA DE QUADROS E TABELAS}

Quadro 1 - Parâmetros de Aquisição don MMN.

Tabela 1 - Características gerais dos grupos, segundo gênero, idade, média tritonal audiométrica e incômodo com o zumbido.

Tabela 2 - Distribuição das notas de incômodo atribuídas pelos pacientes com zumbido, segundo localização do zumbido.

Tabela 3 - Médias da pontuação da HAD - ansiedade e depressão.

Tabela 4 - Médias dos quesitos funcional, emocional e catastrófico avaliados pelo THI...

Tabela 5 - Dados referentes à latência do MMN (ms)

Tabela 6 - Dados referentes à amplitude do MMN (uV)

Tabela 7 - Dados referentes à latência (ms) do MMN na orelha direita (OD)

Tabela 8 - Dados referentes à latência do MMN na orelha esquerda (OE)

Tabela 9 - Dados referentes à amplitude do MMN na orelha direita (OD)

Tabela 10 - Dados referentes à amplitude do MMN na orelha esquerda $(\mathrm{OE})$

Tabela 11 - Médias de amplitude e latência do MMN no grupo zumbido e no grupo controle.

Tabela 12- Dados das comparações entre orelhas dentro dos grupos 


\section{LISTA DE FIGURAS}

Figura 1 - Distribuição das notas de incômodo atribuídas pelos pacientes com zumbido na EAV...

Figura 2 - Achados específicos de cada subescala do THI.

Figura 3 - Distribuição das medidas de latência (ms).

Figura 4 - Distribuição das medidas da amplitude (uV). 52

Figura 5 - Distribuição das medidas de latência (ms) na OD.

Figura 6 - Distribuição das medidas de latência (ms) na OE.

Figura 7 - Distribuição das medidas da amplitude (uV) da OD.

Figura 8 - Distribuição das medidas da amplitude $(\mathrm{uV})$ da $\mathrm{OE}$ 


\section{LISTA DE ABREVIAÇÕES}

MMN Potencial Evocado Relacionado a Evento Mismatch Negativity $\mathrm{dB}$ Decibéis

$\mathrm{Hz}$ Hertz

LRF Limiar de Reconhecimento de Fala

IRF Índice de Reconhecimento de Fala

ms

Milissegundos

$\mathrm{uV}$ Microvolts ( $0 \mathrm{~dB}=1 \mathrm{uV} / \mathrm{m}$ para campo eletromagnético)

CEP/FS Comitê de Ética em Pesquisa da Faculdade de Ciências da Saúde

OD Orelha direita

$\mathrm{OE}$ Orelha esquerda

OI Orelha interna

THI Questionário de Repercussão do Zumbido (Tinnitus Handicap Inventory)

HAD .Escala Hospitalar de Ansiedade e Depressão (Hospitalar Ansiety and

Depression Scale)

PEA Potenciais Evocados Auditivos $\%$ Percentagem

SAC Sistema Auditivo Central

SNC Sistema Nervoso Central dp Desvio Padrão 


\section{SUMÁRIO}

1 - INTRODUÇÃ

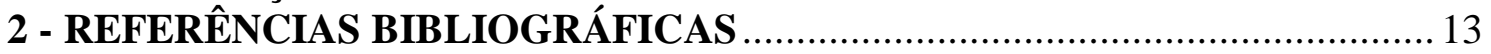

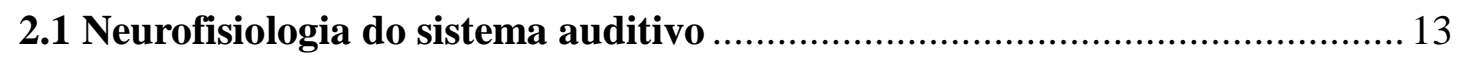

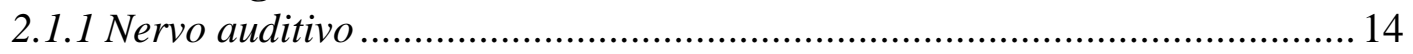

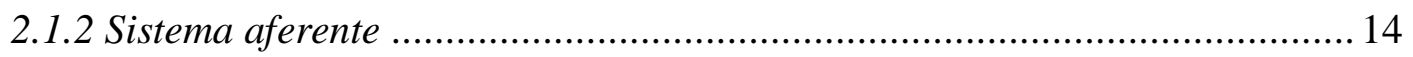

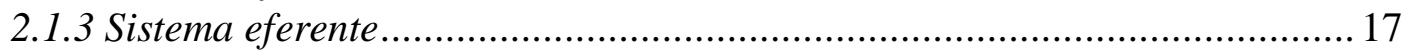



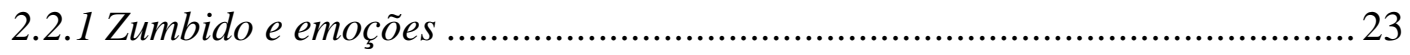

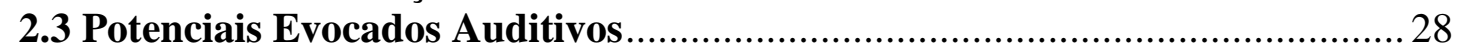

2.3.1 Potenciais evocados auditivos de longa latência ..........................................2 28

2.3.2 Mismatch Negativity Response - MMN....................................................2 29

2.3.3 Potenciais de longa latência relacionados a eventos e zumbido ................... 34

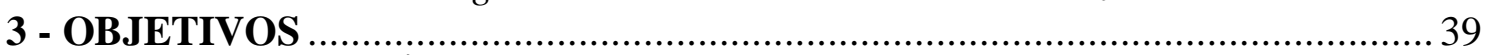

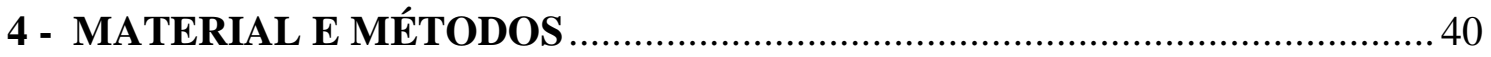

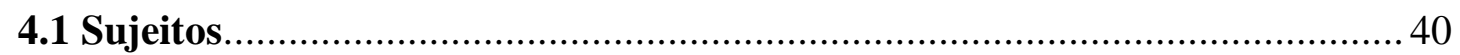

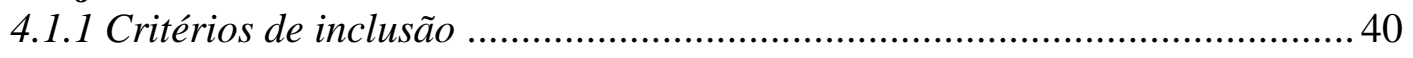

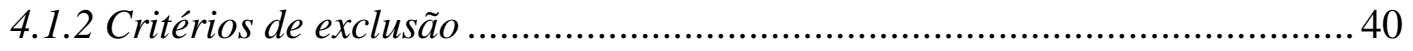

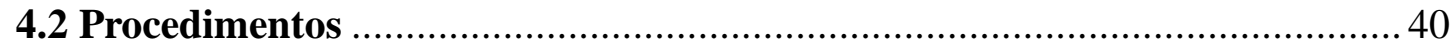

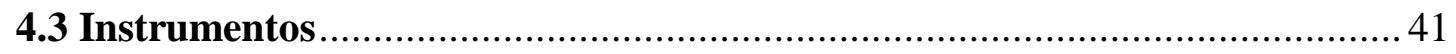



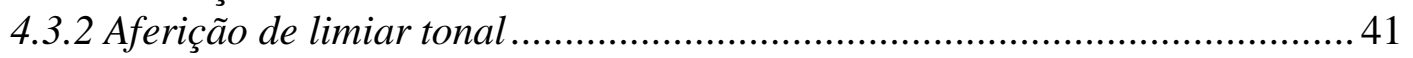

4.3.3 Medidadas de Imitâncio Acustica .................................................................. 41

4.3.4 Potenciais evocados relacionados a eventos - Mismatch Negativity ........... 42

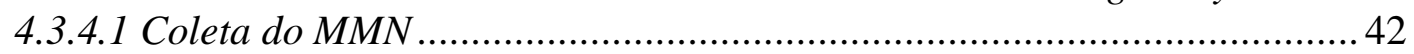

4.3.5 Questionário de Repercussão do Zumbido - THI ....................................... 43

4.3.5.1 Classificação do zumbido pelo THI segundo Mc Combe et al. (2001) ...... 44

4.3.6 Escala Hospitalar de Ansiedade e Depressão - HAD ............................... 44

4.3.7 Escala Analógico-Visual de incômodo/intensidade do zumbido .................... 44

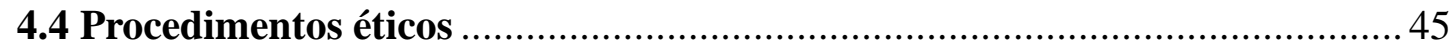

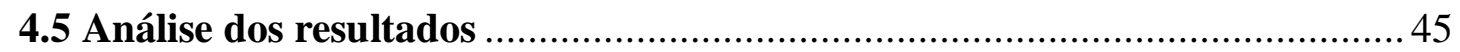

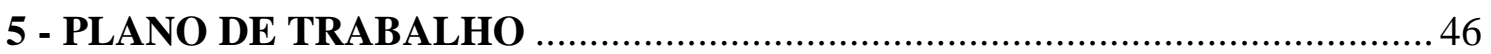

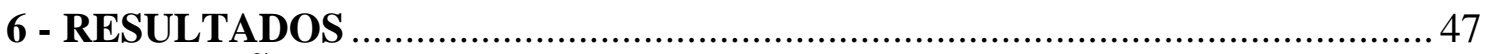

7 - DISCUSSÃO

8 - CONCLUSÃO

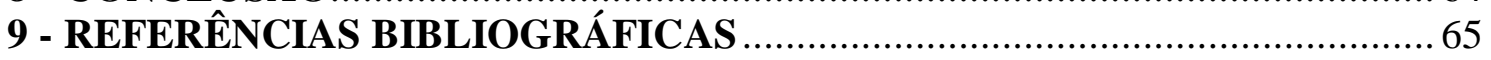

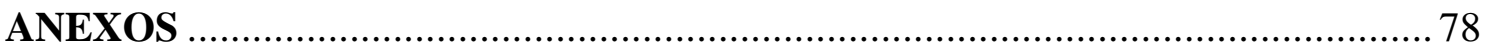




\section{1 - INTRODUÇÃO}

Zumbido é a percepção de um som ao qual não é atribuída fonte sonora externa (Jastreboff, 1990). Ele afeta cerca de 40 milhões de pessoas nos Estados Unidos, sendo o zumbido severo considerado o terceiro pior problema que pode acometer o ser humano (Jastreboff e Hanzell, 1993). Segundo Castagno e Castagno (1985), o zumbido apresenta prevalência elevada, estando presente em 63,3\% dos indivíduos acima de 45 anos. Quanto aos prejuízos ocasionados por esse sintoma, observam-se falhas no raciocínio, na memória e na concentração. Essas alterações podem prejudicar as atividades de lazer, o repouso, a comunicação, o ambiente social e doméstico, repercutindo na esfera psíquica, por provocarem irritação, ansiedade, depressão e insônia. Aproximadamente 17\% da população é afetada pelo zumbido, dos quais $15 \%$ a $25 \%$ apresentam interferência em sua qualidade de vida (Bento et al., 1997).

Cerca de $20 \%$ das pessoas que apresentam zumbido referem incômodo intenso ao som (Ferrari e Sanchez, 2004) . No princípio, as pesquisas em zumbido procuraram explicar o que diferencia o zumbido considerado incômodo daquele que não provoca desconforto algum. Acreditou-se que a diferença entre o zumbido considerado incômodo e o não incômodo seria explicada pela intensidade do som: quanto mais forte o zumbido, maior o incômodo. Essa hipótese não se confirmou, pois os estudos comprovaram que a intensidade do zumbido não ultrapassa 10/15 dB do limiar auditivo em qualquer pessoa, sendo, portanto, a intensidade indiferente naqueles que se incomodam com o zumbido em comparação com os que não referem qualquer incômodo ao som. O mesmo aconteceu quanto ao tipo de som do zumbido (cachoeira, panela de pressão, etc.); os estudos mostraram que o tipo de som do zumbido não determina o grau de incômodo ligado a ele (Zenner, 2006).

Para explicar os mecanismos de desenvolvimento do zumbido crônico, Hallam (1987) desenvolveu a teoria de habituação do zumbido. Postulou ser o som do zumbido apenas um sinal do corpo ao qual se presta muita atenção. Segundo essa teoria há um déficit da habituação apenas nos pacientes com queixa de zumbido importante (Hallam et al., 1984, Zenner, 2006).

A partir dessas pesquisas, Jastreboff (1990) idealizou o modelo neurofisiológico do zumbido no qual a origem do zumbido é mais do que um "problema" do sistema auditivo, ela pode envolver o sistema límbico e o sistema nervoso autônomo. Ou seja, o zumbido, mesmo sendo gerado por uma lesão no sistema auditivo periférico, pode receber 
uma contribuição dos mecanismos auditivos centrais, sistema límbico e sistema nervoso autônomo, que agem engrandecendo o zumbido.

Segundo Gerken (1996), o estudo do zumbido central é difícil, uma vez que ele recebe interferência de alterações periféricas e de intricada intercorrelação de complexos sistemas com o sistema auditivo. Altas estruturas cerebrais estão envolvidas no zumbido, e estas podem ser percebidas por meio das diferentes maneiras de lidar com o som interno (Hallam, 1996; Jakes e Stephens, 1987).

Attias et. al. (1993) afirmam que as informações contrastantes da literatura sobre zumbido podem ser conseqüência da avaliação de pacientes com zumbido de diversas etiologias, com afecções diferentes ao longo das vias auditivas, assim como do uso de diversas técnicas e parâmetros de análise. Para os autores, uma avaliação precisa do zumbido exige uma população homogênea, com uma doença conhecida e sintomas comuns, como aspectos relacionados ao zumbido e estado geral de saúde. Conclusões controversas nos estudos de avaliação objetiva do zumbido também foram relacionadas a diferenças metodológicas (Jacobson et al., 1991, Seidman e Jacobson, 1996, Melcher et al., 2000).

Uma maneira objetiva de avaliar a neuroplasticidade auditiva é por meio dos potenciais evocados auditivos de longa latência relacionados a eventos, como, por exemplo, o Mismatch Negativity (MMN). A pesquisa e a literatura atuais sobre potenciais evocados auditivos relacionados a eventos em pessoas com zumbido são ainda bastante escassas e inconclusivas, já que os resultados obtidos nos estudos publicados são discordantes e estas pesquisas, em sua maioria, apresentam desenhos experimentais e protocolos difrentes na seleção do grupo de pesquisa, incluindo pacientes com perda auditiva ou deixando de usar grupo controle (Gerken, 1996; Weisz et al., 2004; Weisz et al., 2005).

O uso dos potenciais evocados auditivos relacionados a eventos - MMN- ainda não foi estendido à clínica audiológica em geral, sendo usado basicamente para pesquisas. No Brasil, a bibliografia sobre esse potencial é extremamente escassa e ainda não surgiram pesquisas avaliando MMN em pessoas com queixa de zumbido.

O potencial evocado auditivo é a atividade elétrica gerada pela cóclea, pelo nervo auditivo ou pelas vias auditivas centrais, que é produzida ou evocada por sons (estímulo auditivo ou acústico). De maneira simples, pode-se entender que os potenciais evocados auditivos são potenciais elétricos gerados quando uma pessoa é estimulada com sons (Hall III, 2006). 
Entre os potenciais evocados auditivos, o MMN é um exame que possibilita estudar a plasticidade e os déficits de habituação supostamente presentes nos pacientes com queixa de zumbido. O MMN é uma resposta elétrica do cérebro a um sinal repetitivo da estimulação auditiva. É um exame objetivo capaz de avaliar a plasticidade do sistema auditivo central (SAC). Segundo Hall III (2006), o MMN é talvez a mais acurada medida objetiva do processamento auditivo dentro do sistema nervoso central, não sendo necessária atenção para provocar o potencial. O MMN reflete a medida objetiva da discriminação auditiva e dos processos cognitivos, como memória sensorial (Näätänen, 2002), queixas essas bastante comuns em portadores de zumbido crônico.

Estudos sugerem uma falha no processo de habituação em pacientes com zumbido (Hallam, 1987 e Zenner, 2006) e achados de pesquisas recentes que se utilizaram do MMN indicam a existência de uma reorganização cortical diferenciada nesses sujeitos (Weisz, 2005; Mahmoudian et al., 2013 e Yang et al., 2013). Näätänen (2003) justifica a aplicabilidade do MMN em pesquisa clínica por poder ser pesquisado mesmo com o paciente dormindo ou em coma. Além disso, o MMN é o único método objetivo que mede com exatidão o processo auditivo central, a duração da memória ecóica (dado auditivo retido por um curto período de tempo) e os traços da memória auditiva permanente. $\mathrm{O}$ MMN é uma medida objetiva para a janela temporal de integração na percepção auditiva e os geradores e as significâncias funcionais são relativamente bem conhecidas. Ou seja, o MMN pode ser uma forma objetiva de verificar os déficits de habituação existentes nos pacientes com grande incômodo com o zumbido.

O presente trabalho descreve os achados do MMN de pacientes com queixa de zumbido, sem perda auditiva e os compara com os do grupo controle. 


\section{2 - REFERÊNCIAS BIBLIOGRÁFICAS}

\subsection{Neurofisiologia do sistema auditivo}

Segundo Sousa et al. (2008), a percepção auditiva é resultante de um processo eletrofisiológico que se inicia quando o som atinge a cóclea.

A distribuição do fluxo corrente no espaço extracelular (extraneuronal) é um campo potencial. A transmembrana iônica do fluxo corrente da célula, no caso dos potenciais evocados do neurônio, é a origem das voltagens que estão subjacentes nos potenciais evocados auditivos. O fluxo corrente da transmembrana pode ser associado com o potencial de ação que viaja juntamente com o axônio do neurônio ou com a atividade sináptica entre dois ou mais neurônios. O fluxo corrente dentro de uma porção de uma célula cria despolarização que é relacionada a um potencial de carga negativa na região extracelular nas proximidades. Este afluxo é equilibrado pela vazão em outra parte da célula, que está relacionada a um potencial de tensão positiva. O campo elétrico resultante, com polaridade negativa em uma extremidade e polaridade positiva na outra extremidade, é denominado dipolo. O potencial positivo, portanto, constitui a transmissão neuronal. Após a ativação do órgão sensorial, a cóclea, em um potencial evocado auditivo, tal fluxo de corrente sequencial na transmembrana evocada por estímulo ocorre em neurônios em uma direção periférica para a central, ou seja, desde a orelha até o córtex cerebral (Hall III, 2006).

De forma resumida, pode-se dizer que os potenciais evocados auditivos refletem, na verdade, os campos elétricos, que consistem na somatória da atividade elétrica transmembrana de milhares de neurônios localizados em feixes e fibras nervosas ou núcleos do sistema nervoso central (Hall III, 2006).

Pode-se dividir o sistema auditivo central (SAC) em duas vias auditivas: a primária, ascendente ou aferente, e a inespecífica ou descendente. Esses sistemas atuam conjuntamente, sendo a via aferente responsável por conduzir as informações auditivas das vias periféricas (orelha interna -OI) para o sistema nervoso central (SNC) e a via eferente por conduzir as informações auditivas do SNC para a cóclea. (Hungria, 2000; Bonaldi et al., 2004). Para Teixeira e Griz (2012), o sistema auditivo pode ser didaticamente dividido em três níveis: periférico, responsável pela captação dos estímulos; tronco encefálico, onde ocorre o início do processamento auditivo por meio da modulação e integração dos sinais; e o tálamo-cortical, no qual os processos mais 
avançados de integração dos estímulos sensoriais podem gerar respostas emocionais, linguísticas e cognitivas.

\subsubsection{Nervo auditivo}

O nervo auditivo possui dois tipos de fibras: I e II. As fibras do tipo I são mielinizadas e conectadas com as células ciliadas internas e representam 95\% das fibras do nervo auditivo. As fibras do tipo II não são mielinizadas e estão conectadas com as células ciliadas externas (Teixeira e Griz, 2012).

\subsubsection{Sistema aferente}

A via aferente apresenta representação bilateral, com predomínio contralateral no córtex. Seu centro integrador localiza-se nos núcleos cocleares, que são responsáveis pela codificação dos sons complexos, uma vez que possui organização tonotópica para a representação espacial das frequências sonoras. (Bonaldi et al., 1997; Teixeira e Griz, 2012).

\subsubsection{Núcleos cocleares}

Nos núcleos cocleares, existem locais que correspondem a frequências especificas: frequências graves (relacionadas a fibras apicais) nas regiões ventral, rostral e lateral, e frequências agudas (fibras basais) nas regiões dorsal, caudal e medial. Grande parte dos neurônios dos núcleos cocleares dirige-se ao complexo olivar superior contralateral e o restante segue ipsilateralmente para o complexo olivar superior (Bonaldi et al., 1997; Bonaldi et al., 2004).

\subsubsection{Complexo olivar superior}

O complexo olivar superior é a primeira região do sistema auditivo onde ocorre o processamento bilateral do som. Constitui um conjunto de núcleos situados na ponte: oliva superior lateral, oliva superior medial, núcleos periolivares e núcleo medial do corpo trapezoide. Tal característica permite o envolvimento dessa estrutura na lateralização e na localização sonora, sendo capaz de processar diferenças interaurais de tempo e intensidade (Aquino e Araújo, 2002; Moller, 2006). Essa estrutura ainda está relacionada 
ao 'arco reflexo', que é responsável pela proteção da orelha a sons de alta intensidade (Oliveira, 1994; Musiek e Baran, 2007).

\subsubsection{Lemnisco lateral}

O estímulo continua seu trajeto através do lemnisco lateral, estrutura que se situa na ponte, constitui grandes vias ascendentes da sensibilidade e recebe aferências de fibras dos núcleos cocleares e do complexo olivar superior. Possui três núcleos: dorsal, cuja aferência é binaural; ventral, que possui aferência contralateral, e o intermédio, cuja aferência é ipsilateral (Lopes Filho, 1994; Hungria, 2000).

\subsubsection{Colículo inferior}

As fibras de ambos os lados seguem para o colículo inferior, estrutura localizada na porção dorsal do mesencéfalo que recebe fibras dos núcleos cocleares dorsal e ventral, complexo olivar superior e dos núcleos do lemnisco lateral. Nessa região, 60\% dos

neurônios respondem a estímulos contralaterais. É a primeira estrutura no SAC com neurônios sensíveis à duração do estímulo, importante no processamento temporal. Recebe diversos tipos de informações, como frequência, intensidade, complexidade temporal, localização no espaço (Aquino e Araújo, 2002; Bonaldi et al., 1997; Teixeira e Griz, 2012).

O colículo inferior possui aferências auditivas e extra-auditivas. Está envolvido com a localização sonora e com funções motoras, como, por exemplo, medula espinhal e colículo superior, que ativa a musculatura extraocular, formando mapas de representações funcionais que permitem representar os parâmetros do "espaço sonoro". Realiza aferências periféricas com todos os núcleos inferiores, exceto núcleo ventral contralateral do lemnisco lateral, descendentes (centrais) com o córtex auditivo e corpo geniculado medial, e possui eferências para o corpo geniculado medial, núcleos auditivos do tronco cerebral e estruturas extra-auditivas colículo superior, formação reticular, mesencéfalo, cerebelo. (Aquino e Araújo, 2002; Bonaldi et al., 1997; Teixeira e Griz, 2012).

\subsubsection{Corpo geniculado medial}


O corpo geniculado medial está localizado no tálamo. Possui abundante inervação descendente, que, em conjunto com a ascendente, forma os tratos auditivos tálamocortical. Recebe fibras ipsilaterais do colículo inferior e estas se projetam ipsilateralmente ao córtex primário (lobo temporal). Porém, tanto neurônios do corpo geniculado (tálamo) como os do córtex auditivo respondem à estimulação bilateral em $90 \%$ das vezes, demonstrando que a audição neste ponto é predominantemente bilateral (Aquino e Araújo, 2002; Bonaldi et al., 1997).

Recebe aferências auditivas, visuais, somáticas e vestibulares. Possui três divisões: dorsal, ventral e medial. O corpo geniculado medial está relacionado à capacidade de discriminação e codificação de frequência e intensidade sonoras, possuindo um padrão temporal e de localização sonora, bem como participa da vigília do córtex auditivo - atenção auditiva (Oliveira, 1994; Agaeva, 2004).

\subsubsection{Córtex auditivo}

O córtex auditivo localiza-se na parte póstero-superior do lobo temporal, dentro da cisterna de Sylvius, no giro de Heschel (temporal superior), nas áreas 41 e 42 de Brodman. Posteriormente, localiza-se o giro angular ou plano temporal (Wernicke), que é responsável pelo reconhecimento dos estímulos da fala. Tem representação bilateral, sendo assim, apesar da extensa conexão entre as vias aferentes, a maioria da atividade neural que atinge o córtex auditivo primário origina-se no ouvido contralateral. (Oliveira et al., 1994, Aquino e Araújo, 2002; Teixeira e Griz, 2012).

Os neurônios corticais não são sensíveis a estímulos sonoros contínuos diferentemente dos núcleos do tronco cerebral -, mas a estímulos cujas características de frequência e intensidade variam rapidamente, uma vez que ambos os hemisférios comunicam-se entre si por um espesso feixe de fibras denominado corpo caloso. Essas características são importantes para separar um sinal auditivo de um ruído de fundo (Aquino e Araújo, 2002; Teixeira, 2005; Teixeira e Griz, 2012). O tipo de resposta de cada célula cortical pode variar em função da intensidade, localização espacial e espectro do som. Sendo assim, apresenta organização tonotópica e tem a capacidade de discriminação de intensidade, frequência e reconhecimento de sons específicos, importantes no processamento auditivo do padrão temporal e de localização sonora. (Oliveira et al., 1994; Bonaldi et al., 1997; Bonaldi et al., 2004). 
O córtex auditivo faz interações binaurais, excitatórias e inibitórias. É uma região importante para a memória e a emoção. No córtex auditivo, a mensagem é reconhecida, memorizada e possivelmente integrada numa resposta motora, uma vez que foi sendo descodificada pelos núcleos inferiores (Hungria, 2000).

Em 95\% dos seres humanos, o hemisfério esquerdo é predominante para linguagem verbal e escrita, pensamento lógico, cálculo e funções simbólicas, lógicas e analíticas, sendo assim, concentra as áreas que controlam a fala. $\mathrm{O}$ hemisfério direito é responsável pela análise da mensagem sonora, discriminação da intensidade, duração e timbre do som, organização das percepções espaciais, compreensão da entonação emocional da informação sonora, pensamento concreto e formação de imagens, imaginação e criatividade (Baran e Musiek, 2001; Teixeira e Griz, 2012).

É no córtex auditivo que termina a via auditiva aferente e começa a via auditiva eferente.

\subsubsection{Sistema eferente}

No que se refere à via eferente, ainda não há conhecimento extenso. Sabe-se que ela segue o mesmo percurso da via aferente, no entanto no sentido oposto, entrando na orelha interna pelo nervo vestibular e terminando nas células ciliadas internas na cóclea. Possui dois sistemas principais: segmento rostral, constituído por estruturas acima da região olivar superior e abrange o córtex auditivo, áreas de associação secundárias, o corpo geniculado medial, o colículo inferior e o lemnisco lateral; e o segmento caudal, que abrange o complexo olivar superior e estruturas eferentes abaixo dela, como os núcleos cocleares, nervo auditivo, terminando nas células ciliadas cocleares (Musiek e Baran, 2007).

Sabe-se que ele é responsável por modular a atividade das células ciliadas externas, pois inibe sua contração mecânica, diminuindo assim as emissões otoacústicas. Diminui também o potencial de ação do nervo coclear (VIII par) em ambientes silenciosos e o aumenta em locais ruidosos, melhorando a discriminação sonora e contribuindo para a percepção sonora (Aquino e Araújo, 2002). O sistema eferente ainda aumenta o microfonismo coclear e diminui o potencial de ação do nervo auditivo, diminuindo os movimentos da membrana tectoria e alterando, assim, a estimulação das células ciliadas internas e o potencial de somação (Bonaldi et al., 1998). O comportamento do sistema eferente ainda não é completamente entendido. 


\subsection{Zumbido}

O zumbido, ou acúfeno, caracteriza-se pela presença de um ou mais sons nas orelhas ou na cabeça e pela ausência de estímulo sonoro externo correspondente (Jastreboff, 1996; American Tinnitus Association, 1997). É uma sensação subjetiva não mensurável objetivamente, com diversos fatores etiológicos, nem sempre identificáveis, como doenças do sistema auditivo e labiríntico, distúrbios endócrinos, vasculares, neurológicos, psiquiátricos, fatores odontológicos, efeitos colaterais de medicamentos, envelhecimento e até mesmo etilismo, tabagismo e consumo excessivo de cafeína (Habets, 2000). Ainda no que se refere às causas do zumbido, pode-se considerar como principais as drogas ototóxicas, disfunções metabólicas, agressões infecciosas, traumáticas (trauma acústico, lesões de mastóide, entre outros), tumorais e vasculares (Fukuda em Ganança, 1998).

Comumente, a causa do zumbido é algum dano no sistema auditivo periférico. Estruturas altas do córtex cerebral também estão envolvidas no surgimento e na permanência da percepção desse som. Algumas pessoas não apresentam qualquer incômodo à presença do zumbido. No entanto, outras apresentam incômodo muito intenso, podendo até mesmo desenvolver alterações psiquiátricas como estresse, irritabilidade, problemas de concentração, ansiedade, depressão, desordens do sono, entre outras (Hallam, 1996; Jakes e Stephens, 1987; Walpurger et al., 2003, Holdefer et al., 2010).

Segundo Jastreboff e Jastreboff (2000), o zumbido pode causar maior ou menor impacto na vida do paciente, desde uma leve irritação a uma completa incapacitação, podendo, em alguns casos mais graves, levar ao suicídio. Há, normalmente, queixas quanto à dificuldade de dormir e/ou de se concentrar, que afeta a vida profissional, social e, conseqüentemente, a qualidade de vida do paciente.

Cerca de $20 \%$ das pessoas que apresentam zumbido referem incômodo intenso a ele (Ferrari e Sanchez, 2004). Para Fukuda (em Ganança, 1998) afirma que um terço da população urbana adulta sofre ou já sofreu com essa manifestação, sendo que a maioria não se incomoda com o zumbido, percebendo-o apenas em determinadas ocasiões, como, por exemplo, após ingestão de álcool ou quando em locais silenciosos. Cinco por cento, porém, apresentam queixas variáveis, sendo que, em algumas pessoas, chegam a ser bastante perturbadoras, dificultando as funções mentais normais, o trabalho, lazer, descanso, situações sociais e domésticas. Dessa forma, podem existir consequências no nível psíquico, de maneira que essas pessoas mostrem-se irritadiças, ansiosas, 
angustiadas, deprimidas e insones. $\mathrm{O}$ autor coloca ainda que, em raras vezes, o zumbido torna-se intolerável, havendo casos de suicídio. Já Jastreboff et al. (1996) afirmam que, embora a maioria das pessoas já tenha experimentado algum tipo de zumbido ao menos uma vez na vida, $17 \%$ da população apresenta zumbido constante, com aumento da incidência para $33 \%$ em idosos, sem preferência por sexo. Em 20\% dos casos, adquire forma severa, chega a afetar de maneira direta ou indireta o indivíduo em atividades profissionais e de lazer e interfere em relacionamentos familiares e sociais, podendo levar até mesmo ao suicídio, em casos extremos. Pode estar presente em uma ou nas duas orelhas e/ou na cabeça, tem características psicoacústicas que podem ser diferentes para cada pessoa ou que podem ter variações no mesmo indivíduo (zumbidos múltiplos e zumbido com intensidade flutuante, por exemplo).

Uma das questões motivadoras dos avanços na compreensão dos mecanismos neurofisiológicos do zumbido surgiu da observação de que indivíduos com zumbidos muito semelhantes na freqüência, intensidade, lateralização, constância e tempo de instalação poderiam ter reações completamente diferentes ao sintoma. Dados clínicos mostraram que a descrição psicoacústica do zumbido, tal como frequência, intensidade e nível mínimo de mascaramento, não tinham nenhum valor prognóstico e estavam vagamente associados ao nível de incômodo provocado pelo zumbido (Jakes et. al., 1985; Jastreboff, 1990; Hazell, 2000; Henry e Meikle, 2000). Como a gravidade do zumbido não apresenta correlação imediata com suas características psicoacústicas, outros fatores deveriam determinar o impacto emocional causado por ele. Também o entendimento sobre os mecanismos da habituação, definida por Norré (1979) como "um processo fisiológico caracterizado pelo declínio progressivo de respostas a estimulações repetitivas", trouxe uma maior compreensão dos mecanismos de percepção do zumbido.

Uma vez estabelecido por algumas semanas, o zumbido torna-se crônico. Em conjunto com suas associações mais comuns, como presbiacusia, significa que sua prevalência cresce com a idade, sendo ambos os sexos afetados igualmente. (Hawthorne e O’Connor, 1987)

Além dos aspectos médicos e audiológicos, as reações psicológicas e as consequências psicossociais do zumbido têm sido considerados fatores fundamentais para a compreensão do incômodo referido por esses pacientes. Estudos vêm comprovando aquilo que pode ser facilmente observado na prática clínica: tanto aspectos psicológicos pré-existentes ao zumbido - tais como crenças, medos, ansiedade e distúrbios da personalidade - podem influenciar na percepção e no agravamento do zumbido quanto 
este pode alterar o desempenho do sujeito em suas atividades profissionais, sociais e de lazer, interferindo muitas vezes também nas relações familiares.

Há certas peculiaridades no zumbido que o tornam um tema de difícil compreensão e pouco valorizado por alguns profissionais que trabalham com pacientes portadores dessa queixa. Não há como medir, pesar, quantificar ou até mesmo classificar objetivamente esse sintoma senão por meio de escalas análogo-visuais ou artifícios como a medida subjetiva do loudness (intensidade) e do pitch (frequência). A inexistência de um modelo animal e a dificuldade de criação de ensaios clínicos tornam o estudo do zumbido ainda mais difícil (Onishi, 2004).

Kirsch et al. (1989) comparam o zumbido à dor crônica, no sentido da não existência de uma medida realmente objetiva do zumbido. Mesmo avaliações de medidas audiológicas nas quais o zumbido é medido em níveis de audição, em decibéis, e níveis de sensação possuem um grau de subjetividade. Por isso, deve-se confiar na medida subjetiva individual do paciente no referente à intensidade e ao incômodo do zumbido.

Kau et al. (1997) afirmam que o diagnóstico precoce é de extrema importância, pois, após três meses com sintomas persistentes, se o zumbido não for tratado, pode atingir o estado crônico. Uma vez atingido o estado crônico, não há tratamento conhecido que elimine completamente os sintomas.

Sanchez et al (2005) avaliou pessoas com queixa de zumbido contínuo, que apresentavam limiares auditivos de $250 \mathrm{~Hz}$ a $8 \mathrm{KHz}$ dentro do padrão de normalidade. Observou que indivíduos com zumbido e audiometria normal constituem um grupo raro (7,4\% da sua amostra de pacientes com zumbido). As características clínicas do zumbido (tempo do sintoma, tipo, localização) eram semelhantes nos pacientes com zumbido com e sem perda auditiva Além disso, os pacientes com zumbido e perda auditiva apresentavam mais queixas relacionadas à dificuldade de concentração e equilíbrio emocional que aqueles sem perda de audição. No entanto, a interferência do zumbido no sono e nas atividades sociais foi semelhante em ambos os grupos com e sem perda auditiva.

Para explicar os mecanismos de desenvolvimento do zumbido crônico, Hallam (1987) desenvolveu a teoria de habituação do zumbido. Hipotetizou que o som do zumbido é apenas um sinal do corpo ao qual se presta muita atenção. Segundo esta teoria há um déficit da habituação apenas nos pacientes com queixa de zumbido importante (Hallam et al., 1984). 
A partir dessas pesquisas, Jastreboff (1990) hipotetizou o modelo neurofisiológico do zumbido por meio do qual afirma que a origem do zumbido é mais do que um 'problema' do sistema auditivo, ela pode envolver o sistema límbico e o sistema nervoso autônomo. Ou seja, o zumbido, mesmo sendo gerado por uma lesão no sistema auditivo periférico, pode receber uma contribuição dos mecanismos auditivos centrais, sistema límbico e sistema nervoso autônomo, que agem engrandecendo o zumbido. Nesse modelo, entram em cena o sistema límbico e o sistema nervoso autônomo como determinantes do incômodo relacionado ao zumbido.

Segundo Gerken (1996) o estudo do zumbido central é difícil, uma vez que ele recebe interferência de alterações periféricas e de intricada intercorrelação de complexos sistemas, como o sistema auditivo. Altas estruturas cerebrais estão envolvidas no zumbido, e estas podem ser percebidas por meio das diferentes maneiras de lidar com o som interno (Hallam, 1996; Jakes e Stephens, 1987).

Rief et al. (2005) afirmam que, se o zumbido é crônico (tem duração maior que 6 meses), a remissão espontânea é rara. Segundo os autores, muitas pessoas podem lidar bem com o zumbido, no entanto um subgrupo de 1 a $2 \%$ da população em geral sofre com o zumbido e frequentemente desenvolve doenças, como depressão, comportamento de esquiva, introversão, entre outras.

Ferreira et al. (2009) desenvolveram um estudo buscando avaliar e qualificar o zumbido em idosos. Observaram que $35 \%$ dos pacientes avaliados afirmaram que o zumbido interfere no seu equilíbrio emocional, o que, segundo os autores, reflete-se na nota de incômodo dada pelos pacientes, que classificaram o zumbido como um incômodo acentuado. Ressaltaram que o incômodo gerado pelo zumbido é acrescido na deficiência auditiva própria da idade, a presbiacusia, provocando isolamento social em função da dificuldade de comunicação. O mesmo ocorre com o déficit de atenção, de concentração e os distúrbios do sono comuns no idoso, que são aumentados pela presença do zumbido, dificultando as atividades diárias. Não encontraram correlação entre o grau de perda auditiva, segundo a audiometria, e o nível de incômodo do paciente com o zumbido, o que indica que o incômodo está ligado à maneira como o paciente encara o seu zumbido, e não a uma medida física ou anatômica. Ou seja, para os autores, o sistema límbico está muito mais envolvido na gênese e na perpetuação do zumbido que o próprio sistema auditivo. As afirmações de Ferreira et al. (2009) são contrárias às de Sanchez et al. (2005), pois esses autores acreditam que a presença de perda auditiva aumenta o risco de o zumbido provocar problemas de concentração e de afetar o equilíbrio emocional. 
O zumbido está ligado a mudanças ou anormalidades em um ou mais níveis ao longo da via auditiva. Estudos de imagem cerebral em humanos têm identificado atividade alterada em áreas auditivas relacionadas ao zumbido, incluindo o colículo inferior e o córtex auditivo. Quando há perda auditiva associada, o sistema auditivo central parece aumentar o seu ganho para compensar a redução de entrada neurossensorial da cóclea induzida por trauma acústico, agentes ototóxicos ou outras causas (Kaltenbach et al., 2005; Finlayson et al., 2009).

Além de hiperatividade, alterações no sistema auditivo relacionadas ao zumbido também incluem o aumento da atividade de disparo neural. Similar atividade tem sido relatada no colículo inferior depois de tratamentos com salicilato (Wallhäusser-Franke, 1997) e cisplatina (Bauer et al., 2008). Modelos animais que têm corroborado para essa elucidação apontam para a presença de uma reorganização dos mapas tonotópicos e um aumento espontâneo da atividade ou sincronia neural no córtex auditivo na origem do zumbido (Roberts et al., 2010). Há também uma crescente quantidade de estudos em animais e humanos evidenciando que o zumbido está relacionado ao aumento da excitabilidade de algumas regiões do córtex auditivo (Dong et al., 2010).

Enquanto aproximadamente 75 a $80 \%$ dos pacientes mostram alguma habituação ao zumbido, em $20 \%$ deles este som é associado a alterações significantes na rotina diária quando a habituação falha, levando frequentemente a estados depressivos e ansiosos (Anderson, 2001; Cuny et al., 2004 e Robinson et al, 2007).

Embora exista muita incerteza em relação aos mecanismos neurobiológicos subjacentes ao zumbido, existem convincentes evidências de neuroimagem e neurofisiologia apontando que esta situação está relacionada com o funcionamento anormal do sistema auditivo central (Lanting et al., 2010 e Weiz et al., 2007). Além disso, durante as últimas décadas, vários autores argumentaram que deficiências em processos de atenção podem estar envolvidas no zumbido, particularmente por dificultarem o mecanismo de habituação, o que é reforçado pelo fato de o zumbido não estar apenas relacionado com atividade anormal no sistema auditivo, mas também em regiões não auditivas do cérebro (Anderson, 2002; Lanting et al., 2009; Leaver et al., 2011; Roberts et al., 2013)

Alterações foram encontradas no córtex pré-frontal de sujeitos com zumbido, uma região que possui um papel crucial nos processos de atenção (Wang et al., 2010). Diversas pesquisas apontam que essas alterações podem estar especificamente 
relacionadas com a prevenção da habituação do zumbido, bem como com as suas consequências psicológicas na vida cotidiana dessas pessoas (McDonald et al., 2000; Stevens et al., 2007; De Ridder et al., 2014).

\subsubsection{Zumbido e emoções}

Zenner (2006) afirma que, no caminho do som dentro do córtex auditivo, o sinal sonoro é comparado com experiências prévias, armazenadas na memória, ligadas à emoção. O mecanismo do SAC seleciona e filtra os sons que serão levados à consciência, que conta com a participação do sistema límbico e pode determinar o foco atencional e gerar alterações físicas e o desenvolvimento de estratégias adaptativas (Jastreboff, 1990; Zenner, 2006).

As reações emocionais ao zumbido são consideradas muito importantes na determinação do desconforto provocado por ele. A ansiedade e a depressão são frequentemente descritas e associadas a um maior incômodo com esse som (Henry e Wilson, 2000).

Nos últimos anos, observa-se crescente atenção aos fatores psicológicos e cognitivos da percepção do zumbido. Enquanto apenas estudos longitudinais podem clarear completamente se psicopatologia é "causa" ou "efeito" de um incômodo e gravidade subjetiva com o zumbido, as pesquisas geralmente suportam a ideia de que altos níveis de psicopatologia são encontrados em indivíduos com queixa de níveis de zumbido perturbadores (Kirsch et al., 1989).

Para Hawthorne e O’Connor (1987), o comum e frequente incômodo com o zumbido é geralmente entendido como não sendo de causa psicogênica. Porém, fatores psicológicos determinam como as pessoas reagem à queixa, e os médicos devem, portanto, considerá-los com cuidado.

Já Habets (2000) afirma que nem todos os casos de zumbido estão correlacionados diretamente com estresse, ansiedade ou depressão, mas a maneira como cada indivíduo vai reagir e ser afetado por esta desordem vai, frequentemente, ser fortemente influenciada pelo seu estado mental. O nível de estresse das pessoas modifica-se conforme os acontecimentos diários, porém uma dificuldade crônica, como o zumbido, cujos sintomas podem ser ainda mais difíceis de serem ignorados, será, por si só, um motivo para um considerável adicional de estresse. Apesar de serem desordens separadas, há ligação próxima entre ansiedade e depressão, uma frequentemente precede à outra. Os 
sintomas de qualquer doença, incluindo o zumbido, têm sua percepção aumentada quando o paciente encontra-se em um estado depressivo ou ansioso. Não é incomum encontrar um círculo vicioso, em que o zumbido cria ansiedade, ou outro problema psicológico aliado; o aumento da ansiedade faz, então, com que o zumbido pareça pior do que realmente é, o que retroalimenta a ansiedade. O autor diz ainda que, se este círculo não pode ser quebrado com a cura (ou melhora) do zumbido, uma possibilidade de ajuda efetiva seria a redução do nível de ansiedade.

Os estudos com diversos tipos de instrumentos mostram que $50 \%$ dos pacientes com zumbido apresentam desordem afetiva média a moderada. Os pacientes que somatizam seus problemas no zumbido são difíceis de ajudar. Outros se tornam seriamente deprimidos (Hawthorne e O’Connor, 1987).

Segundo Rief et al. (2005), um problema em fornecer intervenções psicológicas para os pacientes com zumbido é a discrepância entre as atribuições orgânicas da doença do paciente e o enfoque da intervenção psicológica.

Muitos processos parecem estar envolvidos na percepção do zumbido. Entre eles, destacaremos os mais citados pela literatura: atenção, afetividade, crenças, estratégias usadas para lidar com o sintoma (coping strategies).

A atenção é a focalização consciente e específica sobre alguns aspectos ou algumas partes da realidade. Ele acrescentou que a consciência poderia, voluntariamente ou espontaneamente, privilegiar determinado conteúdo e determinar a inibição de outros conteúdos vividos. É o que nos permite conversar em ambientes ruidosos, por exemplo, quando o sinal da fala é privilegiado em detrimento dos outros sons ambientais, mesmo que os últimos fossem mais intensos. Esse processo é chamado de atenção seletiva, ou ainda, de abstração seletiva, ou seja, "capacidade de focalizar um aspecto da situação, ignorando questões menos importantes ou irrelevantes” (Falcone em Rangé, 1995).

A afetividade é responsável pela valorização de fatos e acontecimentos, de medos, fantasias, conflitos, anseios, etc., tanto de acontecimentos passados quanto de perspectivas futuras e, quanto maior for o grau de afetividade envolvida na apreensão de uma determinada situação, maior será a importância dessa situação. Imagine como exemplo um músico portador de zumbido com a crença - conjunto de conhecimentos tácitos, fundamentais e profundos do indivíduo, que se formam nas relações do indivíduo com o meio e com os outros (Beck, 1997) - de que o barulho vindo dos ouvidos possa ser sinal de que ele está perdendo a capacidade auditiva (o que não é necessariamente verdade), podendo impedir sua atuação profissional. Nessa situação, o zumbido poderia 
ser bastante valorizado por esse indivíduo, o que aumentaria sua percepção, trazendo-lhe forte incômodo.

Este fato foi evidenciado no trabalho de Hallam et al. (1984). Os autores criaram a hipótese de que a exposição repetida e persistente a altos níveis de estímulo auditivo ou a associação do zumbido a um significado afetivo impediriam a habituação a esse som "fantasma", denominado zumbido. Os autores sugeriram que os sistemas neurais envolvidos na percepção do zumbido estariam ligados ao hipocampo, uma parte do sistema límbico que é a porta de entrada para os centros mediadores de controle emocional e importante componente do sistema de memória.

Também Jakes et al. (1985) identificaram que o aspecto afetivo seria responsável pelo sofrimento (distress) em relação ao zumbido. Identificaram que a persistência do zumbido foi apontada como uma qualidade negativa do som por $87 \%$ dos seus 110 sujeitos com zumbido. Os autores levantaram ainda a possibilidade de ser a "incontrolabilidade" do zumbido uma das causas da aversão ao sintoma, além de acreditarem que as crenças e atitudes do indivíduo em relação ao zumbido pudessem ser importantes mediadores do sofrimento.

Carlsson e Erlandsson (1991) recorreram à premissa de que a relação entre o estado de saúde subjetivo e a afetividade negativa explicaria a rotulação negativa que é dada a determinadas sensações físicas. Afetividade negativa é a tendência de se descrever o humor e os estados emocionais com termos negativos. Segundo os autores, a afetividade negativa exacerbada de alguns indivíduos provoca um estado de vigilância permanente, em que qualquer estímulo é considerado ameaçador e, por isso, é permanentemente checado, o que propicia a percepção de pequenas dores. Fazendo um paralelo com a percepção auditiva, é possível que indivíduos ansiosos que tenham por hábito checar suas sensações físicas tenham a percepção do zumbido mais evidenciada que outras pessoas com zumbidos semelhantes. Pode-se observar a presença de mecanismos psicológicos semelhantes e processos cognitivos subjacentes à ansiedade e à depressão, uma vez que, segundo Wainer et al. (em Caminha et al., 2003), os pacientes depressivos apresentam também comportamento viciado em pensamentos negativos e tendência a interpretar suas experiências de forma negativa.

Jastreboff (1990) e Jastreboff e Jastreboff (2000) sugeriram que a associação do zumbido a situações desagradáveis (por ser contínuo, repetitivo e fora do controle da pessoa) ou de perigo (associação com doenças graves, perda de audição e outros) contribuiria para a percepção do zumbido e o aumento do incômodo. A presença contínua 
do estímulo, nesse caso, aumentaria ainda mais o incômodo, que, por sua vez, reforçaria a ativação dos centros de percepção sonora. Jastreboff (1990) propôs que o resultado da interação dinâmica entre os centros auditivos e não auditivos do sistema nervoso central, especialmente do sistema límbico e do sistema nervoso autônomo, fosse responsável pelo desencadeamento de associações emocionais negativas e reações de incômodo referidas pelos pacientes com zumbido clinicamente significativo. É interessante observarmos que tanto as crenças quanto as emoções foram consideradas como motivo para uma maior percepção do zumbido acompanhada de reações de incômodo e que, ao mesmo tempo, as reações de incômodo seriam responsáveis pela perpetuação da percepção do estímulo. Percebe-se que indivíduos ansiosos possuem uma percepção exagerada de perigo e ameaça, combinada a uma percepção diminuída de sua capacidade em lidar com eles. Apresentam vieses de memória para material que inclua sinais de ameaça. Dedicando recursos excessivos de atenção para descobrir ou detectar perigo, tendem a interpretar erroneamente mensagens ou estímulos ambíguos como ameaças e fazem associações mais rápidas e predominantes com o perigo. Sendo assim, parece haver um ciclo vicioso de detecção de ameaça, com decorrente ativação e inibição somáticas, o desencadeamento do pensamento perturbador que gera preocupação e previsões negativas acerca de eventos futuros e perpetua a resposta de ansiedade (Schinohara, Nardi em Rangé, 2001).

Quando Jastreboff (1990) discute a ausência de controle sobre o zumbido, podese pensar nos desencadeadores e reforçadores de ansiedade e depressão. A percepção de falta de controle sobre as situações gera ansiedade e, tentando diminuir essa ansiedade, o paciente faz uso de estratégias de enfrentamento que visam a reduzir o grau de desconforto gerado por ela. Caso não consiga controlar a ansiedade com suas tentativas, tende a criar crenças a respeito de sua incapacidade em lidar com problemas novos, gerando baixa autoestima. Verifica-se aí um espectro entre ansiedade e depressão. De um lado, o sujeito sente-se incapaz de lidar com situações difíceis, gerando ansiedade. De outro, a exposição a situações "sem controle" leva-o a uma posição de desespero/desamparo, característica de quadros depressivos (Wainer et al. em Caminha et al., 2003).

Budd e Pugh (1995) encontraram dados indicando que crenças pessoais a respeito do zumbido, assim como as atitudes dos outros (amigos e familiares) em relação a esse sintoma, poderiam ser consideradas fatores de influência significativa no processo de habituação do zumbido. De modo semelhante, Hallam et al. (2004) defenderam que, além das crenças, sentimentos e atitudes negativas do indivíduo em relação ao zumbido, 
as estratégias adotadas para lidar com ele (coping strategies) influenciariam fortemente a redução da percepção e a atenção auditiva do zumbido, e a habituação ocorreria de maneira passiva ao longo do tempo.

Carpenter-Thompson et al. (2014) compararam os achados de imagem de ressonâncias magnéticas funcionais com contraste de três diferentes grupos de sujeitos estimulados com sons desencadeadores de distintas respostas emocionais. Os grupos foram assim divididos: um com indivíduos com perda auditiva bilateral e queixa de zumbido; outro com perda auditiva bilateral e sem zumbido; e o último sem perda auditiva. Concluíram que a maior influência do zumbido deve estar fora das áreas do córtex auditivo primário (pois não encontraram diferenças entre os grupos nessas regiões), nas regiões do sistema límbico do parahipocampo e da ínsula. Encontraram evidências de diferenças no processamento emocional e comportamental entre os participantes do grupo controle e do grupo com zumbido, sugerindo uma inteiração entre o zumbido e o sistema límbico. A resposta aumentada observada no parahipocampo pode indicar uma falta de habituação ao novo preceito, resultando na persistência do zumbido. O aumento da atividade na ínsula pode, segundo os autores, ser uma indicação de mecanismos compensatórios para manejar o incômodo com o zumbido.

Budd e Pugh (1995) propuseram que o modo com o qual os indivíduos lidam com o sintoma também estaria associado ao grau de severidade do zumbido. Os autores classificaram o estilo de lidar com o zumbido em três categorias: (1) "enfrentamento mal adaptado" (maladaptive coping), caracterizado por pensamentos catastróficos a respeito das conseqüências do zumbido; (2) "enfrentamento efetivo" (effetive coping), no qual o indivíduo se adapta à situação usando recursos como self-talk, focar a atenção em atividades prazerosas para diminuir o grau de "intrusão" do zumbido; e (3) "enfrentamento passivo" (passive coping), que envolveria o uso de sons ambientais, aparelhos mascaradores de zumbido para encobrir o barulho dos ouvidos. No intuito de verificar o sofrimento emocional e a severidade do zumbido, os autores aplicaram o Beck Depression Inventory (BDI), o State-Trait Anxiety Inventory (STAI), o Locus of Control Behavior (LCB) e um questionário específico para acessar o grau de severidade do zumbido em um grupo de 108 indivíduos que sofriam desse sintoma. Observaram forte correlação entre o estilo "enfrentamento mal adaptado" a altos níveis de ansiedade, depressão e severidade aumentada do zumbido, enquanto, surpreendentemente, o oposto não foi verdadeiro ("enfrentamento efetivo", baixos níveis de ansiedade e depressão e menor severidade do zumbido). De acordo com os autores, tal achado estaria 
evidenciando que não seria o uso de estratégias para lidar com o zumbido que ajudaria esses indivíduos (até porque o seu uso não garante sua eficácia e ainda contém o risco de serem usadas obsessivamente pelos pacientes), mas sim a ausência de comportamentos mal adaptativos, como evitar criar fantasias catastróficas sobre o zumbido e evitar monitorar o zumbido, por exemplo, que prediria o sucesso da sua habituação.

\subsection{Potenciais Evocados Auditivos}

\subsubsection{Potenciais evocados auditivos de longa latência}

Potencial evocado é a atividade bioelétrica provocada por uma estimulação. Ele decorre de dois potenciais determinantes: potencial de membrana e potencial de ação. $\mathrm{O}$ potencial de membrana decorre do excesso de ânions e cátions que se acumulam nas faces interna e externa das células nervosas, por meio de transporte ativo ou gradiente de concentração, promovendo assim uma diferença de potencial. O potencial de ação é a sequência de alterações rápidas do potencial de membrana deflagradas por qualquer agente elétrico, químico ou físico que perturbe o estado normal de repouso da fibra nervosa. (Sousa et. al., 2008)

Expertises moldam a anatomia e a fisiologia cerebral. Dessa forma, especialistas mostram maior habilidade nas suas áreas de especialização que naquelas nas quais não são especializados. Habilidadades de navegação, por exemplo, foram associadas a um relativo aumento do volume da substância cinzenta no hipocampo posterior acompanhado de um relativo decréscimo no hipocampo anterior em motoristas de táxi londrinos. Sabese que jogadores de xadrez profissionais ativam diferentes sistemas cerebrais que os novatos (Campitelli et al., 2007, Maguire et al., 2006). Em um estudo longitudinal, Hyde et al. (2009) encontraram alterações estruturais no cérebro após um período relativamente curto, de 15 meses, de treinamento musical, que foram correlacionadas a melhorias nas habilidades motoras e auditivas musicalmente relevantes.

A medida direta dos disparos neuronais em humanos é possível apenas pelo uso de métodos invasivos (Yang et al., 2013). Como alternativa, as mudanças funcionais na atividade do córtex auditivo podem ser reveladas nas pessoas com zumbido por meio de imagens de ressonância magnética funcional ou eletroencefalografia de alta resolução (Johnson, 2007). Ressonância magnética funcional e tomografia com emissão de positron revelaram diferenças nas respostas evocadas por som entre sujeitos com e sem zumbido (Lanting et al., 2009). 
Os potenciais evocados auditivos relacionados a eventos também podem refletir o estado funcional do córtex auditivo, mas os resultados não são totalmente consensuais. Para Frizzo et al. (2001), as áreas auditivas cerebrais geradoras dos potenciais tardios ainda não estão muito claras. Sabe-se que esses potenciais são consequência da participação conjunta de várias estruturas neurais, tendo, portanto, geradores múltiplos. Participam na geração desses potencias as regiões central e parietal. O lobo parietal é ativado para as habilidades de orientação e atenção de eventos relevantes e, em conjunto com áreas pré-frontais, age nos processos de atenção e interage com o hipocampo, ativando a memória. (Smith et al., 1990, Picton \& Hillyard, 1974).

\subsubsection{Mismatch Negativity Response - MMN}

Quaisquer mudanças nas características sonoras invariáveis do meio são de extrema importância para a sobrevivência. Sendo assim, a detecção fácil, rápida e sensível das alterações auditivas é de crucial importância para o organismo.

Em humanos, a detecção pré-atencional das alterações auditivas é evidenciada por uma resposta elétrica do cérebro, com uma distribuição no couro cabeludo fronto-central, chamada de MMN (Ruusuvirta et al., 2013).

O MMN (negatividade descombinada ou MMN) foi descoberto por Risto Näätänen et al. (1978). Desde que foi descrito pela primeira vez, no final dos anos 70, o MMN tem sido largamente usado nas pesquisas teóricas e clínicas (Wacongne et al., 2012). O MMN é um componente endógeno negativo dos Potenciais Relacionados a Eventos e é correlacionado com a função cognitiva (Roggia in Bevilacqua et al., 2011).

A denominação Mismatch Negativity foi adotada porque o nome "mismatch" denota a detecção de mudança, indicando uma discordância entre um input sensorial novo e a representação de um estímulo padrão gravado na memória sensorial auditiva. Já o termo "negativity" foi utilizado porque representa a polaridade do potencial, que é sempre negativa (Roggia in Bevilacqua et al., 2011).

Para Haal III (2006) o MMN é frequentemente categorizado como uma resposta relacionada ao evento (potencial), uma resposta evocada cognitiva ou uma resposta discriminante cortical evocada, em contraste com a assim chamada "resposta obrigatória de latência prematura" (ECochG, ABR, AMLR).

O MMN mostra o processamento central em resposta a mudanças sutis no estímulo acústico, como duração, intensidade e frequência do estímulo (Junqueira e 
Frizzo, 2002). Nos 30 anos que seguiram à descoberta dessa onda, investigações clínicas e laboratoriais extensivas foram produzidas, confirmando os geradores no córtex auditivo no lobo temporal e no lobo frontal e também a contribuição de outras regiões subcorticais. O MMN é, talvez, a medida objetiva mais acurada do processamento auditivo no sistema nervoso central (Haal III, 2006).

No domínio auditivo, muitos estudos têm utilizado um paradigma raro (Näätanen, 1992), em que os participantes são apresentados a uma sequência de eventos que obedecem a uma determinada regra, pontuados por ocasionais "raros", ou eventos que violam essa regra. Esses oddballs, ou estímulos raros, frequentemente evocam atividade neurofisiológica distinta, refletindo na chamada "negatividade por incompatibilidade de resposta" (MMN).

O MMN é mais bem detectado com eletrodos no couro cabeludo, acima da região centro-frontal do cérebro. O MMN é o reflexo de inúmeros processos cerebrais, simultâneos ou sequenciais e fundamentais, incluindo análise pré-atencional de características sonoras (ex: frequência, intensidade, duração, características de fala), extraídos ou derivados de múltiplos estímulos acústicos, um traço de memória sensorial na modalidade auditiva que representa a estimulação sonora, e uma comparação existente do estímulo frequente versus o estímulo raro (Haal III, 2006).

O MMN pode ser observado nas gravações eletroencefalográficas (EEG) com um tempo de latência de cerca de 100 a 200 ms, segundo Näätanen (1992); já conforme Haal III (2006) e Roggia in Bevilacqua et al. (2011), ele acontece entre 100 e 300 ms. No paradigma clássico e mais simples, a sequência principal compreende estímulos tonais idênticos, chamados "padrões". Os excêntricos (raros) são eventos que diferem das normas em algum aspecto físico, tais como a frequência (Doeller et al., 2003; Baldeweg et al., 2004; Garrido et al., 2008; Boly et al., 2011), a duração (Schroger e Wolff, 1998), a amplitude (Garrido et al., 2011) ou o intervalo de estímulo (Ford e Hillyard, 1981). A resposta do MMN em todos esses casos representa um marcador neurofisiológico tanto da internalização da regularidade quanto da detecção de alterações.

Pode ser evocada por inúmeros tipos de sons, desde tons simples até complexos moldes de estímulo acústico e estímulos de fala. Alguns experimentos observaram sinais de MMN associados à violação de regras mais sofisticadas. Os exemplos incluem: uma sequência tonal em que, quanto maior a frequência de um tom, mais alta a sua amplitude, com violação por um tom alto de frequência baixa ou de alta frequência (Paavilainen et al., 2001); uma sequência de pares de tom descendente regularmente quebrados por uma 
combinação ascendente ocasional (Tervaniemi et al., 1994); ou um padrão rítmico normal violado por um evento inesperado (Vuust et al., 2005).

Segundo Lang et al. (1995), o MMN reflete a discriminação auditiva préatencional, automática, e a ativação da memória ecóica, sendo um indicador de discriminação auditiva extremamente valoroso (Näätänen, 2001).

Duas características do MMN são especialmente atrativas sob a perspectiva clínica. A primeira é que o MMN não depende de respostas da atenção consciente a sinais acústicos (excelente para crianças novas), outra é a população de pacientes que são desafiados e não respondem bem a técnicas audiológicas comportamentais devido a déficits no estado atencional, motivacional, cognitivo e a outras variáveis subjetivas.

$\mathrm{O}$ fato de o paciente estar atento ou ignorando o estímulo desviante tem pouco efeito na amplitude do MMN. É fato que o MMN puro é mais bem gravado em condições passivas, em que o sujeito não presta atenção aos estímulos auditivos (lendo, vendo filme, ou mesmo dormindo). Pode ser gravado em crianças em sono profundo e em pacientes em coma.

É possível eliciar o MMN com sutis distinções entre o estímulo não variante e o estímulo alvo (variável). Uma relevância particular da aplicação clínica do MMN em audiologia é o fato de o MMN ser um reflexo objetivo, um catálogo, um indicador do processo auditivo automático central.

O MMN reflete a pré-consciência ou a detecção perceptual de uma mudança no estímulo acústico, mesmo uma pequena mudança, praticamente imperceptível (Haal III, 2006). É frequentemente interpretado como código preditivo, assumindo-se que o cérebro não responde passivamente aos inputs recebidos, mas aprende as regularidades de inputs e usa esse conhecimento para ativamente predizer qual o som que acontecerá a seguir (Rao e Ballard, 1999; Lee e Mumfors, 2003). O sistema auditivo adquire um modelo interno de regularidades dos inputs auditivos, incluindo aqueles abstratos, que são utilizados para gerar previsões ponderadas sobre os estímulos recebidos. Se essas previsões se diferenciarem do estímulo atual, isso resulta em um sinal incompatível (Paavilainen et al., 2001; Näätänen et al., 2005; Winkler, 2007).

Gene-Cos et al. (2005) afirmou que a amplitude do MMN tende a ser maior em pacientes com epilepsia que em controles saudáveis. Pode-se hipotetizar que as amplitudes maiores observadas nos pacientes epiléticos indicam uma ativação aumentada de neurônios estimulados em relação ao grupo controle, ou que circuitos neurais outros são ativados nos pacientes epiléticos (Myatchin et al., 2009). 
A literatura estudada oferece formas discrepantes de como o MMN é afetado em pacientes esquizofrênicos. Áreas envolvidas no processamento auditivo mostram-se anormais em esquizofrêncos, e anormalidades estruturais e metabólicas também estão alteradas nesses pacientes. Por exemplo, Dierks et al. (1999) encontraram um aumento do nível de sangue e oxigênio no giro de Heschl's durante as alucinações dos pacientes com esquizofrenia, sugerindo o envolvimento de áreas do sistema auditivo primário em alucinações verbais auditivas. Todd et al. (2013) afirmam que há mais de 150 artigos sobre pequenas mudanças na amplitude do MMN em pessoas com esquizofrenia, sendo esse potencial cortical agora reconhecido como a anormalidade eletrofisiológica mais replicável nesse grupo. Revisaram pesquisas que utilizaram o MMN na avaliação de esquizofrênicos e concluíram que o MMN é uma boa ferramenta para o estudo dos processos biológicos que acontecem em esquizofrênicos (ou que potencialmente possam desenvolver essa doença).

Estudos como os de Kraus et al. (1995) e os de Han et al. (2013), utilizando o MMN com estímulo sonoro silábico, concluíram ser este potencial uma boa ferramenta na avaliação da plasticidade do SAC. Sendo assim, é plausível sugerir que o MMN pode ser um bom instrumento na avaliação da plasticidade do sistema auditivo de sujeitos com zumbido.

\subsubsection{Geradores do MMN}

Como a detecção do som desviante (raro) requer armazenamento de informações e comparação com outras informações auditivas adquiridas ao longo do tempo, isso pode ser considerado como uma forma de processamento cognitivo, ou "inteligência primitiva" (Näätänen et al., 2001). Segundo Ayala e Malmierca (2013), a detecção do estímulo desviante acontece no córtex auditivo.

Os geradores do MMN são, em grande parte, desconhecidos. Vêm sendo propostas explicações diferenciadas e parcialmente contraditórias (Jääskeläinen et al., 2004, Näätänen et al., 2005, Wacongne et al., 2012). No entanto, é consenso que o MMN tem sua geração nas áreas corticais temporal, e subsequentemente, frontal, com uma 
possível contribuição de níveis mais baixos na via auditiva (Giard et al., 1990, Kropotov et al., 1995, Rinne et al., 2000, Rosburg et al., 2007).

Estudos sugerem que a detecção de desvio pode ser uma propriedade básica da organização funcional do sistema auditivo, ocorrendo em níveis múltiplos ao longo da via auditiva (Grimm et al. 2011; Grimm e Escera, 2012) e provavelmente reflete estágios pré-atencionais do processamento da informação e da análise sensorial do input auditivo e sua codificação em traço de memória (Näätänen, 1995)

Para Roggia (2011), o gerador principal do MMN está localizado no córtex auditivo. No entanto, ela afirma que a localização acurada desse potencial depende dos componentes geradores do MMN e modifica-se conforme o tipo (tons ou sons complexos, por exemplo) ou a característica do estímulo modificado (duração, intensidade, frequência, etc.) utilizados para eliciar o potencial.

Segundo Alho (1995), as principais fontes corticais do MMN captado no couro cabeludo estão localizadas bilateralmente no córtex auditivo primário e secundário e sua localização precisa depende da característica sonora do estímulo.

Ruusuvirta et al. (2013) sugerem a participação do hipocampo na formação do MMN. Segundo os autores, não há pesquisas comprovando a participação do hipocampo provavelmente porque, para observação de respostas nessa região, o som desviante deve apresentar grande variação do estímulo frequente e o indivíduo deve estar em total repouso (dormindo ou anestesiado), não sendo essa as aplicações mais comuns do MMN.

Anatomicamente, a origem do MMN inclui o plano supra-temporal e regiões posteriores do córtex auditivo e regiões dentro do córtex do lobo frontal. A formação da memória auditiva sensorial acontece dentro de $200 \mathrm{~ms}$, janela de integração temporal, independentemente do tipo de estímulo - tons, fala ou mesmo música (Näätänen, 1990). A resposta de MMN reflete informações processadas que precedem e podem ser prérequisitos para o processo da atenção comportamental (consciente) das mudanças auditivas no ambiente.

Näätänen (1992) constatou que o MMN gerado por mudança de frequência apresenta dois componentes, um no lobo temporal e outro no lobo frontal, sendo este maior no hemisfério direito do que no hemisfério esquerdo, independentemente da orelha estimulada. 


\subsubsection{Potenciais de longa latência relacionados a eventos e zumbido}

Norena et al. (1999) hipotetizaram que há diferenças no processamento da informação auditiva cortical entre pessoas com diferentes formas/queixas de zumbido e sujeitos sem queixa de zumbido (controle). Optaram por analisar os potenciais de longa latência N1-P2, com diferentes intensidades, em sujeitos com zumbido e hipersensibilidade. Para o grupo com zumbido, recrutaram 16 sujeitos com zumbido bilateral e 9 com zumbido unilateral; e, para o grupo controle (sem zumbido), 13 indivíduos. Foram excluídos aqueles que apresentaram limiar acima de $20 \mathrm{~dB}$ em $1 \mathrm{kHz}$ (nas demais frequências, os avaliados com zumbido apresentavam perda auditiva). Concluíram que há diferenças eletrofisiológicas entre sujeitos que possuem zumbido quando comparados com aqueles que não têm zumbido. Observaram que a amplitude do complexo N1-P2 era aumentada nas orelhas com zumbido quando comparadas com as orelhas sem o sintoma em pacientes com zumbido unilateral. Observaram também que a latência da onda $\mathrm{N} 1$ foi menor nos sujeitos com zumbido bilateral do que no grupo controle, achado este corroborado pela pesquisa de Jacobson e McCaslin (2003)

Walpurger et al. (2003) avaliaram as ondas N1 e P2 dos potenciais evocados de longa latência relacionados a eventos, com o intuito de verificar os indicadores de processamento automático do estímulo. Para a coleta das ondas, utilizaram um aparelho de eletroencefalograma, e os participantes contavam mentalmente os sons (tone pips) apresentados. Dividiram um total de 32 sujeitos em 3 grupos: 10 no grupo com zumbido com incômodo; 12 com zumbido sem incômodo; e 10 no grupo controle. Observaram que a latência do complexo N1-P2 do grupo controle era maior do que a encontrada nos pacientes com zumbido. Segundo os autores, os achados do estudo suportam o conceito do déficit de habituação neurofisiológica em pacientes com zumbido, que pode ser a causa do desconforto gerado por ele.

Weisz et al. (2004) utilizaram o MMN por meio de eletroencefalograma para avaliar 15 pessoas com queixa de zumbido, cujos achados foram comparados aos de 15 sujeitos sem queixas auditivas. Avaliaram o incômodo provocado pelo zumbido com o Questionário Alemão padrão (Tinnitus Fragebogen). O grupo com zumbido apresentava moderada a severa perda auditiva em frequências agudas, e o grupo controle era composto por normoouvintes. Encontraram diferenças na amplitude do MMN dos sujeitos com maior incômodo com o zumbido quando comparados com os que apresentavam menor incômodo (nestes foram evidenciadas maiores anormalidades na amplitude do MMN). 
Porém, o padrão do MMN nos sujeitos com grande incômodo com o zumbido não pôde ser comparado com o padrão coletado no grupo controle (com audição normal), já que há uma considerável mudança no foco de ativação neural em função da alteração auditiva. Os autores referem também um possível envolvimento, especialmente de áreas préfrontais do hemisfério direito, no zumbido (dado o cuidado da baixa resolução espacial oferecida pelo eletroencefalograma). Com base nesses achados, hipotetizaram que a lesão nos receptores auditivos da orelha interna dispararia um processo de reorganização, levando a um padrão de MMN anormal, como encontrado em sujeitos com baixo incômodo com o zumbido. Com o aumento do incômodo, no entanto, regiões frontais do cérebro envolvidas na regulação emocional e atencional modulariam a resposta do MMN.

No intuito de avaliar os efeitos da estimulação magnética transcraniana em pessoas com zumbido subjetivo, Yang et al. (2013) utilizaram eletroencefalografia para coletar potenciais evocados auditivos relacionados a eventos, associando-os com mapas topográficos cerebrais de 20 sujeitos com zumbido subjetivo e 16 sujeitos sem zumbido. Utilizaram o THI antes e depois do tratamento para graduar a severidade do zumbido naqueles com este sintoma. Verificaram que os sujeitos com zumbido apresentam diferenças na latência e na amplitude das ondas N1, P2 e MMN, sendo essas diferenças estatisticamente significantes (exceto amplitude de P2). Após a aplicação da estimulação meganética transcraniana durante o período de uma semana, houve novamente mudanças nos achados das ondas avaliadas, no entanto nenhuma delas foi estatisticamente significante. É importante ressaltar que os sujeitos do grupo sem zumbido não apresentavam perda auditiva, no entanto 12 dos 20 participantes com zumbido apresentavam perda auditiva leve (média tritonal de $500 \mathrm{~Hz}, 1,2 \mathrm{e} 4 \mathrm{KHz}$ ), que pode interferir nos achados apresentados.

Mahmoudian et al. (2013) utilizaram o MMN para avaliar 28 sujeitos com zumbido crônico e 33 voluntários saudáveis. Concluíram que o zumbido pode causar uma redução na duração da memória sensorial no córtex auditivo. Segundo os autores, essa redução pode causar a diminuição da latência e da amplitude da área abaixo da curva de três variáveis: frequência, duração e gap de silêncio. Sugerem um possível déficit nos mecanismos do processamento auditivo central automático envolvendo a detecção préatencional de mudanças. Aparentemente, essas alterações podem ser a causa das mudanças neuroplásticas no cérebro que possuem uma representação neural separada na memória sensorial. Os autores afirmam que o MMN avalia os correlatos neurais da discriminação auditiva e da memória sensorial, por isso pode ser usado para investigar os 
processos cerebrais em sujeitos com zumbido, que ocorrem durante a percepção e a cognição auditivas. No entanto, o trabalho de Mahmoudian et al. (2013) levanta alguns questionamentos, uma vez que os sujeitos da pesquisa não foram separados por orelha em que percebiam zumbido, todas as orelhas, independentemente da localização do som, foram consideradas. Além disso, os participantes apresentavam limiares até $20 \mathrm{~dB}$ HL nas frequências de 250 a $2000 \mathrm{~Hz}$ e limiares até $40 \mathrm{~dB}$ HL nas frequências de 4 a 8 kHz.

Diversos autores, mediante o uso de diferentes protocolos e da seleção de grupos para a avaliação do sistema auditivo central por meio dos potenciais de média e longa latência, sugeriram que esses potenciais podem representar um método de avaliação das falhas de habituação (Walpurger et al., 2003; Weisz et al., 2004, Weisz et al., 2005).

Weisz et al. (2004) afirmaram que o zumbido representa um fenômeno mais complexo do que a pura reorganização das respostas neurais do córtex auditivo pós- danos nos receptores e reforçam a implicação de regiões responsáveis por emoções e atenção na percepção do zumbido, regiões essas envolvidas na produção do MMN.

\subsubsection{MMN e emoções}

As pessoas estão constantemente observando os padrões no ambiente, o que lhes permite aprender as suas regularidades. Essas regularidades são fundamentais em possibilitar que se possa prever o que pode ocorrer a seguir (Garrido et al., 2013). A habilidade de detectar mudanças emocionais no ambiente é essencial para adaptação comportamental. Os eventos emocionais frequentemente modulam a atenção e a percepção, facilitando os processos cognitivos e as respostas comportamentais. (Fujimura e Okanoya, 2013).

A sobrevivência de um organismo depende muitas vezes da sua capacidade de formar expectativas sobre a estrutura do seu ambiente sensorial e de monitorar o ambiente para as violações de tais expectativas, de modo a responder a eventos inesperados e potencialmente ameaçadores (Mumford, 1991; Mumford, 1992; Rao e Ballard, 1999; Friston, 2005 e Yuille e Kernsten, 2006). Em muitos casos, esse objetivo torna-se um desafio pela imprevisibilidade do ambiente normal (Yu e Dayan, 2005). Vários estudos examinaram a capacidade que os seres humanos têm de aprender implicitamente regularidades em estímulos observados (Näätanen et al., 1997).

Em um estudo que avaliou se os potenciais evocados auditivos para estímulo ambiental são influenciados pelo contexto emocional, Sugimoto et al. (2007) pesquisaram 
os potencias de 13 estudantes enquanto eles olhavam slides positivos, negativos e neutros do International Affective Picture System. Utilizaram um estímulo padrão (1kHz) e dois raros $(1050 \mathrm{~Hz}$ e $2 \mathrm{kHz})$. O tom raro mais agudo provocou onda $\mathrm{N} 1$ com maior latência enquanto os participantes viam slides positivos. A amplitude de P2 eliciado pelo estímulo padrão foi menor quando os participantes estavam observando os slides positivos do que quando observavam os negativos ou neutros. Encontraram amplitudes reduzidas do MMN durante a apresentação dos slides positivos. Os achados sugerem que estados emocionais induzidos visualmente têm um efeito sequencial no processamento da informação auditiva, em que a influencia da emoção negativa aparece em uma fase mais precoce do que a emoção positiva.

O estudo fisiológico da extração da regularidade tem focado principalmente em regras baseadas em sequências repetitivas dentro do ambiente sensorial, ou em associações de estímulo para os resultados no contexto da tomada de decisão baseada em recompensa (Garrido et al., 2013).

Parmentier (2013) realizou uma revisão bibliográfica com o objetivo de examinar determinantes cognitivos do comportamento de distração decorrente do estímulo sonoro desviante (raro). As evidências indicam que a distração decorrente do estímulo raro é mediada por uma série de fatores - alguns aumentam a distração, como a idade ou emoções induzidas, outros a diminuem, como a carga mnemônica ou o controle cognitivo. Segundo o autor, contrariando a visão que se tinha de que os sons desviantes inexoravelmente geram distração, pesquisas recentes demonstram que os sons desviantes não provocam distração por serem raros, mas porque violam as previsões do sistema cognitivo e podem ser manipulados por meio de regra de aprendizagem implícita ou pista explícita.

Reeb-Sutherland et al. (2009) avaliaram potenciais relacionados a eventos em crianças e adolescentes com risco de ansiedade (crianças que apresentavam temperamento de inibição comportamental e, portanto, ofereciam mais risco de desenvolver ansiedade) em um estudo longitudinal (quatro medidas). Os achados do MMN não apresentaram diferença estatisticamente significante entre as médias das avaliações, fato considerado surpreendente pelos autores.

Schirmer e Escoffier (2010) avaliaram a ansiedade de 20 sujeitos por meio de um questionário e, posteriormente, gravaram o MMN e mediram a frequência cardíaca, enquanto os participantes assistiam a um filme mudo e ouviam uma sequência auditiva. A sequência auditiva era composta por um estímulo padrão formado por sílabas sem 
sentido e alguns estímulos raros, sendo esses sons de fala carregados de irritação e braveza ou com características neutras. Encontraram MMN maior em amplitude para os sons de fala raivosa, correlacionado com aumento do batimento cardíaco. Observaram que o aumento da amplitude do MMN e do batimento cardíaco vinha acompanhado do crescimento da ansiedade. Esse efeito não foi encontrado para os estímulos vocais neutros. Os resultados sugerem que o processo pré-atencional para ameaça (visualizado por meio do MMN) está ligado a uma ativação do sistema nervoso simpático. Além disso, este link está mais ativado em pessoas com estado ansioso aumentado. O estudo sugere que o MMN pode ser utilizado como um marcador para um estado de sensibilidade dependente do indivíduo à automática mudança emocionalmente relevante. 


\section{3 - OBJETIVOS}

Estudar as características emocionais, compartamentais e o potencial relacionado a eventos - MMN (Mismatch Negativity) - em sujeitos com queixa de zumbido, sem perda auditiva, em comparação com o grupo controle.

\section{Objetivos específicos:}

- Verificar o grau de incômodo com o zumbido nos sujeitos pesquisados com esta queixa;

- Verificar se o grupo com presença de zumbido apresenta diferença na triagem para ansiedade e depressão quando comparado com o grupo controle

- Verificar se existem diferenças estatísticas significantes nas médias das latências e amplitudes do MMN entre o grupo com zumbido e o grupo controle. 


\section{4 - MATERIAL E MÉTODOS}

\subsection{Sujeitos}

Foram convidados a participar da pesquisa pacientes do Ambulatório de Zumbido do Hospital Universitário de Brasília bem como usuários e funcionários do Hospital Universitário de Brasília e estudantes da Universidade de Brasília.

\subsubsection{Critérios de inclusão}

- $\quad$ Ausência de outras queixas otológicas;

- Exames otológicos e audiológicos normais (limiar até $20 \mathrm{~dB}$ em todas as frequências de $250 \mathrm{~Hz}$ a $8 \mathrm{KHz}$ );

Adultos de ambos os sexos.

\subsubsection{Critérios de exclusão}

- Presença de outras queixas otológicas (malformação de orelha, presença de cerúmen, perfuração timpânica, entre outras);

- Exames otológicos e audiométricos alterados.

\subsection{Procedimentos}

Esta pesquisa foi aprovada pelo Comitê de Ética em Pesquisa da Faculdade de Ciências da Saúde da Universidade de Brasília, processo 079/2007 (Anexo I).

Após o paciente assinar o termo de consentimento livre e esclarecido (Anexo II) e responder à escala EAV e a questionamentos quanto à localização do zumbido (para aqueles sujeitos com queixa de zumbido), eram iniciados os procedimentos para o exame.

Inicialmente, eram realizadas a meatoscopia, a imitânciometria e a audiometria em cabine acústica. A audiometria tonal e vocal era feita no audiômetro Midimate 622 / Madsen ${ }^{\circledR}$ (Dinamarca) e a imitânciometria no imitanciômetro Zodiac 901 / Madsen ${ }^{\circledR}$ (Dinamarca). Caso o paciente preenchesse os critérios de inclusão, era encaminhado para a avaliação dos potenciais evocados auditivos relacionados a eventos MMN. A avaliação dos potenciais evocados foi feita no equipamento Audiotest 615 / Interacoustics ${ }^{\circledR}$ (Dinamarca).

Todas as avaliações foram realizadas pelo mesmo examinador. 


\subsection{Instrumentos}

Os participantes foram avaliados por um profissional Otorrinolaringologista e realizaram uma audiometria tonal e vocal e imitanciometria, para aferir a audição e as condições de orelha média. A partir desses exames, foi feita a avaliação das vias centrais por meio do MMN.

\subsubsection{Avaliação clínica e laboratorial}

Em todos os participantes, foi realizado exame clínico otorrinolaringológico, composto de otoscopia, orofaringoscopia e rinoscopia. Todos os participantes apresentaram exame clínico otorrinolaringológico normal, em ambos os grupos.

\subsubsection{Aferição de limiar tonal}

Foi realizada audiometria tonal limiar, em cabine acústica, nas frequências de 250, 500, 1000, 2000, 3000, 4000, 6000 e $8000 \mathrm{~Hz}$ com intuito de se obter os limiares tonais. Foi utilizada a técnica descendente e tom warble. Também foi avaliada a compreensão de fala por meio dos exames de logoaudiometria: limiar de reconhecimento de fala (reconhecimento de $50 \%$ de trissílabos com intensidade até $20 \mathrm{~dB}$ ) e de índice de reconhecimento de fala (reconhecimento mínimo de 92\% - 2 erros - de uma lista 25 de monossílabos), ambos realizados a viva voz. Seguindo o critério adotado para seleção da amostra, todos os participantes deveriam apresentar limiares audiométricos de até $20 \mathrm{~dB}$ nas frequências de $500 \mathrm{~Hz}$ a $8000 \mathrm{~Hz}$.

\subsubsection{Medidadas de Imitâncio Acustica}

Para assegurar a integridade de orelha externa e média em todos os participantes, antes dos procedimentos de aferição do limiar, todos foram submetidos à timpanometria, para descartar alterações de orelha média. Seguindo o critério adotado para seleção da amostra, todos os participantes apresentaram curva tipo 'A', indicando bom funcionamento do sistema tímpano-ossicular e reflexos ipsilaterais e contralaterais presentes em 500, 1000, 2000 e 4000Hz. 


\subsubsection{Potenciais evocados relacionados a eventos - Mismatch Negativity}

Os resultados obtidos neste exame foram analisados quanto à presença de potencial, à amplitude e à latência da onda, comparando-se o grupo com queixa de zumbido com o grupo controle.

\subsubsection{Coleta do MMN}

A coleta dos dados foi realizada no Ambulatório de Saúde Auditiva do Hospital Universitário de Brasília. Os participantes da pesquisa assinaram o Termo de Consentimento Livre e Esclarecido anteriormente à coleta dos dados. O equipamento utilizado na coleta foi o Interacoustics e o protocolo foi o descrito no Quadro 1.

A sala de exames era individualizada, possuía duas cadeiras e uma mesa e o aterramento no qual o equipamento de potenciais auditivos evocados era conectado. A pele era limpa com gaze e éter no vértex (eletrodo vértex), atrás das orelhas (eletrodos orelha direita e orelha esquerda) e na testa à esquerda (eletrodo terra), onde os eletrodos eram então posicionados.

Foram utilizados eletrodos adesivos descartáveis da 3M e pasta condutiva TEM20. Os eletrodos eram posicionados no vértex $(\mathrm{Fp})$, nas mastóides bilateralmente e o eletrodo terra era colocado na testa à esquerda. Os estímulos eram transmitidos por meio de fones de inserção e feitas as medidas de impedância acústica, que deveriam ser inferior a 3 kohms (via de regra não deve exceder 5 kohms, medidos ao redor de $15 \mathrm{~Hz}$, Durrant e Ferraro, 2001). O paciente era orientado a permanecer sentado, movimentar-se o mínimo possível, tirar sua atenção dos estímulos sonoros e focar a atenção em revistas de assuntos gerais durante a avaliação. As medidas eram feitas nas duas orelhas separadamente enquanto o paciente permanecia lendo.

Nem todos os sujeitos com queixa de zumbido apresentavam zumbido em ambas as orelhas, assim foi realizada a coleta em ambas as orelhas, no entanto foram considerados apenas os achados daquelas orelhas que os avaliados referenciavam perceber o som.

\subsubsection{Parâmetros de Aquisição}

O quadro abaixo (Quadro 1) apresenta os parâmetros utilizados na aquisição dos potenciais MMN: 
Quadro 1 - Parâmetros de Aquisição do MMN (Hall III, 2006)

\begin{tabular}{|c|c|c|}
\hline Ferramentas & Parâmetros & Observações \\
\hline Transdutor & Fones de inserção & $\begin{array}{l}\text { Fones de inserção são mais confortáveis e atenuam barulhos } \\
\text { ambientes pois promovem maior vedação do conduto auditivo } \\
\text { externo. }\end{array}$ \\
\hline Tipo & Frequência & $\begin{array}{l}\text { Uma variedade de diferenças entre o estímulo raro e o frequente } \\
\text { é efetiva na produção do MMN, incluindo frequência, duração, } \\
\text { intensidade e fonte no espaço. Diferenças nos moldes de algumas } \\
\text { características dos tons (ex: frequência) também podem ser } \\
\text { usadas no MMN. }\end{array}$ \\
\hline $\begin{array}{l}\text { Paradigma do } \\
\text { sinal raro }\end{array}$ & $20 \%$ & $\begin{array}{l}\text { No MMN, há invariavelmente pelo menos dois estímulos, } \\
\text { diferentes. O estímulo frequente apresentado em intervalos } \\
\text { regulares e previsíveis evoca uma onda convencional de resposta } \\
\text { tardia. O estímulo raro, que é não previsível (apresentado de } \\
\text { maneira "casual") e com uma probabilidade de ocorrência de } 5 \text { a } \\
20 \% \text {. }\end{array}$ \\
\hline $\begin{array}{l}\text { Diferença de } \\
\quad \text { sinal }\end{array}$ & $\begin{array}{c}\text { Frequente: } 1 \mathrm{KHz} \\
\text { Raro: } 1500 \mathrm{~Hz}\end{array}$ & $\begin{array}{l}\text { A distinção entre estímulo frequente e raro pode envolver } \\
\text { diversas características do som, como frequência }(1000 \mathrm{~Hz} \\
\text { versus } 1100 \mathrm{~Hz}) \text {, intensidade e duração. Diferenças relativamente } \\
\text { pequenas são melhores. As outras características do som que não } \\
\text { aquelas que diferenciam o estímulo raro do frequente são } \\
\text { normalmente as mesmas, ou seja, se o que diferencia os } \\
\text { estímulos é a frequência, então a duração e a intensidade } \\
\text { permanecem iguais para o estímulo raro e o frequente. }\end{array}$ \\
\hline Probabilidade & $\begin{array}{l}\text { Estímulo frequente: } \\
\qquad 80 \% \\
\text { Estímulo raro: } 20 \%\end{array}$ & $\begin{array}{l}\text { Normalmente de } 100 \% \text { para o estímulo frequente e de } 20 \% \text { para } \\
\text { o raro. A probabilidade de } 10 \% \text { para o estímulo raro é citada } \\
\text { frequentemente. O estímulo raro não pode ser o primeiro } \\
\text { apresentado, bem como dois estímulos raros não podem } \\
\text { acontecer em sucessão, deve sempre haver um ou mais estímulos } \\
\text { frequentes entre a apresentação de dois estímulos raros. }\end{array}$ \\
\hline Polaridade & Rarefeito & $\begin{array}{l}\text { A polaridade do estímulo não é um parâmetro importante na } \\
\text { aquisição do MMN. }\end{array}$ \\
\hline Intensidade & $70 \mathrm{~dB} H \mathrm{HL}$ & $\begin{array}{l}\text { Níveis modestos de intensidade de estímulo são tipicamente } \\
\text { usados no MMN. }\end{array}$ \\
\hline $\begin{array}{c}\text { Orelha de } \\
\text { apresentação }\end{array}$ & Monoaural & Estímulos monoaural e binaural podem ser usados. \\
\hline $\begin{array}{l}\text { Tempo de } \\
\text { análise } \\
\text { (janela) }\end{array}$ & $600 \mathrm{~ms}$ & $\begin{array}{l}\text { O tempo de análise precisa ser longo o suficiente para envolver } \\
\text { a onda ampla de MMN. }\end{array}$ \\
\hline $\begin{array}{l}\text { Filtro band- } \\
\text { pass }\end{array}$ & $0.1 \mathrm{a} 30 \mathrm{~Hz}$ & $\begin{array}{l}\text { O MMN consiste de frequências baixas (de } 50 \text { a } 10 \mathrm{~Hz}) \text {. Filtros } \\
\text { band-pass mais restritos }(0.1 \text { a } 20 \mathrm{~Hz}) \text { podem aumentar a razão } \\
\text { sinal-ruído. }\end{array}$ \\
\hline $\begin{array}{l}\text { Localização } \\
\text { dos eletrodos }\end{array}$ & $\begin{array}{l}\text { Fpz, Mastóides } \\
\text { bilateralmente e } \\
\text { Testa à esquerda } \\
\quad \text { (Fp1) }\end{array}$ & $\begin{array}{l}\text { Fpz, Mastóides direita e esquerda e eletrodo terra na testa à } \\
\text { esquerda (Fp1) }\end{array}$ \\
\hline
\end{tabular}

\subsubsection{Questionário de Repercussão do Zumbido - THI}

O Tinnitus Handicap Inventory (THI - Anexo III), desenvolvido por Newman et al. (1996), é um questionário específico que avalia os aspectos emocional, funcional e catastrófico, de fácil interpretação e aplicação. Denominado Questionário de Repercussão do Zumbido, o THI é um instrumento validado internacionalmente e adaptado ao português brasileiro (Ferreira et al., 2005). 
É composto por 25 questões, divididas em três escalas: funcional, emocional e catastrófica. São três as opções de resposta para cada uma das questões, pontuadas da seguinte maneira: $\operatorname{sim}$ (4 pontos), às vezes (2 pontos) e não (nenhum ponto) (Newmanm, 1996; Dias et al., 2006). A escala funcional (F) mede a interferência do zumbido em atividades mentais, sociais, ocupacionais e físicas e consiste em 11 questões, alcançando pontuação máxima de 44. A escala emocional (E) mede as respostas afetivas, como ansiedade, raiva e depressão, corresponde a 9 questões e pode ter pontuação máxima de 36. A escala catastrófica (C) quantifica o desespero e a incapacidade referida pelo paciente em lidar com o sintoma; representa 5 perguntas do inventário e pode atingir o máximo de 20 pontos.

\subsubsection{Classificação do zumbido pelo THI segundo Mc Combe et al. (2001)}

Mc Combe et al. (2001) propuseram a utilização do THI para classificar o zumbido em zumbido categorizado. Segundo os autores, somando-se os pontos obtidos no THI, o zumbido pode ser classificado como: desprezível (0- 16\%), leve (18- 36\%), moderado (38- 56\%), severo (58-76\%) ou catastrófico (78-100\%). Categorização como "grave" ou "catastrófica" deveria ser, por avaliação epidemiológica, muito rara.

\subsubsection{Escala Hospitalar de Ansiedade e Depressão - HAD}

A escala HAD (Hospital Anxiety and Depression Scale) - Anexo IV - é um triagem para depressão e ansiedade completado pelo próprio paciente. Consiste em quatorze perguntas: sete voltadas para ansiedade e sete para depressão. Cada uma apresenta 4 opções de respostas, quantificadas de 0 a 3. Dessa forma, a pontuação para ansiedade pode variar de 0 a 21 , assim como também para a avaliação da depressão. A pontuação acima de 8 para ansiedade é sugestiva da presença de estado ansioso, e pontuação acima de 9 para depressão é sugestivo de estado depressivo (Snaith, 2003; Castro et al., 2006). Foi validada para o português brasileiro em 2006 por Castro et al.

\subsubsection{Escala Analógico-Visual de incômodo/intensidade do zumbido}

A Escala Analógico-Visual (EAV) consiste em uma escala com pontuação de 0 a 10, em que o paciente subjetivamente classifica o incômodo do zumbido. A nota 0 corresponde a pouco incômodo com o zumbido, e a nota 10 representa um incômodo 
muito grande. Por meio da escala análogo-visual, pode-se pontuar com notas $0,1,2,3,4$, $5,6,7,8,9$ ou 10 .

\subsection{Procedimentos éticos}

O Termo de Consentimento Livre e Esclarecido (Anexo I) foi redigido em termos acessíveis a qualquer grupo sociocultural, sendo lido e explicado para todos os participantes.

Os participantes assinaram o Termo de Consentimento Livre e Esclarecido atestando assim sua vontade em participar na pesquisa. Não houve casos de recusa de participação.

Os procedimentos desta pesquisa ofereceram riscos mínimos à saúde dos participantes.

\subsection{Análise dos resultados}

Os achados desta pesquisa foram analisados estatisticamente, comparando-se os resultados encontrados no grupo controle com os do grupo de pacientes com queixa de zumbido. A análise estatística inclui métodos descritivos e teste t-Student para comparar médias de dois grupos de interesse. Foi considerado nível de significância de 5\% (p<0.05 entre as médias). As análises foram realizadas no software SPSS 17. 


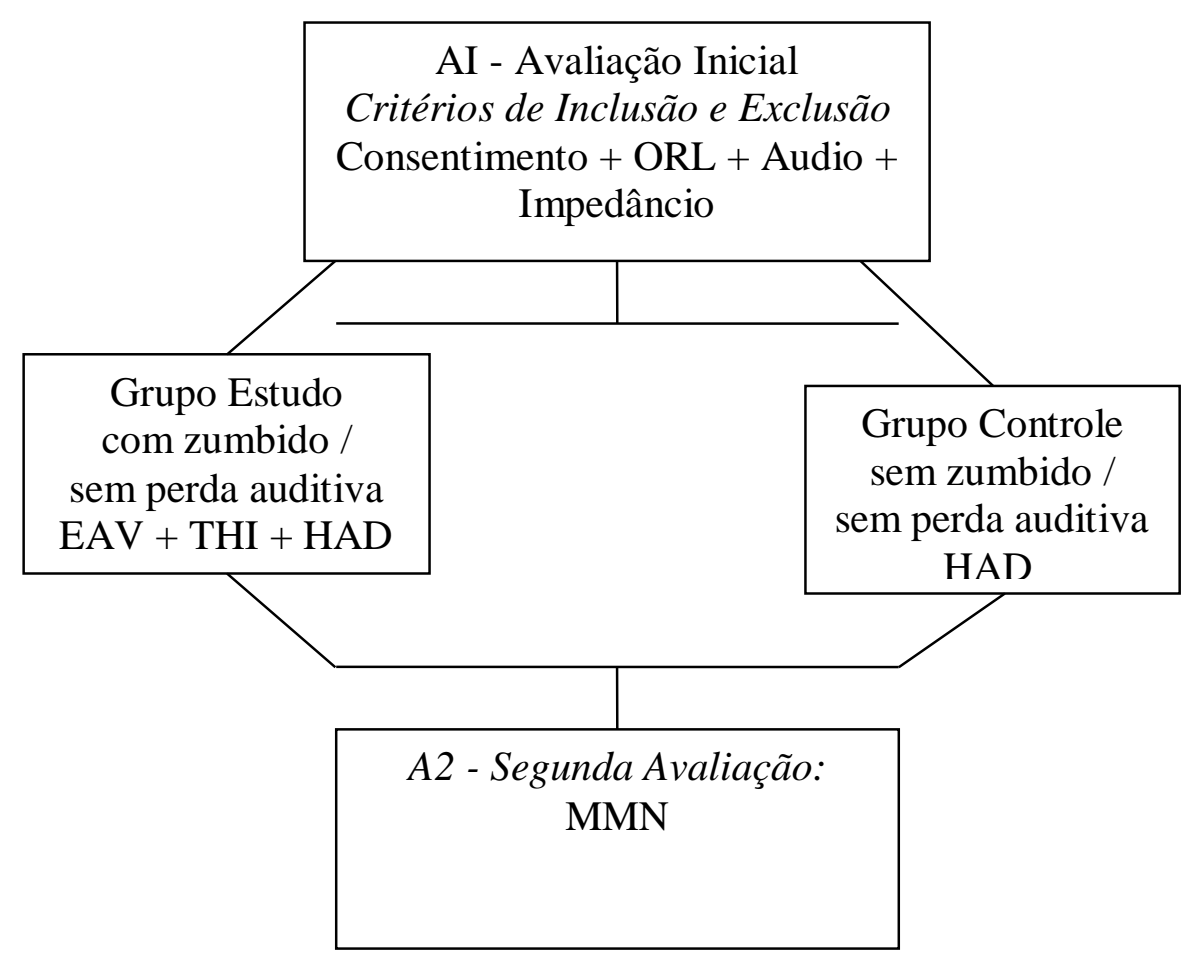




\section{6 - RESULTADOS}

Foram avaliadas 25 pessoas com queixa de zumbido e audição normal, totalizando 45 orelhas avaliadas ( 5 orelhas foram descartas, pois os sujeitos pesquisados afirmavam não perceber o zumbido nessas orelhas). $\mathrm{O}$ grupo com zumbido contou com 16 homens e 9 mulheres, com idade média de 49 anos (29 a 73, dp+- 11,91), todos destros. Todos apresentavam zumbido crônico (há mais de 6 meses). Os achados da audiometria encontraram uma média tritonal bilateral de $9 \mathrm{~dB}$. O valor médio na Escala AnalógicoVisual de incômodo foi de 8,5.

O grupo controle totalizou 13 participantes, perfazendo 26 orelhas avaliadas. Esse grupo contou com 5 homens e 8 mulheres, todos destros, que apresentaram idade média de $35 \operatorname{anos}(21$ a 74, dp+- 15,99) e média tritonal, verificada na audiometria, de $8 \mathrm{~dB}$. Os achados de ambos os grupos podem ser observados na Tabela 1, a seguir.

Tabela 1 - Características gerais dos grupos, segundo gênero, idade, média tritonal audiométrica e incômodo com o zumbido

\begin{tabular}{|c|c|c|c|c|c|c|}
\hline \multirow[t]{2}{*}{ Grupo } & \multirow{2}{*}{$\begin{array}{c}\text { Orelhas } \\
\text { Avaliadas }\end{array}$} & \multirow{2}{*}{$\begin{array}{l}\text { Idade } \\
\text { Média } \\
\text { (dp) }\end{array}$} & \multicolumn{2}{|c|}{ Gênero } & \multirow{2}{*}{$\begin{array}{c}\text { Média } \\
\text { tritonal } \\
\text { (dB) }\end{array}$} & \multirow{2}{*}{$\begin{array}{c}\text { Incômodo } \\
\text { EAV } \\
\text { Média }\end{array}$} \\
\hline & & & Homens & Mulheres & & \\
\hline Zumbido & $45^{*}$ & $\begin{array}{c}49 \\
(+-11,91)\end{array}$ & 16 & 9 & 8,0 & 8,5 \\
\hline Controle & 26 & $\begin{array}{c}35 \\
(+-15,99)\end{array}$ & 5 & 8 & 9,0 & -- \\
\hline
\end{tabular}

Nota: * Orelhas sem zumbido não foram avaliadas no grupo com zumbido

A nota individual atribuída pelos pacientes do grupo que apresentou zumbido para o incômodo causado por esse sintoma na EAV pode ser visualizada na figura 1, a seguir. 


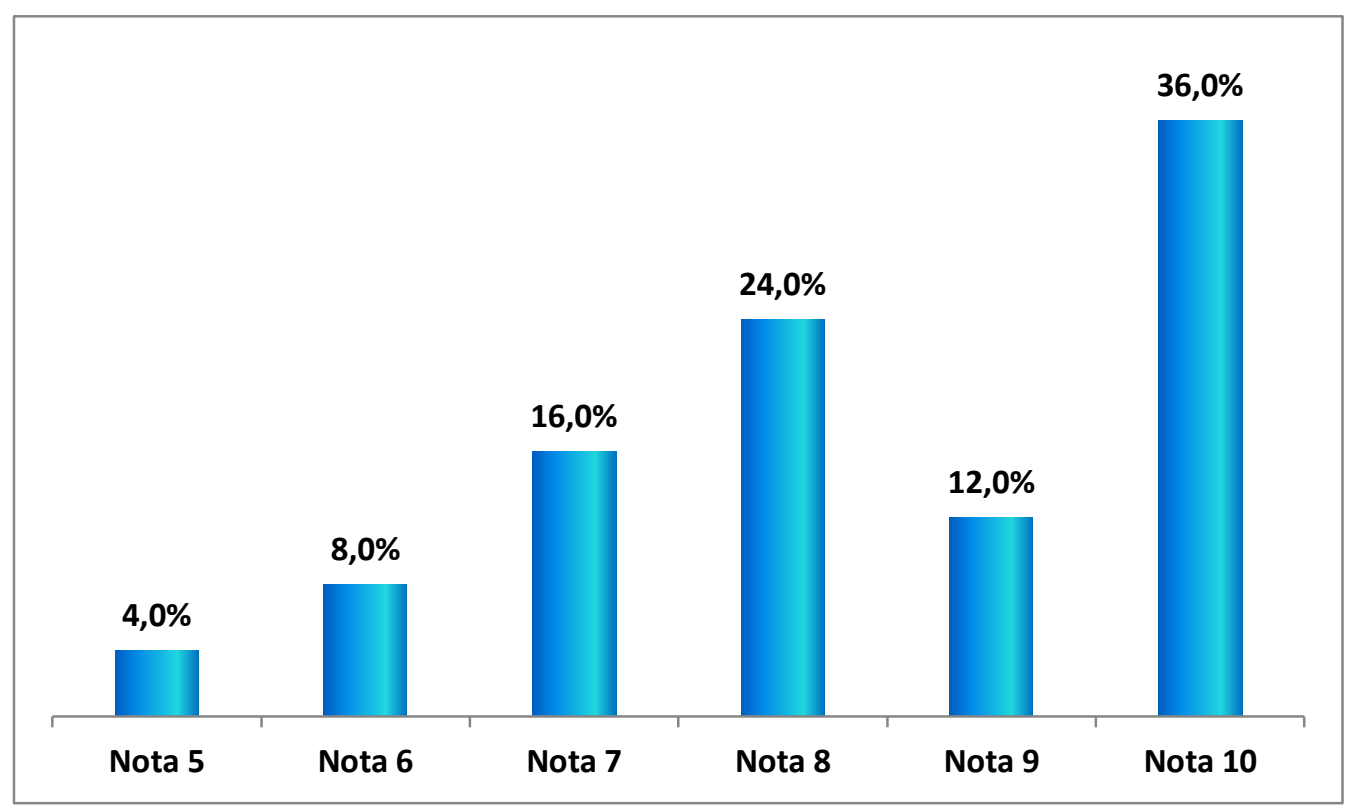

Figura 1 - Distribuição das notas de incômodo atribuídas pelos pacientes com zumbido na EAV

Do total de 25 participantes com zumbido, 4 (16\%) apresentaram zumbido apenas na orelha esquerda, 1 (4\%) apenas na direita e 20 (52\%) com zumbido bilateral. Sendo assim, foram consideradas e avaliadas 45 orelhas no grupo zumbido, sendo estas as orelhas nas quais os sujeitos referenciavam a percepção do som. Na tabela 2 é possível visualizar a relação entre o incômodo atribuído ao zumbido na EAV e a localização da percepção desse som.

Tabela 2 - Distribuição das notas de incômodo atribuídas pelos pacientes com zumbido, segundo localização do zumbido

\begin{tabular}{c|c|c|c}
\hline Incômodo & \multicolumn{2}{|c|}{ Localização do zumbido } & Total \\
\hline & Bilateral & Unilateral & \\
\hline 5 & 1 & 0 & 1 \\
\hline 6 & 1 & 1 & 2 \\
\hline 7 & 4 & 0 & 4 \\
\hline 8 & 4 & 2 & 6 \\
\hline 9 & 3 & 0 & 3 \\
\hline 10 & 7 & 2 & 9 \\
\hline Total & $\mathbf{2 0}$ & $\mathbf{5}$ & $\mathbf{2 5}$ \\
\hline
\end{tabular}

Foram utilizados a escala HAD e o THI para distinguir os aspectos emocionais dos sujeitos avaliados, bem como para identificar as caracteristicas relacionadas ao zumbido no grupo com essa queixa. 
Os achados da Escala HAD evidenciaram valores sugestivos de ansiedade, acima de 8, no grupo com zumbido (média: 9,2; dp+- 4,54), e valores médios abaixo de 9 para depressão (média: 7,3; dp+- 4,42), sendo estes não sugestivos. No entanto, no grupo sem zumbido, os achados não foram sugestivos de ansiedade (média: 4,1; dp+- 2,93) e depressão (média: 1,4; dp+- 1,98). Resultados observados na Tabela 3, a seguir.

Tabela 3 - Médias da pontuação da HAD - ansiedade e depressão

\begin{tabular}{c|c|c}
\hline HAD & $\begin{array}{c}\text { Grupo Zumbido } \\
\text { Média } \\
(\mathrm{dp})\end{array}$ & $\begin{array}{c}\text { Grupo Sem Zumbido } \\
\text { Média } \\
(\mathrm{dp})\end{array}$ \\
\hline Ansiedade & 9,2 & 4,1 \\
Depressão & $(4,54)$ & $(2,93)$ \\
\hline
\end{tabular}

Análise das médias entre os grupos

No intuito de delinear, nos sujeitos com zumbido, o comprometimento causado por ele na qualidade de vida desse grupo, aplicou-se o THI. As médias da pontuação do THI nos sujeitos com zumbido foram as seguintes - funcional: 20,8; emocional: 19,2; catastrófico: 12,1, que somadas geram uma média total de 52,1 pontos $(52,1 \%)$. Os resultados podem ser observados na Tabela 4, a seguir, e dados mais específicos dos achados do THI na Figura 2 em sequência.

Tabela 4 - Médias dos quesitos funcional, emocional e catastrófico avaliados pelo THI

\begin{tabular}{c|c}
\hline THI & Pontos (Média) \\
\hline Funcional & 20,8 \\
\hline Emocional & 19,2 \\
\hline Catastrófico & 12,1 \\
\hline Total & 52,1 \\
\hline
\end{tabular}

Teste T para comparação de médias 


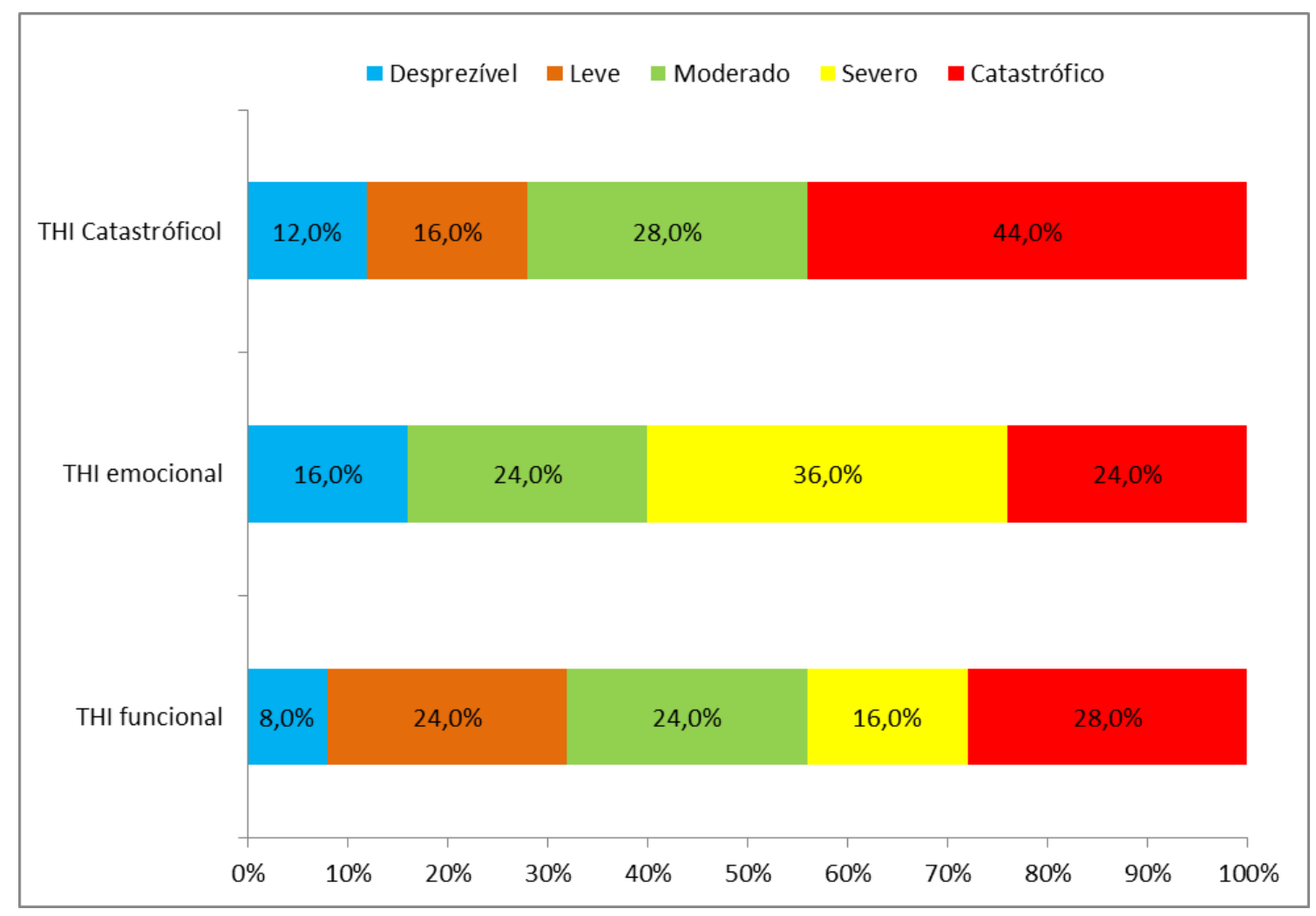

Figura 2 - Achados específicos de cada subescala do THI no grupo zumbido

Quando observados os achados de latência do MMN no total das orelhas em cada grupo, a média da latência do grupo zumbido foi de 209,91 ms, e a do grupo controle foi de 216,54 ms, dados descritos na Tabela 5, a seguir. A diferença entre os grupos é estatisticamente significante, com um valor de $\boldsymbol{p}=\mathbf{0 , 0 2 2}$ entre as médias (teste t-Student).

Tabela 5 - Dados referentes à latência do MMN (ms)

\begin{tabular}{|c|c|c|}
\hline & Zumbido & Controle \\
\hline Num. Registros & 45 & 26 \\
\hline Mínimo (ms) & 188 & 200 \\
\hline Máximo (ms) & 232 & 230 \\
\hline Média (ms) & 209,91 & 216,54 \\
\hline Desvio-padrão & 12,89 & 8,42 \\
\hline IC $(95 \%) \quad$ LI (ms) & 206,04 & 213,14 \\
\hline LS (ms) & 213,78 & 219,94 \\
\hline
\end{tabular}




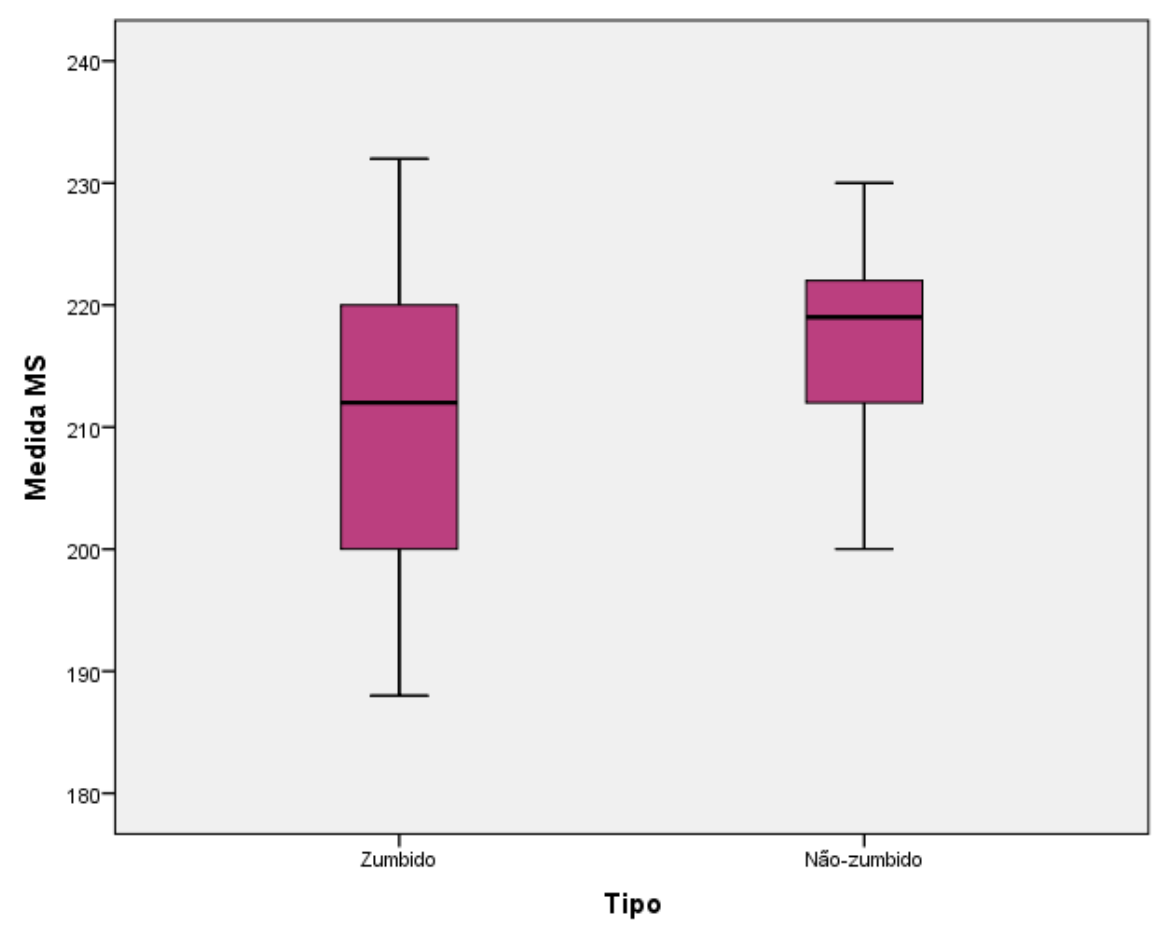

Figura 3 - Distribuição das medidas de latência (ms)

Os achados para latência do MMN na orelha direita apresentaram, no grupo zumbido, uma média de 208,57 ms e, no grupo controle, uma média de 217,38 ms, sendo a diferença entre as médias estatisticamente significante (valor de $\boldsymbol{p}=\mathbf{0 , 0 3 9}$; teste tStudent), conforme tabela 7, a seguir.

Tabela 6 - Dados referentes à latência (ms) do MMN na orelha direita (OD)

\begin{tabular}{|c|c|c|}
\hline & Zumbido & Controle \\
\hline Num. Registros & 21 & 13 \\
\hline Mínimo (ms) & 190 & 200 \\
\hline Máximo (ms) & 232 & 230 \\
\hline Média (ms) & 208,57 & 217,38 \\
\hline Desvio-padrão & 12,82 & 9,22 \\
\hline $\mathrm{IC}(95 \%)$ & 202,73 & 211,82 \\
\hline LS & 214,41 & 222,95 \\
\hline
\end{tabular}

Teste T para comparação de médias 




Figura 4 - Distribuição das medidas de latência (ms) na OD

$\mathrm{Na}$ orelha esquerda, a média da latência (ms) do grupo zumbido foi de 211,08ms, e a do grupo controle foi de $215,69 \mathrm{~ms}$, não sendo a diferença entre as médias estatisticamente significante (valor de $\boldsymbol{p = 0 , 2 5 5}$ ), conforme demonstra a Tabela 8 , a seguir.

Tabela 7 - Dados referentes à latência do MMN na orelha esquerda (OE)

\begin{tabular}{|c|c|c|}
\hline & Zumbido & Controle \\
\hline Num. Registros & 24 & 13 \\
\hline Mínimo (ms) & 188,00 & 202,00 \\
\hline Máximo (ms) & 228,00 & 226,00 \\
\hline Média (ms) & 211,08 & 215,69 \\
\hline Desvio-padrão & 13,11 & 7,83 \\
\hline $\mathrm{IC}(95 \%)$ & 205,55 & 210,96 \\
\hline LS (ms) & 216,62 & 220,42 \\
\hline
\end{tabular}

Teste $\mathrm{T}$ para comparação de médias 




Figura 5 - Distribuição das medidas de latência (ms) na $\mathrm{OE}$

$\mathrm{Na}$ avaliação da amplitude do MMN, encontrou-se, no grupo zumbido, a média de $-1,01 \mathrm{uV}$ e, no grupo controle, a média de $-1,10 \mathrm{uV}$, achados expostos na tabela 6 , a seguir. A diferença entre as médias dos grupos não se revelou estatisticamente significante (valor de $\boldsymbol{p}=\mathbf{0 , 6 8 2}$; teste t-Student).

Tabela 8 - Dados referentes à amplitude do MMN (uV)

\begin{tabular}{l|r|r}
\hline & \multicolumn{2}{|c|}{ Zumbido } \\
\hline Num. Registros & 45 & Controle \\
\hline Mínimo (uV) & $-4,20$ & 26 \\
\hline Máximo (uV) & $-0,04$ & $-3,47$ \\
\hline Média (uV) & $-1,01$ & $-0,02$ \\
\hline Desvio-padrão & 0,87 & $-1,10$ \\
\hline IC(95\%) LI (uV) & $-1,27$ & 0,83 \\
\hline \multicolumn{1}{c|}{ LS (uV) } & $-0,75$ & $-1,43$ \\
\hline
\end{tabular}

Teste T para comparação de médias 


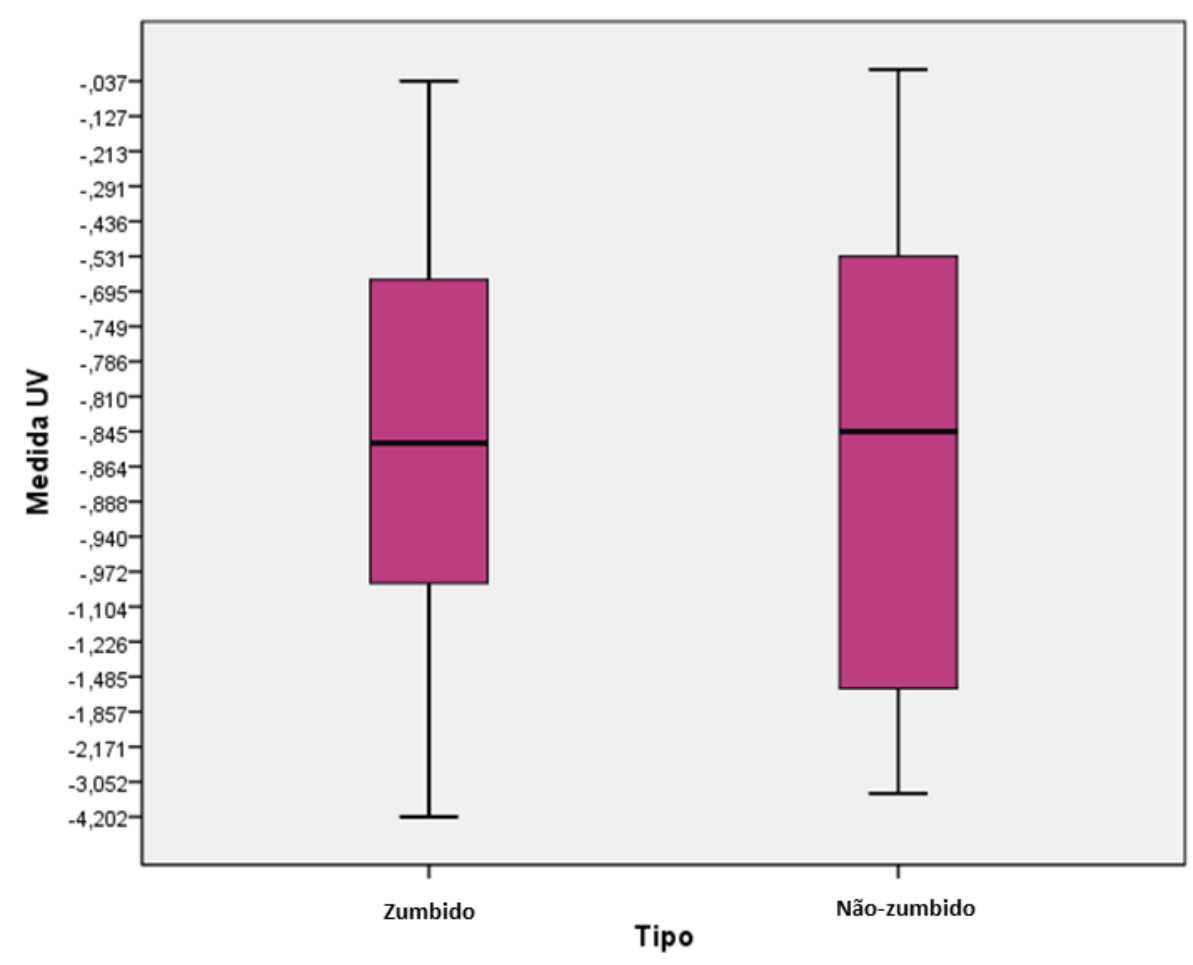

Figura 6 - Distribuição das medidas da amplitude (uV)

$\mathrm{Na}$ avaliação do $\mathrm{MMN}$ na orelha direita, a média da amplitude (uV) do grupo zumbido foi de $-0,88 \mathrm{uV}$, e a do grupo controle foi de $-1,01 \mathrm{uV}$, como observado na Tabela 9, a seguir. Esses achados não apresentam diferença estatisticamente significante entre as médias dos dois grupos (valor de $\boldsymbol{p}=\mathbf{0 , 5 5 7}$; teste $\mathrm{t}$-Student).

Tabela 9 - Dados referentes à amplitude do MMN na orelha direita (OD)

\begin{tabular}{|c|c|c|}
\hline & Zumbido & Controle \\
\hline Num. Registros & 21 & 13 \\
\hline Mínimo (uV) & $-3,05$ & $-2,25$ \\
\hline Máximo (uV) & $-0,04$ & $-0,19$ \\
\hline Média $(\mathrm{uV})$ & $-0,88$ & $-1,01$ \\
\hline Desvio-padrão & 0,67 & 0,64 \\
\hline $\mathrm{IC}(95 \%)$ & $-1,18$ & $-1,40$ \\
\hline $\mathrm{LS}(\mathrm{uV})$ & $-0,57$ & $-0,63$ \\
\hline
\end{tabular}

Teste T para comparação de médias 




Figura 7 - Distribuição das medidas da amplitude (uV) da OD

$\mathrm{Na}$ orelha esquerda, a média da amplitude $(\mathrm{uV})$ do grupo zumbido foi de $-1,13$ $\mathrm{uV}$, e a do grupo controle foi de $-1,19 \mathrm{uV}$, conforme a Tabela 10, e a diferença entre essas médias não se configura estatisticamente significante ( $\boldsymbol{p}=\mathbf{0 , 8 8 1}$; teste t-Student).

Tabela 10 - Dados referentes à amplitude do MMN na orelha esquerda (OE)

\begin{tabular}{|c|c|c|}
\hline & Zumbido & Controle \\
\hline Num. Registros & 24 & 13 \\
\hline Mínimo (uV) & $-4,20$ & $-3,47$ \\
\hline Máximo (uV) & $-0,05$ & $-0,02$ \\
\hline Média $(\mathrm{uV})$ & $-1,13$ & $-1,19$ \\
\hline Desvio-padrão & 1,01 & 1,00 \\
\hline $\mathrm{IC}(95 \%)$ & $-1,56$ & $-1,79$ \\
\hline $\mathrm{LS}(\mathrm{uV})$ & $-0,71$ & $-0,58$ \\
\hline
\end{tabular}

Teste T para comparação de médias 


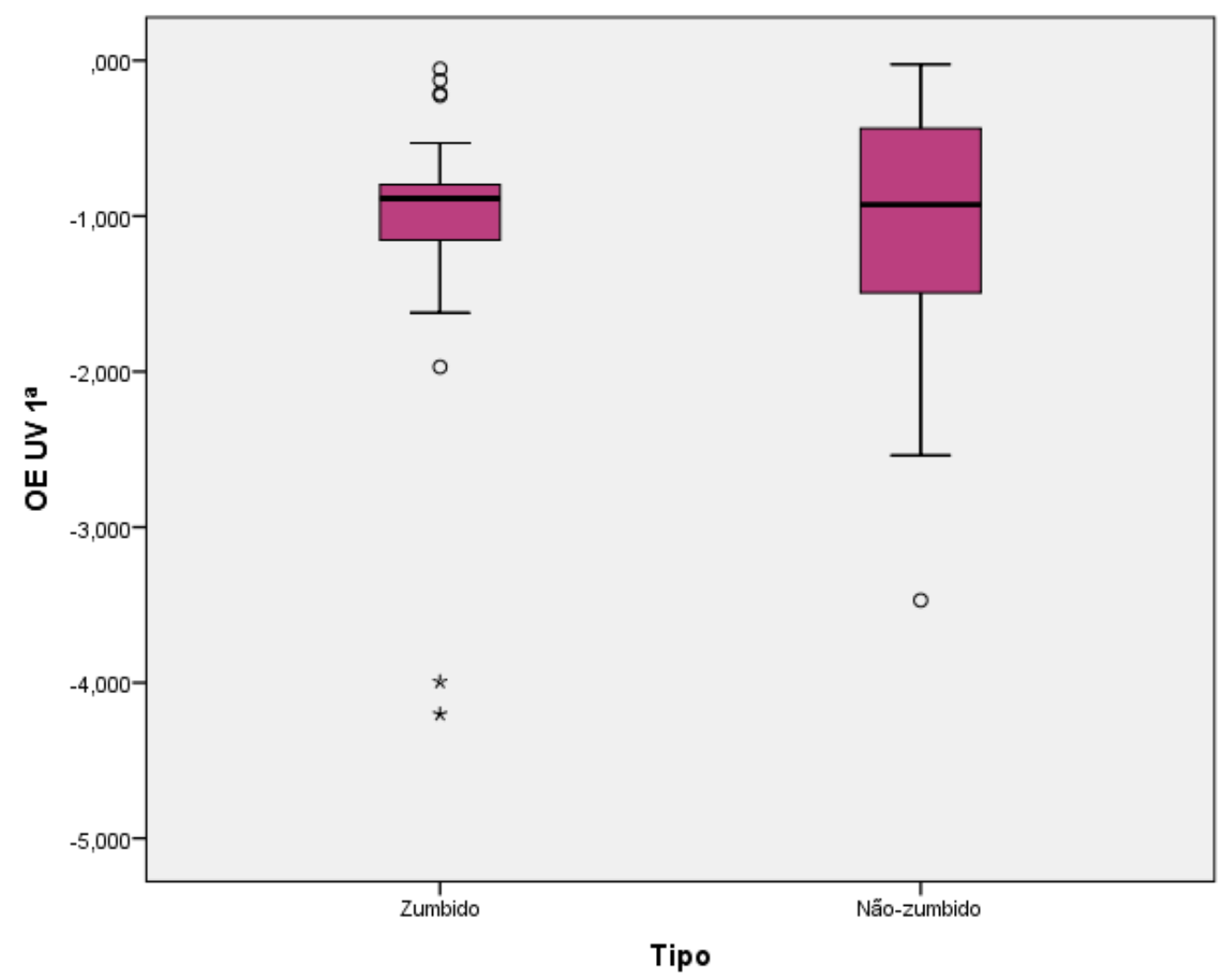

Figura 8 - Distribuição das medidas da amplitude (uV) da OE

Na tabela abaixo (Tabela 11), pode-se observar, de forma resumida, os achados de latência e amplitude nas orelhas, individual e conjuntamente.

Tabela 11 - Médias de amplitude e latência do MMN no grupo zumbido e no grupo controle

\begin{tabular}{l|c|c|c|c|c|c|c|c|c}
\hline Grupo & \multicolumn{3}{|c|}{ Orelha direita } & \multicolumn{3}{c|}{ Orelha esquerda } & \multicolumn{3}{c}{ Total de orelhas } \\
\cline { 2 - 9 } & $\begin{array}{c}\text { Número } \\
\text { de } \\
\text { orelhas }\end{array}$ & $\begin{array}{c}\text { Amplitude } \\
(\mathrm{uV}) \\
\text { Média }\end{array}$ & $\begin{array}{c}\text { Latência } \\
(\mathrm{ms}) \\
\text { Média }\end{array}$ & $\begin{array}{c}\text { Número } \\
\mathrm{de} \\
\text { orelhas }\end{array}$ & $\begin{array}{c}\text { Amplitude } \\
(\mathrm{uV}) \\
\text { Média }\end{array}$ & $\begin{array}{c}\text { Latência } \\
(\mathrm{ms}) \\
\text { Média }\end{array}$ & $\begin{array}{c}\text { Número } \\
\text { de } \\
\text { orelhas }\end{array}$ & $\begin{array}{c}\text { Amplitude } \\
(\mathrm{uV}) \\
\text { Média }\end{array}$ & $\begin{array}{c}\text { Latência } \\
(\mathrm{ms}) \\
\text { Média }\end{array}$ \\
\hline Zumbido & 21 & -0.88 & 208.57 & 24 & -1.13 & 211.08 & 45 & -1.01 & 209.91 \\
\hline Controle & 13 & -1.01 & 217.38 & 13 & -1.19 & 215.69 & 26 & -1.10 & 216.54 \\
\hline
\end{tabular}

Teste T para comparação de médias

Foram realizadas avaliações dos achados de amplitude e latência intragrupo, para observar a possibilidade de diferenças significativas nos resultados quando comparados os hemisférios cerebrais. Não foram encontratadas diferenças significativas na amplitude e na latência na avaliação entre as orelhas dentro do grupo controle, nem mesmo no grupo zumbido, conforme detalhado na Tabela 12 a seguir. 
Tabela 12 - Dados das comparações entre orelhas dentro dos grupos

\begin{tabular}{|c|c|c|c|c|}
\hline & \multicolumn{2}{|c|}{ Zumbido } & \multicolumn{2}{|c|}{ Controle } \\
\hline & OD & OE & OD & OE \\
\hline Média $\quad m$ & 208,57 & 211,08 & 217,38 & 215,69 \\
\hline $\mathrm{DP}$ & 12,82 & 13,11 & 9,215 & 7,825 \\
\hline $\begin{array}{l}\text { IC }(95 \%) \\
\text { LI }\end{array}$ & 202,73 & 205,55 & 211,82 & 210,96 \\
\hline LS & 214,41 & 216,62 & 222,95 & 220,42 \\
\hline Média $u$ & $-0,877$ & $-1,133$ & $-1,015$ & $-1,186$ \\
\hline DP & 0,667 & 1,011 & 0,634 & 0,998 \\
\hline $\begin{array}{l}\text { IC }(95 \%) \\
\text { LI }\end{array}$ & $-1,18$ & $-1,561$ & $-1,404$ & $-1,789$ \\
\hline LS & $-0,573$ & $-0,706$ & $-0,626$ & $-0,583$ \\
\hline
\end{tabular}

Teste $\mathrm{T}$ para comparação de médias

*ms grupo zumbido (p-valor = 0,218, teste t-Student, comparação OD e OE)

*ms grupo controle ( $\mathrm{p}$-valor $=0,217$, teste t-Student, comparação OD e OE)

*uV grupo zumbido ( $\mathrm{p}$-valor $=0,346$, teste t-Student, comparação OD e OE)

$* \mathrm{uV}$ grupo controle ( $\mathrm{p}$-valor $=0,480$, teste t-Student, comparação OD e OE) 


\section{7 - DISCUSSÃO}

A Escala Analógico-Visual de incômodo obteve uma média de 8,5 pontos na avaliação do incômodo gerado pelo zumbido nos 25 participantes da pesquisa, o que pode ser considerado um zumbido com incômodo severo. Foram encontrados mais indivíduos com zumbido no lado esquerdo do que no direito e, ao que parece, existe uma tendência, na população com zumbido, de apresentar mais zumbido no lado esquerdo do que no direito (Axelsson e Ringdahl, 1989).

Holdefer et al. (2010) aplicaram o THI em um grupo de pacientes com zumbido (e perda auditiva) e encontraram valores médios de 29,16 no item funcional, 24,11 no emocional e de 12,53 no quesito catastrófico, somando um valor médio de 65,8, considerado um zumbido severo, segundo a classificação de McCombe et al. (2001). Nos achados da presente pesquisa, o grupo pesquisado revela valores mais baixos, sendo a média do item funcional de 20,8; de 19,2 no emocional; e de 12,1 no catastrófico - média total de 52,1 -, resultado que é classificado como zumbido moderado (McCombe et al., 2001). Esses valores, no entanto, evidenciam que o zumbido possui um impacto relevante na qualidade de vida e no equilíbrio emocional desses sujeitos, o que é corroborado pelos achados emocionais da escala HAD.

Nos sujeitos zumbido avaliados neste trabalho, as médias da Escala HAD foram de 9,2, para ansiedade, e de 7,3, para depressão, valores que sugerem ansiedade (média acima de 8), no entanto não sugerem depressão (média acima de 9). Já no grupo controle, esses valores apresentam-se bastante baixos: 4,1 para ansiedade e 1,4 para depressão, que denotam ausência de transtorno de ansiedade e depressão. Esses achados corroboram com os demais estudos que utilizaram como instrumento de avaliação emocional do zumbido a Escala HAD (Londero et al., 2006; Holdefer et al., 2010) - Londero et al. (2006), que avaliaram a eficácia do tratamento cognitivo comportamental em pacientes com zumbido e utilizaram HAD como ferramenta de avaliação. Os valores médios para ansiedade foram considerados elevados antes do tratamento - 10,7 para ansiedade e 7,1 para depressão (este último não sugestivo). Holdefer et al. (2010) encontraram valores médios de 11,84 para ansiedade e de 9,74 para depressão na aplicação da escala HAD.

O MMN é um marcador para detecção de sinais que são inesperados, tendo como base um som regular (Kuchenbuch et al., 2013). Ele vem sendo largamente usado em populações saudáveis e em pesquisas de diversas doenças, como esquizofrenia e alterações cognitivas, por exemplo (Jessen et al., 2001 e Kujala et al., 2007). Não existe 
um padrão de normalidade estabelecido para valores de latência e amplitude do MMN (Roggia, 2012). A determinação da latência ocorre no tempo necessário para que o córtex diferencie o estímulo padrão do estímulo desviante, já a amplitude sofre interferência da variação da apresentação do estímulo raro, bem como das características acústicas desse estímulo (Hall III, 2006). A análise do MMN é feita basicamente pela identificação visual, sendo necessário comparar os achados da média de um grupo controle com os de um grupo de pesquisa (Ponton et al., 1997; Näätanen et al., 2004; Takegata, 2005).

Não foram observadas diferenças significantes quando comparadas as médias da latência e da amplitude do MMN da orelha direita com a orelha esquerda dentro do mesmo grupo, tanto no grupo zumbido quanto no grupo controle. Na literatura relativa ao uso do MMN, não evidenciamos trabalhos utilizando esse tipo de correlação e observação das diferenças inter-hemisféricas. Frizzo et al. (2001) avaliaram diferenças interhemisféricas utilizando potenciais de longa latência, no entanto empregaram os potenciais N1, P2, N2, e P3 para essa pesquisa. Também não encontraram diferenças estatisticamente significantes na latência e na amplitude entre as orelhas, ou seja, não observaram diferenças inter-hemisféricas.

Brossi et al. (2007) também utilizaram um equipamento de potenciais evocados auditivos para avaliar o MMN em sujeitos adultos normais. Encontraram valores médios de amplitude entre $-1,435$ a $-3,584 \mathrm{uV}$. Os achados do presente trabalho mostram valores de amplitude entre -0,6 a -3,994 uV no grupo zumbido (média de -1,01 uV) e entre -0,193 a -2,254 uV no grupo controle (média de $-1,10 \mathrm{uV}$ ).

Em alguns estudos sobre diferentes doenças e sintomas, que não o zumbido, a amplitude mostrou-se um bom parâmetro de avaliação. Umbricht e Krljes (2005) fizeram uma meta-análise dos achados do MMN em pacientes com esquizofrenia e concluíram que a amplitude dessa onda nesses pacientes é menor, podendo, inclusive, sugerir o desenvolvimento futuro da doença (Higuchi et al., 2013). No entanto, na avaliação das médias da amplitude do MMN neste trabalho, não foram encontradas diferenças estatisticamente significantes quando avaliadas as orelhas direita e esquerda juntas, nem mesmo quando analisadas em separado. Ao contrario do observado neste estudo, Yang et al. (2013) encontraram diferença significante na média da amplitude do MMN entre o grupo controle (sem zumbido e com audição normal) e o grupo com zumbido, todavia esse grupo era composto por mais da metade dos participantes com perda auditiva leve, o que pode explicar a diferença dos achados. 
Os achados da amplitude não se mostraram um bom parâmetro de avaliação para os grupos pesquisados. Frizzo et al. (2001) afirmam que, para os potenciais evocados auditivos de longa latência, o fator amplitude é pouco discutido, sendo mais comuns as discussões a respeito da latência desses potencias. Acredita-se que isso ocorra especialmente no meio audiológico e otorrinolaringológico, uma vez que os trabalhos sobre potenciais evocados realizados por neurologistas parecem enfatizar a amplitude em detrimento da latência.

No que se refere à latência, autores relatam que o MMN ocorre em torno de 100 a 200 ms (Garrido et al., 2013; Ayala e Malmierca, 2013). Para Näätänen (1990), o MMN pode ser suscitado na faixa de latência entre 150 a 250 ms. Segundo Hall III (2007), o componente do MMN é visível na região entre 100 a 300 ms. A média das respostas de MMN encontradas nesta pesquisa variam em torno de 200 a 220 ms. Brossi et al. (2007) encontraram valores médios de latência entre 150 e $184 \mathrm{~ms}$. Na pesquisa de Roggia e Colares (2008), utilizando o mesmo equipamento de coleta deste trabalho (equipamento de potenciais evocados auditivos da marca Interacoustics EP 25), obtiveram a média da latência do grupo controle de $220 \mathrm{~ms}$. Os achados da presente pesquisa evidenciam valores médios de latência entre 188 a 232 ms (média de 209,91 ms) no grupo zumbido e 200 a 230ms (média de 216,54 ms) no grupo controle, e a diferença entre as médias é estatisticamente significante $(\mathrm{P}=0,022)$.

Os achados deste estudo denotam diferença significante estatisticamente na latência do MMN da orelha direita quando comparados os indivíduos com e sem zumbido ( $p=0,039)$. Weiz et al. (2005), ao estudarem os potenciais de longa latência, encontraram respostas aumentas da onda N1 no hemisfério direito quando comparadas com o esquerdo no grupo com zumbido em relação ao grupo controle (sem queixas auditivas). Kang et al. (2003) estudaram diferenças hemisféricas em adultos e crianças com e sem perda auditiva e encontraram um metabolismo aumentado no córtex auditivo direito de sujeitos com perda auditiva bilateral. Weisz et al. (2005) afirmam que é possível que a lateralidade do zumbido não necessariamente implique definir em qual hemisfério (zumbido relevante) a reorganização cortical ocorra, mas que poderia haver uma independência entre a orelha em que o zumbido é percebido e o hemisfério envolvido no zumbido. Dessa forma, os autores acreditam em uma predisposição dos neurônios do córtex auditivo direito em sincronizar sua atividade após uma perda auditiva. Neste estudo não foram incluídos na amostra sujeitos com qualquer tipo ou grau de perda auditiva. No entanto, esse achado, neste estudo, chama a atenção para uma possível ativação maior no hemisfério direito dos 
sujeitos com zumbido, independentemente de apresentarem perda auditiva, em relação àqueles sem essa queixa.

Outra possível justificativa para esse achado pode ser o fato de os estímulos auditivos verbais terem seu reconhecimento no hemisfério esquerdo, enquanto os estímulos auditivos não verbais são inicialmente processados pelo hemisfério direito (Luria, 1966). Uma vez que o zumbido é um estímulo não verbal, pode-se sugerir a existência de uma neurofisiologia diferenciada no córtex auditivo no hemisfério direito em pessoas com esse sintoma. Kimura (1997) e Morgan et al. (1997) estudaram potencias corticais P300 em gagos e não gagos e encontraram menor amplitude de P300 no hemisfério esquerdo para estímulos tonais. Justificaram o achado pela assimetria funcional hemisférica, já que encontraram maior amplitude no hemisfério direito, sendo este responsável pelo processamento dos estímulos não verbais. O curioso, no entanto, é que a diferença na latência do MMN não é significativa estatisticamente, ao compararmos a média de ambas as orelhas entre os grupos.

Sendo assim, os achados desta pesquisa evidenciaram que sujeitos com zumbido apresentam latência do MMN diminuída quando comparados com aqueles sem zumbido, sendo esta diferença estatisticamente significante não apenas na comparação das médias do MMN na orelha direita, mas também na comparação entre médias das duas orelhas em conjunto ( $\mathrm{p}=0,022)$. Mahmoudian et al. (2013) avaliaram, por meio do MMN, 28 sujeitos com zumbido crônico e 33 voluntários saudáveis. Concluiram que zumbido pode causar uma redução na duração da memória sensorial no córtex auditivo. Essa redução, segundo os autores, pode causar a redução na latência e na amplitude da área abaixo da curva de três variáveis: frequência, duração e gap de silêncio. Na avaliação com a variável frequência, encontraram latência menor no grupo zumbido (média de 173,25 ms) quando comparado ao grupo controle (média de 181,75 ms). Nosso estudo corrobora com esses achados referentes à latência do $\mathrm{MMN}$ na avaliação que utilizou como variável a frequência.

Han et al. (2013) avaliaram, com o uso do MMN com estímulo de fala (sílabas), as mudanças neuroplásticas dos sitema auditivo antes e depois de uma aprendizagem de curto prazo (20 minutos). Participaram do treinamento 10 sujeitos, que foram comparados com outras 10 pessoas que não receberam o treinamento (5 homens e 15 mulheres, divididos aleatoriamente entre os grupos). O grupo que recebeu o treinamento, consistente em diferenciar estímulos silábicos durante 20 minutos, apresentou diminuição da latência e aumento da amplitude do MMN após o treinamento. Já os achados do MMN 
do grupo controle, que apenas leu um livro durante os 20 minutos entre as avaliações dos potenciais evocados, não apresentaram modificações. De acordo com estudos de Tremblay et al. (2001) e de Beauchamp e Stelmack (2006), sujeitos com maior habilidade de discriminação mostram menor latência, o que é um tempo de resposta mais rápido e uma ativação dos geradores neurais. Neste estudo, a latência diminuída em sujeitos com zumbido, quando comparados àqueles sem esse sintoma, pode mostrar uma mudança neural nestes indivíduos.

Heeren et al. (2014) avaliaram a atenção de sujeitos com zumbido e concluíram que este grupo possui um comprometimento específico de controle executivo. Ou seja, identificaram alterações nas regiões cerebrais do cortex pré-frontal que podem agir como um mecanismo direto na cronificação do zumbido. Segundo os autores, alterações na atividade do córtex pré-frontal podem estar especialmente relacionadas com a prevenção da habituação do zumbido, assim como com as suas consequências psicológicas. É consenso que o MMN tem sua geração nas áreas corticais temporal e, subsequentemente, frontal, córtex pré-frontal, com uma possível contribuição de níveis mais baixos na via auditiva (Giard et al., 1990, Kropotov et al., 1995, Rinne et al., 2000, Rosburg et al., 2007). Dessa forma, as diferenças encontradas na média da latência entre os grupos com e sem zumbido podem corroborar os achados de Heeren et al. (2014) de uma alteração não apenas no córtex auditivo, mas também no funcionamento atencional do córtex préfrontal e consequente alteração no mecanismo de habituação e cronificação do zumbido.

As diferenças nas médias da latência do MMN entre os grupos avaliados nesta pesquisa sugerem uma ativação do sistema auditivo central, com participação do sistema límbico (evidenciados no HAD e THI) e do córtex pré-frontal, diferenciados no grupo com zumbido em relação àqueles que não apresentam esse sintoma. Esses achados corroboram os encontrados por Mahmoudian et al. (2013), que sugerem a existência de um déficit nos mecanismos do processamento auditivo central automático envolvendo a detecção pré-atencional de mudanças. Essas alterações podem ser a causa das mudanças neuroplásticas no cérebro.

Os achados de Mahmoudian et al. (2013) também fornecem evidência eletrofisiológica, apoiando a teoria de que o processamento auditivo central préatencional automático é prejudicado em pessoas com zumbido crônico, o que também pode ser observado nos achados desta pesquisa. Considerando-se as vantagens oferecidas pelo paradigma $\mathrm{MMN}$, esses dados podem ser um ponto de referência útil para a avaliação 
da memória sensorial em pacientes com zumbido e podem ser aplicados com confiabilidade e sucesso no monitoramento do tratamento.

Os resultados desta pesquisa sugerem que sujeitos com zumbido apresentam um mecanismo pré-atencional para sons diferentes daqueles sem zumbido. Também se pode inferir que existe modificação na plasticidade desses indivíduos quando comparados a pessoas sem queixa de zumbido. Com isso, é possível sugerir a existência de um mecanismo de habituação neural diferenciado entre esses dois grupos. Os resultados também sugerem que o MMN pode ser uma boa ferramenta de avaliação do processo de habituação da via auditiva central em pacientes com zumbido.

Foram encontradas apenas três pesquisas que utilizaram o MMN na avaliação de pessoas com queixa de zumbido e, em todas elas, diferentemente deste estudo, os sujeitos com zumbido estudados apresentavam perda auditiva de diferentes graus (Weiz et al., 2003; Mahmoudian et al., 2013; Yang et al., 2013), o que pode configurar um viés na comparação entre os grupos dessas pesquisas, uma vez que os grupos controle apresentavam audição normal. Este estudo apresenta algumas limitações e observa-se a necessidade de mais pesquisas com o uso do MMN na avaliação de pessoas com queixa de zumbido; diferentes protocolos, níveis de incômodo com o zumbido, avaliação do MMN pré e pós-tratamento podem ser bastante promissores.

Foram encontrados poucos estudos que utilizaram o equipamento de potenciais evocados auditivos na captação do $\mathrm{MMN}$, bem como pesquisas realizadas por audiologistas, especialmente no Brasil. O MMN representa uma grande ferramenta de avaliação do córtex auditivo - não somente de pessoas com zumbido - e ainda pouco explorada por audiologistas e otorrinolaringologistas. 


\section{8 - CONCLUSÃO}

Os achados desta pesquisa denotam que sujeitos que referem zumbido com incômodo considerado severo segundo a EAV, apresentam prejuízo na qualidade de vida (evidenciados pelo THI).

Os participantes deste trabalho que referiam perceber zumbido exibiram diferença na HAD no quesito ansiedade quando comparados com aqueles sem o sintoma, no entanto, em ambos os grupos a media do quesito depressão não se mostrou sugestiva de depressão, segundo o instrumento.

O grupo com zumbido apresentou diminuição da latência do MMN, especialmente na orelha direita quando comparados ao grupo controle. Entretanto, a amplitude da onda do MMN mostrou-se uma medida pouco interessante na tentativa de diferenciar sujeitos com e sem zumbido, uma vez que não foram evidenciadas diferenças de amplitude entre os grupos. 


\section{9 - REFERÊNCIAS BIBLIOGRÁFICAS}

1. AGAEVA, M: Velocity discrimination of auditory image moving in vertical plane. Hear Res, 2004 Dec, 198 (1-2):1-9.

2. ALHO, K. Cerebral generators of mismatch negativity (MMN) and its magnetic ounterpart (MMNm) elicited by sound changes. EarHear, 16:38-51, 1995.

3. AMERICAN TINNITUS ASSOCIATION. Information About Tinnitus. Portland, ATA, 1997.

4. ANDERSON, G. The role of psychology in managing tinnitus: a cognitive behavioral approach. Semin Hear, 2001; 22:65-76.

5. ANDERSON, G. et al. Randomized controlled trial of internet based cognitive behavior therapy for distress associated with tinnitus. Psychosom Med., 2002; 64:810-6.

6. ANDERSON, G. Psychological aspects of tinnitus and the application of cognitivebehavioral therapy. Clin Psychol Rev, 2002; 22:977-90.

7. AQUINO, A. M.; ARAÚJO, M. M. S. Vias auditivas: periférica e central. In: Aquino, A. M. Processamento auditivo electrofisiologia \& psicoacústica. São Paulo: Lovise, 2002 .

8. ATTIAS, J., Urbach, D., GOLD, S., Shemesh, Z. Auditory eventrelated potentials in chronic tinnitus patients with noise induced hearing loss. Hear, Res. 71, 106-113, 1993.

9. AXELSSON, A.; RINGDAHL, A. Tinnitus: a study of its prevalence and characteristics. Br J Audiol, 1989; 23: 53-62.

10. AYALA, Y. A.; MALMIERCA, M. S. Stimulus-epecific adaptation and deviance detection in the inferior colliculus. Frontier in Neural Circuits, 6(89):1-16, 2013.

11. BALDEWEG, T.; KLUGMAN, A.; GRUZELIER, J.; HIRSCH, SR. Mismatch negativity potentials and cognitive impairment in schizophrenia. Schizophr Res, 69:203217, 2004.

12. BARAN, J; MUSIEK, F. Avaliação comportamental do sistema nervoso auditivo central. In: Musiek, F.; Rintelmann, W. Perspectivas atuais em avaliação auditiva. São Paulo: Manole, 2001.

13. BAUER CA, TURNER JG, CASPARY DM, MYERS KS, BROZOSKI TJ (2008) Tinnitus and inferior colliculus activity in chinchillas related to three distinct patterns of cochlear trauma. J Neurosci Res, 86: 2564-2578.

14. BEAUCHAMP, CM.; STELMACK, RM. The chronometry of mental ability: an event-related potential analysis of an auditory oddball discrimi nation task. Intelligence, 34:571-86, 2006.

15. BECK, J. S. Terapia Cognitiva: teoria e prática. Porto Alegre: Artes Médicas, 1997. 
16. BENTO, R.F., SANCHEZ, T.G., Minitti, A., Câmara, J. Zumbido: características e epidemiologia. Rev. Bras. Otorrinolaringol, v. 63, n. 2, p. 229-238, 1997.

17. BOLY, M.; GARRIDO, MI.; GOSSERIES, O.; BRUNO, MA.; BOVEROUX, P. et al. Preserved feedforward but impaired top-down processes in the vegetative state. Science, 332: 858-862, 2011.

18. BONALDI, L. V.; ANGELIS, M. A.; SMITH, R.L. Hodologia do sistema auditivo: vias auditivas. In: Pereira, L. D.; Schochat, E. Processamento auditivo central. São Paulo: Lovise, 1997.

19. BONALDI, L. V.; ANGELIS, M. A.; SMITH, R.L. Anatomia Funcional do Sistema Vestibulococlear. In: Frota, S. Fundamentos em Fonoaudiologia. Rio de Janeiro: Guanabara Koogan, 1998.

20. BONALDI, L. V.; ANGELIS, M. A.; RIBEIRO, E. C.; SMITH, R.L. Bases anatômicas da audição e do equilíbrio. São Paulo: Livraria Santos, 2004.

21. BROSSI, A.B.; BORBA, K.C.; GARCIA, C.F.D.; REIS, A.C.M.B.; ISAAC, M.L. Verificação das respostas do mismatch negativity (MMN) em sujeitos adultos normais Rev Bras Otorrinolaringol, 73(6):793-802, 2007.

22. BUDD, R.J.; PUGH, R. The relationship between locus of control, tinnitus severity and emotional distress in a group of tinnitus sufferers. J Psych Res, v. 39, n. 8, p. 1015$1018,1995$.

23. CAMPITELli, G.; GOBET, F.; HEAD, K.; BUCKLEY, M. Parker A. Brain localization of memory chunks in chessplayers. Int J Neurosci, 117:1641-1659. 2007.

24. CARLSSON, S.G.; ERLANDSSON, S.I. Habituation and tinnitus: an experimental study. J Psychosomatic Res, 35:509-514, 1991.

25. CARPENTER-THOMPSON, J. R.; AKROFI, K.; SCHMIDT, S. A.; DOLCOS, F.; HUSAIN, F. T. Alterations of the emotional processing system may underlie preserved rapid reaction time in tinnitus. Brain Res, 1567:28-41, 2014.

26. CASTAGNO, L.A.; CASTAGNO, S. Tinnitus: a clinical study. Folha Méd., v. 91, n. 5/6, p. 393-395, 1985.

27. CASTRO, M. M. C.; QUARANTINI, L.; NEVES, S.B; KRAYCHETE, D.C.; DALTRO, C.; SCIPPA, A.M. Validade da escala hospitalar de ansiedade e depressão em pacientes com dor crônica. Rev Bras Anestesiologia, 56: 5: 470-477, 2006.

28. CUNY C.; NORENA, A.; EL MASSIOUI, F.; CHERY-CROZE S. Reduced attention shift in response to auditory change in subjects with tinnitus. Audiol Neurootol, 2004; 9:294-302.

29. DE RIDDER, D.; ELGOYHEN, AB.; ROMO, R.; LANGGUTH, B. Phantom percepts: tinnitus and pain as persisting aversive memory networks. Proc Natl Acad Sci, USA $2011 ; 108: 8075-80$. 
30. DE RIDDER, D.; VANNESTE, S.; WEISZ, N.; LONDERO, A.; SCHLEE, W.; ELGOYHEN, AB. et al. An integrative model of auditory phantom perception: tinnitus as a unified percept of interacting separable subnetworks. Neurosci Biobehav Rev, 2014.

31. DIAS, A.; CORDEIRO, R.; CORRENTE, JE. O incômodo causado pelo zumbido medido pelo Questionário de Gravidade do Zumbido. Rev Saúde Pública, 2006; 40(4):706-11.

32. DIERKS, T, Linden DE, Jandl M, Formisano E, Goebel R, et al. (1999) Activation of Heschl's gyrus during auditory hallucinations. Neuron, 22: 615-621.

33. DOELLER, CF.; OPITZ, B.; MECKLINGER, A.; KRICK, C.; REITH, W. et al. Prefrontal cortex involvement in preattentive auditory deviance detection: neuroimaging and electrophysiological evidence. Neuroimage, 20: 1270-1282, 2003.

34. DONG, S.; MULDERS, WH.; RODGER, J.; WOO, S.; ROBERTSON, D. Acoustic trauma evokes hyperactivity and changes in gene expression in guinea-pig auditory brainstem. Eur J Neurosci, 31: 1616-1628, 2010.

35. DORIA FILHO, U. Introdução à bioestatística. 3. ed. São Paulo: Negócio Editora; 2001.

36. DURRANT, JD \& FERRARO, JA. In: Musiek FE \& Rintelmann WF. Perspectivas atuais em avaliação auditiva. 1. ed. bras. Barueri: Manole; 2001. p. 193-238.

37. DURRANT, J. D.; FERRARO, J. A. Potenciais auditivos evocados de curta latência: eletrococleografia e audiometria de tronco encefálico. In: Perspectivas atuais em avaliação auditiva. Edited by: MUSIEK, F.E.; RINTELMANN, W.F. São Paulo: Manole, 2001.

38. EGAN, J. P. Signal detection theory and ROC analysis. New York, USA: Academic Press, 1975.

39. FALCONE, E.O. Fobia Social, In: Rangé, B. (ed.): Psicoterapia Comportamental e Cognitiva de Transtornos Psiquiátricos. Editorial Psy, Campinas, 2001.

40. FERRARI, G.M.S.; SANCHEZ, T.G. O que é zumbido? In: Samelli, A.G. Zumbido: avaliação, diagnóstico e reabilitação. 2004, p.17-22.

41. FERREIRA, L.M.B.M.; RAMOS JÚNIOR, N.A.; MENDES, E.P. Caracterização do zumbido em idosos e possíveis transtornos relacionados. Rev Bras Otorrinolaringol, v. 75 , p. 249-255, 2009.

42. FERREIRA, P.E.A.; CUNHA, F.; ONISHI, E.T.; BRANCO-BARREIRO, F.C.A.; GANANÇA, F.F. Tinnitus handicap inventory: adaptação cultural para o Português Brasileiro. Pró-Fono Revista de Atualização Científica, Barueri (SP), v. 17, n. 3, p. 30310, set.-dez. 2005.

43. FINLAYSON, PG, KALTENBACH, JA. Alterations in the spontaneous discharge patterns of single units in the dorsal cochlear nucleus following intense sound exposure. Hear Res, 256: 104-106. 2009. 
44. FLETCHER, R. H, Fletcher, S. W. Epidemiologia clínica. 4. ed. Porto Alegre: Artmed, 2006.

45. FORD, J.M.; HILLYARD, S.A. Event-related potentials (ERPs) to interruptions of a steady rhythm. Psychophysiology, 18:322-330, 1981.

46. FRISTON, K. A theory of cortical responses. Philos Trans R Soc Lond B Biol Sci, 360: 815-836, 2005.

47. FRIZZO, A.C.F.; Alves, R.P.C.; Colafêmina, J.F. Potenciais evocados auditivos de longa latência: um estudo comparativo entre hemisférios cerebrais. Rev Bras Otorrinolaringol, 67(5): 618-625. 2001.

48. FUJIMORA, T.; OKANOYA, K. Event-Related Potentials Elicited by Pre-Attentive Emotional Changes in Temporal Context. Plos One, v. 8, n. 5, 1-13, Mai 2013.

49. FUKUDA, Y. Zumbido e suas correlações otoneurológicas. In: GANANÇA, M. M. Vertigem tem cura? O que aprendemos nestes últimos 30 anos. São Paulo: Lemos Editorial, 1998.

50. GARRIDO, MI.; DOLAN, RJ.; SAHANI, M. Surprise leads to noisier perceptual decisions. i-Perception, 2: 112-120, 2011.

51. GARRIDO, MI.; FRISTON, KJ.; KIEBEL, SJ.; STEPHAN, KE.; BALDEWEG, T. et al. The functional anatomy of the MMN: a DCM study of the roving paradigm. Neuroimage, 42: 936-944, 2008.

52. GARRIDO, M. I.; SAHANI, M.; DOLAN, R. J. Outlier Responses Reflect Sensibility to Statistical Structure in the Human Brain. Plos Comp Biol, March, 9(3):1-9, 2013.

53. GENE-COS N.; POTTINGER, R.; BARRETT, G.; TRIMBLE, MR.; RING, HA. A comparative study of mismatch negativity (MMN) in epilepsy and non-epileptic seizures. Epileptic Disord, 7: 363-372, 2005.

54. GERKEN, G.M. Central tinnitus and lateral inhibition: an auditory brainstem model. Hearing Research, 97, p. 75-83, 1996.

55. GIARD, MH.; PERRIN, F.; PERNIER, J.; BOUCHET. Brain generators implicated in the processing of auditory stimulus deviance: a topographic event-related potential study. Psychophysiology, 27: 627-640, 1990.

56. GRIMM, S.; ESCERA, C.; SLABU, L.; COSTA-FAIDELLA, J. Electrophysiological evidence for the hierarchical organization of auditory change detection in the human brain. Psychophysiology, 48, 377-384, 2011.

57. GRIMM, S.; ESCERA, C. Auditory deviance detection revisited: evidence for a hierarchical novelty system. Int. J. Psychophysiol. 85, 88-92, 2012.

58. HABETS, B. The tinnitus handbook: a self-help guide. Encinitas: United Research Publishers, 2000. 
59. HAERKÖTTER C; HILLER, W. Combining elements of tinnitus retraining therapy (TRT) and cognitive-behavioral therapy: Does it work? In: Proceedings of Sixth International Tinnitus Seminar. Cambrige (UK), 1999, 399-42.

60. HALL III, J.W. New handbook of auditory evoked responses. University of Florida, 2006.

61. HALLAM, R.S.; RACHMAN, S.; HINCHCLIFFE, R. Psychological aspects of tinnitus. In: Rachman, S. (Ed.). Contributions to Medical Psychology. vol. 3. Pergamon Press, London, p. 31-53, 1984.

62. HALLAM, R.S. Psychological approaches of the evaluation and management of tinnitus distress. In: Hazell, J.W.P. (Ed.). Tinnitus. Churchill Livingstone, Edinburgh, p. 156-175, 1987.

63. HALLAM, R.S. Correlates of sleep disturbance in chronic distressing tinnitus. Scand. Audiol, 25, pp.263-266, 1996.

64. HALLAM, RS.; MCKENNA, L.; SHURLOCK, L. Tinnitus impairs cognitive efficiency. Int J Audiol, 43:218-26, 2004.

65. HAN, W.; PARK, J.; BAHNG, J. The effects of auditory short-term training in passive oddball paradigm with novel stimuli. Korean J Audiol, 17:105-10, 2013.

66. HAWTHORNE, M. O'Connor, S. The psychological side of tinnitus. British Medical Journal 294: 1441-2, 1987.

67. HANZELL, J. Tinnitus retraining therapy based on the jastreboff model. In: International Tinnitus e Hiperacusis Society. London (UK), nov., 2000.

68. HEEREN, A.; MAURAGE, P.; PERROT, H.; DE VOLDER, A.; RENIER, L.; ARANEDA, R.; LACROIX, E.; DECAT, M.; DEGGOUJ, N.; PHILIPPOT, P. Tinnitus specifically alters the top-down executive control sub-component of attention: Evidence from the attention network task. Behavioral Brain Res, 269:147-54, 2014.

69. HENRY, J. A. e Meikle, M. B. Psycoacoustic Measures of Tinnitus. J Am Acad Audiol, v. 11, n. 3, p. 138-155, 2000.

70. HENRY, J. L. e WILSON, P. H. The Psychological Management of ChronicTinnitus - a Cognitive Behavioral Approach. Boston: Allyn e Bacon, p. 270, 2000.

71. HIGUCHI, Y.; SUMIYOSHI, T.; SEO, T.; MIYANISHI, T.; KAWASAKI, Y.; SUZUKI, M. Mismatch Negativity and Cognitive Performance for the Prediction of Psychosis in Subjects wuith At-Risk Mental State. PlosOne, 8(1):1-10, 2013.

72. HOLDEFER, L.; OLIVEIRA, C.A.C.P.; VENOSA, A.R. Sucesso no tratamento do zumbido com terapia em grupo. Rev Bras Otorrinolaringol, v. 76 (1), p. 102-6, 2010.

73. HUNGRIA. H. Otorrinolaringologia. 8. ed, 2000, p. 299-318. 
74. HYDE, KL.; LERCH, J.; NORTON, A.; FORGEARD, M.; WINNER, E.; EVANS, AC.; SCHLAUG, G. Musical training shapes structural brain development. J Neurosci, 29:3019-3025. 2009.

75. JÄÄSKELÄINEN IP.; AHVENINEN J.; BONMASSAR G.; DALE AM; ILMONIEMI RJ,; LEVÄNEN, S.; LIN, F.H.; MAY, P.; MELCHER, J.; STUFFLEBEAM, S.; TIITINEN, H.; BELLIVEAU, J.W. Human posterior auditory cortex gates novel sounds to consciousness. Proc Natl Acad Sci, 17: 6809-6814, 2004.

76. JACOBSON, G.P.; AHMAD, B.K.; MORAN, J.; NEWMAN, C.W.; TEPLEY, N.; WHARTON, J. Auditory evoked cortical magnetic field (M100 - M200) Measurements in tinnitus and normal groups. Hear. Res., v.56, p. 44-52, 1991.

77. JACOBSON, G.P.; CALDER, J.A.; NEWMAN， C.W.; PETERSON， E.L.; WHARTON, J.A.; AHMAD, B.K. Electrophysiological indices of selective auditory attention in subjects with and without tinnitus. Hear. Res. 97, 66-74, 1996.

78. JACOBSON, GP.; MCCASLIN, DL. A reexamination of the long latency N1 response in patients with tinnitus. J Am Acad Audiol, 14: 393-400, 2003.

79. JAKES, S. C.; HALLAM, R. S.; CHAMBERS, C.; HINCHCLIFFE, R. A factor analytic study of tinnitus complaint behaviour. Audiology, 24 : 195-206, 1985.

80. JAKES, S.C.; STEPHENS, S.D.G. Multivariate analyses of tinnitus complaint and change in tinnitus complaint: a masker study. Br. J. Audiol, 21, 259-272, 1987.

81. JASTREBOFF, P.J. Phanton auditory perception (tinnitus): mechanisms of generation and perception. Neurosci. Res., 8, 221-254, 1990.

82. JASTREBOFF, P.J.; HANZELL, W.P. A neurophysiological approach to tinnitus: clinical implications. Brit. Journal of Audiology, 27, 7-17, 1993.

83. JASTREBOFF, PJ.; JASTREBOFF, MM. Tinnitus retraining therapy (TRT) as a method for treatment of tinnitus and hyperacusis patients. J Am Acad Audiol, 2000; 11:162-77.

84. JESSEN, F.; FRIES, T.; KUCHARSKI. C.; NISHIMURA, T.; HOENIG, K.; MAIER, W.; FALKAI, P.; HEUN, R. Amplitude reduction of the mismatch negativity in firstdegree relatives of patients with schizophrenia. Neurosci Lett, 309:185-188. 2001.

85. JOHNSON, I.; ALTER, K.; GRIFFITHS, T. High frequency localised " hot spots" in temporal lobes of patients with intractable tinnitus: a quantitative electroencephalographic (QEEG) study. Neurosci Lett, 426: 23-28, 2007.

86. JUNQUEIRA e FRIZZO, 2002. In: AQUINO, A. M. C. M. Processamento auditivo eletrofisiologia \& psicoacústica. São Paulo: Lovise, 2002.

87. KALTENBACH. J. A.; ZHANG J.; FINLAYSON, P. Tinnitus as a plastic phenomenon and its possible neural underpinnings in the dorsal cochlear nucleus. Hear Res, 206: 200-226. 2005. 
88. KANG, E.; LEE, D. S.; LEE, JS.; Kang H.; HWANG C. H.; Oh S. H. et al. Developmental hemispheric asymmetry of interregional metabolic correlation of the auditory cortex in deaf subjects. Neuroimage, 2003; 19: 777-83.

89. KASAI, K.; YAMADA, H.; KAMIO, S.; NAKAGOME, K.; IWANAMI, A. et al. Do high or low doses of anxiolytics and hypnotics affect mismatch negativity in schizophrenic subjects? An EEG and MEG study. Clin Neurophysiol, 113: 141-150. 2002.

90. KAU, R.J.; SENDTNER-GRESS, K.; GANZER, U.; ARNOLD, W. Efectiveness of hyperbaric oxygen therapy in patients with acute and chronic cochlear disorders. ORL J. Otorhinolaryngol. Relat. Spec., 59, 79-83, 1997.

91. KIMURA, D. Funcional asymmetry of the brain in dichotic listening. Cortex, 3:16378, 1997.

92. KIRSCH, C. B. Psychological Characteristics of Individuals High and Low in Their Ability to Cope with Tinnitus. Psychosomatic Medicine (51): 209-17, 1989.

93. KRAUS, N.; MCGEE, T.; CARRELL, T.D.; KING, C.; TREMBLAY, K.; NICO, T. Central auditory system plasticity associates with speech discrimination training. $J$ Cognitive Neurosci, 7:25-32, 1995.

94. KROPOTOV, JD. NÄÄTÄNEN, R.; SEVOSTIANOV, AV.; ALHO, K.; REINIKAINEN, K.; KROPOTOVA, OV. Mismatch Negativity to Auditory Stimulus Change Recorded Directly from the Human Temporal Cortex. Psychophysiology 32: 418422, 1995.

95. KUCHENBUCH, A.; PARASKEVOPOULOS, E.; HERHOLZ S.C.; PANTEV, C. Effects of musical training and event probabilities on encoding of complex tone patterns. BMC Neuroscience, 14:51, 2013.

96. KUJALA, T.; TERVANIEMI, M.; SCHRÖGER, E. The mismatch negativity in cognitive and clinical neuroscience: theoretical and methodological considerations. Biol Psychol, 74:1-19. 2007.

97. LANG, A.H.; EEROLA, O.; KORPILAHTI, P.; HOLOPAINEN, I.; SALO, S.; AALTONEN, O. pratical issues in the clinical application of Mismatch Negativity. Ear Hear, 16(1):118-30, 1995.

98. LANGGUTH, B.; LANDGREBE, M.; KLEINJUNG T.; SAND, GP.; HAJAK, G. Tinnitus and depression. World J Biol Psychiatry, 2011; 12:489-500.

99. LANTING, CP.; de KLEINE, E.; van DIJK, P. Neural activity underlying tinnitus generation: results from PET and fMRI. Hear Res, 255: 1-13, 2009.

100. LANTING, CP.; De KLEINE, E.; EPPINGA, RN.; Van Dijk, P. Neural correlates of humans somatosensory integration in tinnitus. Hear Res, 267:78-88, 2010.

101. LEAVER, AM.; RENIER, L; CHEVILLET, MA.; MORGAN, S.; KIM, HJ.; Rauschecker, JP. Dysregulation of limbic and auditory networks in tinnitus. Neuron, 69:33-43, 2011. 
102. LEE, T.S.; MUMFORD, D. Hierarchical Bayesian inference in the visual cortex. J. Opt. Soc. Am. A, Vol. 20, No. 7, July, 2003.

103. LEUNG, S.; CROFT, RJ.; BALDEWEG, T.; NATHAN, PJ. Acute dopamine D(1) and $\mathrm{D}(2)$ receptor stimulation does not modulate Mismatch Negativity (MMN) in healthy human subjects. Psychopharmacology, Berl, 194: 443-451, 2007.

104. LONDERO, A. et al. Tinnitus and cognitive behavioral therapy: Results after one year. Presse Med., 2006; 35(9): IVIII.

105. LOPES FILHO, O. Anatomofisiologia clínica dos órgãos da audição. In: Otacílio \& Campos. Tratado de Otorrinolaringologia. 1994, p. 481-509.

106. LURIA, A.R. Higher cortical functions in man. $2^{\text {nd }}$ ed. New York, Basic Books, 1966.

107. MAGUIRE, EA.; WOOLLETT, K.; SPIERS, HJ. London taxi drivers and bus drivers: a structural MRI and neuropsychological analysis. Hippocampus, 16:1091-1101. 2006.

108. MAHMOUDIAN, S.; FARHADI, M.; NAJAFI-KOOPAIE, M.; DARESTANIFARAHANI, E.; MOHEBBI, M.; DENGLER, R.; ESSER, K.H.; SADJEDI, H.; SALAMAT, B.; DANESH, A. A.; LENARZ, T. Central auditory processing during chronic tinnitus as indexed by topographical maps of the mismatch negativity obtained with the multi-feature paradigm. Brain Res, 1527 161-73, 2013.

109. MCCOMBE, A. et al. Guidelines for the grading of tinnitus severity: the results of a working group commissioned by the British Association of Otolaryngologists, Head and Neck Surgeons, 1999. Clin Otolaryngol Allied Sci.; 26:388-93, 2001.

110. MCDONALD, AW.; COHEN, JD; STENGER, AV.; CARTER, CS. Dissociating the role of the dorsolateral prefrontal and anterior cingulate cortex in cognitive control. Science, 288:1835-8, 2000.

111. MCKENNA, LM.; HALLAM, RS.; SHURLOCK, L. Cognitive functioning in tinnitus patients. In: Reich G.; Vernon J. (Editors). Proceedings of the 5 th International Tinnitus Seminar. Portland: American Tinnitus Association, 1996. p. 589-95.

112. MELCHER, J.R.; SIGALOVSKY, T.S.; GUINAN, J.J.; LEVINE, R.A. Lateralized tinnitus studied with functional magnetic resonance imaging: Abnormal inferior colliculus activation. J. Neurophysiol., v.83, p. 1058-1072, 2000.

113. MOLLER, AR. Physiology of the Ear and the Auditory Nervous System. In Brackman, Neurotology, 19-37, 2006.

114. MORGAN, M.D.; CRANFORD, J.L.; BURK, K. P300 event-related potentials in stutterers and nonstutteres. J. Speech Hear. Res., 40:1334-40, 1997.

115. MUMFORD, D. On the computational architecture of the neocortex. I. The role of the thalamo-cortical loop. Biol Cybern, 65: 135-145, 1991. 
116. MUMFORD, D. On the computational architecture of the neocortex. II. The role of cortico-cortical loops. Biol Cybern, 66: 241-251, 1992.

117. MUSIEK, F.; BARAN, J. The auditory system: anatomy, physiology, and clinical correlates. Estados Unidos: Pearson Education, Inc, 2007.

118. MYATCHIN I; MENNES, M.; WOUTERS, H.; STIERS, P.; LAGAE, L. Working memory in children with epilepsy: an event-related potentials study. Epilepsy Res, 86: 183-190, 2009.

119. NÄÄTÄNEN, R; GAILLARD, A.W.K; MÄNTYSALO, S. Early selectiveattention effect on evoked potential reinterpreted. Acta Psychol 1978;42:313-29.

120. NÄÄTÄNEN, R.; PAAVILAINEN, P.; REINIKAINEN, K. Do event-related potentials to infrequent decrements in duration of auditory stimuli demonstrate a memory trace in man? Neurosci Lett., 107:347-352, 1989.

121. NÄ̈̈TÄNEN, R. The role of attention in auditory information processing as revealed by event-related potentials and other brain measures of cognitive function. Behav Brain Sci, 13:201-288, 1990.

122. NÄÄTÄNEN, R. Attention and brain function. Hillsdale, New Jersey: Lawrence Erlbaum, 1992.

123. NÄÄTÄNEN, R. Attention and Brain Function. Psychology Press, p. 494, 1992.

124. NÄÄTÄNEN, R. The mismatch negativity: a powerful tool for cognitive neuroscience. Ear Hear, 16, 6-18, 1995.

125. NAATANEN, R.; LEHTOKOSKI, A.; LENNES, M.; CHEOUR M.; HUOTILAINEN, M. et al. Language-specific phoneme representations revealed by electric and magnetic brain responses. Nature, 385: 432-434, 1997.

126. NÄÄTÄNEN, R.; Tervaniemi, M.; Sussman, E., Paavilainen, P.; Winkler, I. Primitive intelligence. In: The auditory cortex. Trends Neurosci, 24, 283-288. 2001.

127. NÄÄTÄNEN, R. Mismatch negativity: clinical research and possible applications. International Journal of Psychophysioloy, 48, 179-188, 2003.

128. NÄ̈̈TÄNEN, R.; PAKERINEN, S.; RINNE, T.; TAKEGATA.; R. The mismatch negativity (MMN): towards the optimal paradigm. Clin Neurophysiol, Jan; 115(1):140-4. 2004.

129. NÄÄTÄNEN, R.; JACOBSEN T.; WINKLER I. Memory-based or afferent processes in mismatch negativity (MMN): A review of the evidence. Psychophysiology, 42:25-32, 2005.

130. NEWMAN CW; JACOBSON GP; SPITZER JB. Development of the Tinnitus Handicap Inventory. Arch Otolaryngol Head Neck Surg., 122(2):143-8, 1996.

131. NORENA, A.; CRANSAC, H.; CHE'RY-CROZE, S. Towards an objectification by classification of tinnitus. Clin Neurophysiol, 110: 666-675, 1999. 
132. NORRÉ, M. E. The Unilateral Vestibular Hypofunction. Acta Atolaringol, v. 33, n. 3, p. 333-366, 1979.

133. OLIVEIRA, J. A. A. Fisiologia clínica da audição. In: Costa, S.S.; Cruz, O.L.; Oliveira, J. A. A. Otorrinolaringologia. Porto Alegre: Artes Médicas, 1994.

134. ONISHI, E. Abordagem médica do paciente com zumbido: a importância da avaliação otorrinolaringológica. In: SAMELLI, A. Zumbido: avaliação, diagnóstico e reabilitação - abordagens atuais. São Paulo: Lovise, 136, 2004.

135. PAAVILAINEN P.; SIMOLA J.; JARAMILLO M.; NAATANEN R.; WINKLER I. Preattentive extraction of abstract feature conjunctions from auditory stimulation as reflected by the mismatch negativity (MMN). Psychophysiology, 38: 359-365, 2001.

136. PARMENTIER, F. B. The cognitive determinants of behavioral distraction by deviant auditory stimuli: a review. Psychol Res, 2013, Dec 21.

137. PICTON, T.W. \& HILLYARD, S.A. Human auditory evoked potentials. II: Effects of attention. Eletroenceph Clin Neurophysiol, 36:191-9, 1974.

138. PONTON, CW.; DON, M.; EGGERMONT, JJ.; KWONG, B. Integrated mismatch negativity (MMNi): noise-free representation of evoked responses allowing single-point distribution-free statistical tests. Eletroencephalogr Clin Neurophysiol, Mar; 104(2):14350,1997

139. RAO, R.P.; BALLARD, DH. Predictive coding in the visual cortex: a functional interpretation of some extra-classical receptive-field effects. Nat Neurosci, 2: 79-87, 1999.

140. RAUSCHECKER, JP.; LEAVER, AM.; MULHAU, M. Tuning out the noise: limbic-auditory interactions in tinnitus. Neuron, 2010; 66:819-26.

141. REEB-SUTHERLAND, B.; VANDERWERT, R. E; DEGNAN, K. A.; MARSHALL, P. J.; PÉREZ-EDGAR, K.; CHRONIS-TUSCANO, A.; PINE, D. S.; FOX, N.A. Attention to novelty in behaviorally inhibited adolescents moderates risk for anxiety. J. Child Psychol. Psychiatry, Nov., 50(11):1365-72, 2009.

142. RIEF, W.; WEISE, C.; KLEY, N.; MARTIN, A. Psychophysiologictreatment of chronic tinnitus: A randomized clinical trial. Psychosomatic Medicine, 67, 833- 838, 2005.

143. RINNE, T.; ALHO, K.; ILMONIEMI, RJ; VIRTANEN, J; NÄÄTÄNEN, R. Separate time behaviors of the temporal and frontal mismatch negativity sources. Neuroimage, 12: 14-19. 2000.

144. ROBERTS, LE.; EGGERMONT, JJ.; CASPARY, DM.; SHORE, SE.; MELCHER JR. et al. Ringing ears: the neuroscience of tinnitus. J Neurosci, 30: 14972-14979, 2010.

145. ROBERTS, LE.; HUSSAIN, FT.; EGGERMONT, JJ. Role of attention in the generation and modulation of tinnitus. Neurosci Biobehav Rev, 2013; 37: 1754-73. 
146. ROBINSON, SK; VIIRRE, ES.; STEIN, MB. Antidepressant therapy in tinnitus. Hear Res, 2007; 226:221-31.

147. ROGGIA, S.M.; COLARES, N. T. O Mismatch Negativity em pacientes com distúrbios do processamento auditivo (central). Rer Bras Otorrinolaringol, 74(5):705-11, 2008.

148. ROGGIA, S.M. Mismatch Negativity. In: Tratado de audiologia. 1. ed. Edited by Bevilacqua, M.C.; MARTINEZ, M.A.N.; BALEN, S.A.; PUPO, A.C.; REIS, A.C.M.B.; FROTA, S. São Paulo: Santos; 261-78, 2011.

149. ROSBURG, T.; TRAUTNER, P.; LUDOWIG, E.; SCHALLER, C.; KURTHEN, M.; ELGER, CE.; BOUTROS, NN. Hippocampal event-related potentials to tone duration deviance in a passive oddball paradigm in humans. Neuroimage, 37: 274-281. 2007.

150. ROSSISTER, S.; STEVENS C.; WALKER, G. Tinnitus and its effect on working memory and attention. J Speech Lang Hear Res, 49:150-60, 2006.

151. RUUSUVIRTA, T.; LIPPONEN, A.; PELLINEN, E.; PENTTONEN, M.; ASTIKAINEN, P. Auditory Cortical and Hippocampal-System Mismatch Responses to Duration Deviants in Urethane-Anesthetizes Rats. Plos One, Jan, 8(1):1-7, 2013.

152. SANCHEZ, T.G.; MEDEIROS, I.R.T.; LEVY, C.P.D.; RAMALHO, J.R.; BENTO, R.F. Zumbido em pacientes com audiometria normal: Caracterização clínica e repercussões. Ver Bras Otorrinolaringol, 71(4), 427-31, 2005.

153. SCHIRMER, A.; ESCOFFIER, N. Emotional MMN: Anxiety and heart rate correlate with the ERP signature for auditory change detection. Clin Neurophysiol, Jan. 121(1):53-9, 2010.

154. SCHROGER, E.; WOLFF, C. Behavioral and electrophysiological effects of taskirrelevant sound change: a new distraction paradigm. Brain Res Cogn Brain Res, 7: 7187, 1998.

155. SCHINOHARA, H.; NARDI, A.E. Transtorno de ansiedade generalizada. In: Rangé, B. (ed.): Psicoterapia Comportamental e Cognitiva de Transtornos Psiquiátricos. Editorial Psy, Campinas, 2001.

156. SEIDMAN, M.D.; JACOBSON, G.P. Update on tinnitus. Otolaryngol. Clin. North Am.; v.29, n.3, pp.455-465, 1996.

157. SEYDELL-GREENWALD, A.; LEAVER, AM.; TURESKY, TK.; MORGAN, S.; KIM, HJ. Rauschecker, JP. Functional MRI evidence for a role of ventral prefrontal cortex in tinnitus. Brain Res, 1485:22-39, 2012.

158. SMITH, M.E.; HALGREN, E.; SOKOLIK, M.; BAUDEVA, P.; MUSOLINO, A.; LIEGEOIS-CHAUVEL, C.; CHAUVEL, P. The intracranial topography of the P3 eventrelated potential elicited during auditory oddball. Eletroenceph Clin Neurophysiol, 76:235-248, 1990. 
159. SNAITH, R. P. The Hospital Anxiety And Depression Scale. Commentary. Health and Quality of Life Outcomes, 1:20; 1-4, 2003.

160. SOUSA, L.C.A.; PIZA, M.R.T.; ALVARENGA, K.F.; COSER, P.L. Eletrofisiologia da Audição e Emissões Otoacústicas: princípios e aplicações clínicas. São Paulo: Tecmedd, 2008.

161. STEVENS, C.; WALKER, G.; BOYER, M.; Gallagher M. Severe tinnitus and its effect on selective and divided attention. Int J Audiol, 2007; 46:208-16.

162. SUGIMOTO, S.; NITTONO, H.; Hori, T. Visual emotional context modulates brain potentials elicited by unattended tones. Int J Psychophysiol, 2007. Oct. 66(1):1-9.

163. TAKEGATA, R, ROGGIA, SM, WINKLER, I. Effects of temporal grouping on the memory representation of inter-tone relationships. Biol Psychol, Jan; 68(1):41-60. 2005

164. TEIXEIRA, C. Percepção e Processamento Auditivo. In: Menezes, P.; Neto, S. \& Motta, M. Biofísica da audição. São Paulo: Lovise, 2005.

165. TEIXEIRA, C.F.; GRIZ, S M. S. Sistema Auditivo Central. In: Bevilacqua, M C.; Martinez, M. A. N.; Balen, S. A.; Pupo, A. C.; Reis, A. C. M. B.; Frota, S. Tratado de audiologia. São Paulo: Santos, 2012

166. TERVANIEMI, M.; MAURY, S.; NAATANEN, R. Neural representations of abstractstimulus features in the human brain as reflected by the mismatch negativity. Neuroreport, 5: 844-846, 1994.

167. TODD, J.; HARMS, L.; SCHALL, U.; MICHIE, P.T. Mismatch negativity: translating the potential. Front Psychiatry, 4(171):1-22, 2013

168. TREMBLAY, K.; KRAUS, N.; MCGEE, T. The time course of auditory perceptual learning: neurophysiological changes during speech-sound training. Neuroreport, 9:3557-60, 1998.

169. UMBRICH, D.; KRLJES, S. Mismatch Negativity in schizophrenia: a metaanalysis. Schizophr Res, 76: 1-23, 2005.

170. VUUST, P.; PALLESEN, KJ.; BAILEY, C.; VAN ZUIJEN, TL. Gjedde A, et al. To musicians, the message is in the meter pre-attentive neuronal responses to incongruent rhythm are left-lateralized in musicians. Neuroimage, 24: 560-564, 2005.

171. WACONGNE, C.; CHANGEUX, J.P.; DEHAENE, S. A neuronal model of predictive coding accounting for the mismatch negativity. The Journal of Neuroscience, 32(11):3665-3678, 2012.

172. WAINER, R.; PERGHER, G.K.; PICCOLOTO, N.M. Terapia CognitivoComportamental das Depressões. In: CAMINHA, R.M.; WAINER, R.; OLIVEIRA, M.; PICCOLOTO, N.M. Psicoterapias Cognitivo-Comportamentais: teoria e prática. São Paulo. Casa do Psicólogo. 2003. 
173. WALLHÄUSSER-FRANKE, E. Salicylate evokes c-fos expression in the brainstem: implications for tinnitus. Neuroreport, 8: 725-728, 1997.

174. WALPURGER, V.; LENNARTZ, G.H.; DENECKE, H.; PIETROWSKY, R. Habituation deficit in auditory event-related potentials in tinnitus complainers. Hearing Research, 181, 57-64, 2003.

175. WANG, L.; LIU, X.; GUISE, KG,; KNIGHT, RT.; GHAJAR, J.; FAN, J. Effective connectivity of the fronto-parietal network during attention control. J Cognitive Neurosci, 22:543-53, 2010.

176. WEISZ, N.; VOSS, S.; BERG, P.; ELBERT, T. Abnormal auditory mismatch response in tinnitus sufferes with high-frequency hearing loss is associated with subjective distress level. BMC Neuroscience, 5:8, 2004.

177. WEISZ, N.; WIENBRUCH, C.; DOHRMANN, K.; ELBERT, T. Neuromagnetic indicators of auditory cortical reorganization of tinnitus First publ. Brain, 128, 11, p. 2722-31, 2005.

178. WEISZ, N.; MÜLLER. S.; SCHLEE, W.; DOHRMANN, K.; HARTMANN, T.; ELBERT, T. The neural code of auditory phantom perception. J Neurosci, 27:1479-84, 2007.

179. WEISZ, N.; DOHRMANN, K.; ELBERT. The relevance of spontaneous activity for the coding of the tinnitus sensation. Prog Brain Res, 166: 61-70, 2007.

180. WINKLER, I. Interpreting the mismatch negativity (MMN). J Psychophysiol, 21:147-163, 2007.

181. YANG, H.; XIONG, H; YU, R.; WANG, C.; ZHENG, Y.; ZHANG, X. The Characteristic and Changes of the Event-Related Potentials (ERP) and Brain Topographic Maps before and after Treatment with rTMS in subjective Tinnitus Patients. Plos One, 8(8): 1-8, 2013.

182. YU AJ.; DAYAN, P. Uncertainty, neuromodulation, and attention. Neuron, 46: 681-692, 2005.

183. YUILLE, A.; KERSTEN, D. Vision as Bayesian inference: analysis by synthesis? Trends Cogn Sci, 10: 301-308, 2006.

184. ZENNER, HP. Tinnitus sensitization: a neurophysiological pathway of chronic complex tinnitus. Otolaryngol Pol, LX (4):485-89, 2006 


\section{ANEXO I}

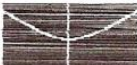 \\ Universidade de Brasilia \\ Faculdade de Ciências da Saúde \\ Comitê de Ética em Pesquisa-CEP/FS \\ PROCESSO DE ANÁLISE DE PROJETO DE PESOUISA}

Registro do Projeto: 079/2007

Título do Projeto: "Potenciais evocados auditivos de média latência em pessoas com queixa de zumbido"

Pesquisadora Responsável: Lisiane Holdefer

Data de Entrada: 16/07/2007.

Com base nas Resoluções 196/96, do CNS/MS, que regulamenta a ética da pesquisa em seres humanos, o Comitê de Ética em Pesquisa com Seres Humanos da Faculdade de Ciências da Saúde da Universidade de Brasília, após análise dos aspectos éticos e do contexto técnico-cientifico, resolveu APROVAR o projeto 079/2007 com o título: "Potenciais evocados auditivos de média latência em pessoas com queixa de zumbido". Analisado na $7^{\mathrm{a}}$ Reunião ordinária, realizada no dia 14 de agosto de 2007.

O pesquisador responsável fica, desde já, notificado da obrigatoriedade da apresentação de um relatório semestral e relatório final sucinto e objetivo sobre o desenvolvimento do Projeto, no prazo de 1 (um) ano a contar da presente data (item VII.13 da Resolução 196/96).

Brasilia, 20 de setembro de 2007.

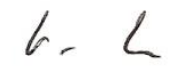

Prof. Volnei Garrafa Coordenador do CEP/FS-UnB

Campus Universitário Darcy Ribeiro

Faculdade de Ciências da Saúde

Cep: $70.910-900$ 


\section{ANEXO II \\ UNIVERSIDADE DE BRASILIA FACULDADE DE CIENCIAS DA SAÚDE}

\section{Pesquisa de Doutorado em Ciências Médicas:}

"Potenciais evocados auditivos de longa latência em pessoas com queixa de zumbido".

\section{Orientadores Responsáveis:}

Professor Doutor Carlos Augusto C. Pires Oliveira.

Área de Pesquisa - Tinnitus

\section{TERMO DE CONSENTIMENTO LIVRE E ESCLARECIDO}

A presente pesquisa visa estudar as vias auditivas centrais de pessoas com queixa de zumbido, sem perda auditiva; comparar com grupo controle; por meio do potencial evocado auditivo de média latência (MMN); no serviço de Fonoaudiologia do Hospital Universitário de Brasília, que será objeto de pesquisa na área de Zumbido do curso de Pós Graduação em Ciências Médicas da Faculdade de Medicina da Universidade de Brasília (UNB), visando o título de Doutorado.

Você está sendo convidado a participar desta pesquisa $\mathrm{O}$ documento abaixo contém todas as informações necessárias sobre a pesquisa que está sendo realizada. Sua colaboração neste estudo é muito importante, mas a decisão em participar deve ser sua. Para tanto, leia atentamente as informações abaixo para então decidir. Se você concordar em participar basta preencher os seus dados e assinar a declaração concordando com a pesquisa. Se você tiver alguma dúvida pode esclarecê-la com o responsável pela pesquisa.

$\mathrm{O} \mathrm{Sr} / \mathrm{a}$ portador

da Carteira de Identidade, RG ), é convidado a, de livre e espontânea vontade, participar da pesquisa sobre "Potenciais evocados auditivos de média latência em pessoas com queixa de zumbido"; a ser executado pela Fonoaudióloga Lisiane Holdefer, como um dos requisitos para obtenção do grau de Doutor, na Faculdade de Ciência Médica e da Universidade de Brasília, sob orientação do Prof. Dr. Carlos Augusto Costa Pires de Oliveira. 
A pesquisa será realizada por testes auditivos que avaliam a audição, a orelha média e a orelha interna. Será também realizado um exame clínico otorrinolaringológico, com o objetivo de obter dados sobre possíveis doenças e hábitos que possam influenciar a qualidade de audição, através de um questionário.

Os testes auditivos serão realizados no ambulatório de Fonoaudiologia/ Otorrinolaringologia do Hospital Universitário de Brasília e os dados serão fornecidos gratuitamente. Os resultados serão repassados para os participantes através do prontuário médico, assim como as orientações e tratamento adequado. Os resultados da pesquisa serão divulgados para fins científicos, sem a identificação de seus participantes, ficando garantido o sigilo e a privacidade.

Os participantes terão acesso, em qualquer etapa do estudo, ao profissional responsável pela pesquisa para esclarecimento de eventuais dúvidas, que poderá ser encontrado no ambulatório de Otorrinolaringologia do Hospital Universitário de Brasília, e através do telefone (61) 32015233.

É permitido ao paciente em qualquer momento, deixar de participar da pesquisa, sem qualquer prejuízo à continuidade de seu tratamento na Instituição.

Estando de acordo com os procedimentos acima informados, o participante e o pesquisador abaixo assinam.

Brasília, de de 2010.

Assinatura do participante

Pesquisador:

Assinatura 


\section{ANEXO III}

\section{Questionário de Repercussão do Zumbido}

Nome:

Idade:

Sexo:

\begin{tabular}{|c|c|}
\hline 01F. Devido ao seu zumbido é difícil se concentrar? & sim $\square \quad$ não $\square \quad$ às vezes $\square$ \\
\hline $\begin{array}{l}\text { 02F. O volume (intensidade) do seu zumbido faz com que seja difícil } \\
\text { escutar as pessoas? }\end{array}$ & sim $\square \quad$ não $\square \quad$ às vezes $\square$ \\
\hline 3E. O seu zumbido deixa você nervoso? & sim $\square$ não $\square$ às vezes $\square$ \\
\hline 4F. O seu zumbido deixa você confuso? & sim $\square \quad$ não $\square \quad$ às vezes $\square$ \\
\hline 5C. Devido ao seu zumbido, você se sente desesperado? & sim $\square$ não $\square$ às vezes $\square$ \\
\hline 6E. Você se queixa muito do seu zumbido? & sim $\square \quad$ não $\square \quad$ às vezes $\square$ \\
\hline $\begin{array}{l}\text { 7F. Devido ao seu zumbido, você tem dificuldade para pegar no sono à } \\
\text { noite? }\end{array}$ & sim $\square \quad$ não $\square \quad$ às vezes $\square$ \\
\hline 8C. Você sente como se não pudesse se livrar do seu zumbido? & sim $\square \quad$ não $\square \quad$ às vezes $\square$ \\
\hline $\begin{array}{l}\text { 9F. O seu zumbido interfere na sua capacidade de aproveitar atividades } \\
\text { sociais (tais como sair para jantar, ir ao cinema)? }\end{array}$ & sim $\square \quad$ não $\square \quad$ às vezes $\square$ \\
\hline 10E. Devido ao seu zumbido, você se sente frustrado? & sim $\square$ não $\square$ às vezes $\square$ \\
\hline 11C. Devido ao seu zumbido, você pensa que tem uma doença grave? & sim $\square \quad$ não $\square \quad$ às vezes $\square$ \\
\hline 12F. O seu zumbido torna difícil aproveitar a vida? & sim $\square \quad$ não $\square \quad$ às vezes $\square$ \\
\hline 13F. O seu zumbido interfere nas suas tarefas no serviço e em casa? & sim $\square \quad$ não $\square \quad$ às vezes $\square$ \\
\hline 14E. Devido ao seu zumbido, você se sente frequentemente irritado? & sim $\square \quad$ não $\square \quad$ às vezes $\square$ \\
\hline 15F. Devido ao seu zumbido, você acha difícil ler? & sim $\square \quad$ não $\square \quad$ às vezes $\square$ \\
\hline 16E. O seu zumbido deixa você chateado? & sim $\square \quad$ não $\square$ às vezes $\square$ \\
\hline $\begin{array}{l}\text { 17E. Você sente que o seu zumbido atrapalha o seu relacionamento com a } \\
\text { sua família e amigos? }\end{array}$ & sim $\square \quad$ não $\square \quad$ às vezes $\square$ \\
\hline $\begin{array}{l}\text { 18F. Você acha difícil tirar a sua atenção do seu zumbido e se concentrar } \\
\text { em outras coisas? }\end{array}$ & sim $\square \quad$ não $\square$ às vezes $\square$ \\
\hline 19C. Você sente que não tem controle sobre o seu zumbido? & sim $\square \quad$ não $\square$ às vezes $\square$ \\
\hline 20F. Devido ao seu zumbido, você se sente frequentemente cansado? & sim $\square$ não $\square$ às vezes $\square$ \\
\hline 21E. Devido ao seu zumbido, você se sente frequentemente deprimido? & sim $\square \quad$ não $\square$ às vezes $\square$ \\
\hline 22E. O seu zumbido faz com que você se sinta ansioso? & sim $\square$ não $\square$ às vezes $\square$ \\
\hline 23C. Você sente que não pode mais suportar o seu zumbido? & sim $\square \quad$ não $\square$ às vezes $\square$ \\
\hline 24F. O seu zumbido piora quando você está estressado? & sim $\square$ não $\square$ às vezes $\square$ \\
\hline 25E. O seu zumbido faz com que você se sinta inseguro? & sim $\square$ não $\square$ às vezes $\square$ \\
\hline
\end{tabular}

C: aspecto catastrófico: .. pontos; F: aspecto funcional: ..pontos; E: aspecto emocional: .. pontos

TOTAL: ... pontos

OBS: $\operatorname{sim}=4$, às vezes $=2$, não $=0$ 


\section{Escala Hospitalar de Ansiedade e Depressão}

Nome do Paciente

Prontuário

Data

Idade:

Telefone

Este questionário ajudará a saber como você está se sentindo. Leia todas as frases. Marque com um " $X$ " a resposta que melhor corresponder a como você está se sentindo na última semana. Não precisa ficar pensando muito em cada questão. Neste questionário as respostas espontâneas têm mais valor do que aquelas em que se pensa muito. Marque apenas uma resposta para cada pergunta.

1 -A- Eu me sinto tenso ou contrariado

3 ( ) a maior parte do tempo

2 ( ) boa parte do tempo

1 ( ) de vez em quando

0 ( ) nunca

2 -D- Eu ainda sinto gosto pela mesmas coisas de antes

0 ( ) sim, do mesmo jeito que antes

1 ( ) não tanto quanto antes

2 ( ) só um pouco

3 ( ) já não sinto mais prazer em nada

3 -A- Eu sinto uma espécie de medo, como se alguma coisa ruim fosse acontecer

3 ( ) sim, de um jeito muito forte

2 ( ) sim mas não tão forte

1 ( ) um pouco, mas isso não me preocupa

0 ( ) não sinto nada disso

4 -D- Dou risada e me divirto quando vejo coisas engraçadas

0 ( ) do mesmo jeito que antes

1 ( ) atualmente um pouco menos

2 ( ) atualmente bem menos

3 ( ) não consigo mais

5 -A- Estou com a cabeça cheia de preocupações

3 ( ) a maior parte do tempo

2 ( ) boa parte do tempo

1 ( ) de vez em quando

0 ( ) raramente

$6-\mathrm{D}$ - Eu me sinto alegre

3 ( ) nunca

2 ( ) poucas vezes

1 ( ) muitas vezes

0 ( ) a maior parte do tempo 
7 -A- Consigo ficar sentado á vontade e me sentir relaxado

0 ( ) sim, quase sempre

1 ( ) muitas vezes

2 ( ) poucas vezes

3 ( ) nunca

8 -D- Eu estou lento para pensar e fazer as coisas

3 ( ) quase sempre

2 ( ) muitas vezes

1 ( ) de vez em quando

$0($ ) nunca

9 -A- Eu tenho uma sensação ruim de medo, como um frio na barriga ou um aperto no estômago

0 ( ) nunca

1 ( ) de vez em quando

2 ( ) muitas vezes

3 ( ) quase sempre

10 -D- Eu perdi interesse em cuidar da minha aparência

3 ( ) completamente

2 ( ) não estou mais me cuidando como deveria

1 ( ) talvez não tanto quanto antes

0 ( ) me cuido do mesmo jeito que antes

11 - A- Eu me sinto inquieto, como se eu não pudesse ficar parado em lugar nenhum

3 ( ) sim, demais

2 ( ) bastante

1 ( ) um pouco

0 ( ) não me sinto assim

12 -D- Fico esperando animado as coisas boas que estão por vir

0 ( ) do mesmo jeito que antes

1 ( ) um pouco menos do que antes

2 ( ) bem menos do que antes

3 ( ) quase nunca

13 -A- De repente, tenho a sensação de entrar em pânico

3 ( ) a quase todo momento

2 ( ) um pouco menos que antes

1 ( ) de vez em quando

0 ( ) não sinto isso

14-D- Consigo sentir prazer quando assisto um bom programa de televisão, rádio ou leio alguma coisa

0 ( ) quase sempre

1 ( ) várias vezes

2 ( ) poucas vezes

3 ( ) quase nunca 